\title{
Path-Dependencies in Employment Trajectories Around Motherhood: Comparing Native Versus Second-Generation Migrant Women in Belgium
}

\author{
Julie Maes ${ }^{1}$ (D) $\cdot$ Jonas Wood ${ }^{1} \cdot$ Karel Neels $^{1}$ \\ Accepted: 26 December 2020 / Published online: 25 January 2021 \\ (C) The Author(s) 2021
}

\begin{abstract}
A sizeable body of literature has shown that the migrant-native employment gap is larger among women with children than among childless women, suggesting that the transition to parenthood has a stronger impact on the employment trajectories of migrant origin women compared to those of native women. However, due to the limited use of longitudinal data, our understanding of the mechanisms generating differential employment trajectories around the transition to parenthood remains limited. This study adopts a life course perspective to address path-dependencies in employment trajectories around the transition to motherhood. Using longitudinal data and fixed-effects models that compare within-individual changes in contractual working hours around the transition to parenthood between natives and second-generation migrants of Southern European and Turkish or Moroccan origin in Belgium, we find no migrant-native differentials among women with low employment rates before the birth of their first child and only limited differentials in employment trajectories around parenthood among women with medium and high employment rates before parenthood. This indicates that there is a strong path-dependency of employment trajectories around parenthood for migrant women and natives alike, but that second-generation migrant women generally have a lower pre-birth labour market attachment than native women which accounts for the frequently observed migrant-native differentials in maternal employment.
\end{abstract}

Keywords Life course $\cdot$ Path-dependency $\cdot$ Fixed-effects models · Maternal employment . Second generation $\cdot$ Belgium

Julie Maes

julie.maes@uantwerpen.be

1 University of Antwerp, Sint-Jacobstraat 2, 2000 Antwerp, Belgium 


\section{Introduction}

A substantial and increasing share of the population born in Belgium are secondgeneration women having at least one foreign born parent. Research consistently shows that second-generation migrant women - and particularly women of non-European origin - have higher inactivity and unemployment rates compared to native women (i.e. women whose parents are both born in Belgium ${ }^{1}$ ) (FOD WASO and UNIA 2017; Heath et al. 2008). Moreover, the migrant-native employment gap is larger among women with children than among childless women (FOD WASO and UNIA 2017; Holland and de Valk 2017; Rubin et al. 2008). Hence, the question emerges whether the transition to parenthood has a stronger impact on the employment trajectories of migrant origin women compared to native women.

While men's labour market trajectories are relatively stable over the life course, the transition to parenthood strongly affects women's employment trajectories. The literature on women's employment patterns around childbirth is extensive and indicates that although maternal employment has increased over the last 50 years, many women reduce their working hours after the birth of their first child (Gutierrez-Domenech 2005; Kreyenfeld 2015; Kuhhirt 2011; Wood et al. 2016). Research specifically focussing on differences in maternal employment between native and migrant origin women is limited and mainly based on cross-sectional data (Bevelander and Groeneveld 2006; Holland and de Valk 2017; Rubin et al. 2008). Using crosssectional data it is cumbersome, however, to disentangle the effect of family formation on employment from the effect of employment on family formation, and the crosssectional comparison of employment positions between women with and without children also includes the selective subset of women who will never enter parenthood. Recent studies have therefore increasingly turned to longitudinal data and find that migrant origin women - particularly of non-European origin - are more likely than native women to leave employment after the birth of their first child (Kil et al. 2018; Vidal-Coso 2019). However, unless accounted for, comparing employment positions of women entering motherhood over time pools between- and within-subject variation, implying that unobserved individual-level differences between migrants and natives may still bias the estimated effects of childbearing on employment. Although fixedeffects models using longitudinal microdata have been identified as a tool to overcome bias due to the inclusion of between-subject variation (Anderson et al. 2003; Budig and England 2001; Myrskylä and Margolis 2014), this approach has hitherto not been used in research on migrant-native differentials in the motherhood-employment link. As a result, our understanding of the underlying dynamics (potentially) leading to diverging employment trajectories around motherhood between migrant origin and native women has been hampered. By adopting a life course perspective, this study identifies pathdependency as a mechanism potentially generating migrant-native differentials in employment trajectories around motherhood, referring to the key principle in which past states or events affect future life outcomes.

Given the large employment gap between native and second-generation migrant women in Belgium, this study investigates migrant-native differentials in women's

\footnotetext{
${ }^{1}$ In this study, women of the third generation (whose parents are born in Belgium, but who have at least one foreign born grandparent) are considered natives.
} 
employment trajectories around the transition to parenthood using longitudinal microdata for Belgium (1999-2010). More specifically, native women's changes in contractual working hours in the 4-year interval from 1 year before until 3 years after the birth of their first child are compared to corresponding patterns among secondgeneration Southern European and Turkish or Moroccan origin women. We contribute to the existing literature in three ways. First, exploiting within-individual changes in employment over time has been put forward as a more convincing tool to approximate the causal effects of family formation on employment, compared to cross-sectional analyses or longitudinal set-ups that confound within-subject variation in employment trajectories with unobserved heterogeneity between women (Anderson et al. 2003; Budig and England 2001). This study therefore uses fixed-effects models that control for time-constant (un)observed heterogeneity across native and migrant origin women (Allison 2009; Stock and Watson 2015). Second, this study is innovative in unpacking the path-dependency of women's employment trajectories around the transition to parenthood by investigating whether and to what extent migrant-native differentials can be explained by women's differential pre-birth labour market attachment and wage potential. Third, since previous research indicates that omitting partners' characteristics in research on maternal employment may yield biased results (Abroms and Goldscheider 2002; Matysiak and Vignoli 2008), we also take partners' migration background and pre-birth employment and wage potential into account.

\section{The Belgian Context}

\section{Southern European, Turkish and Moroccan Origin Groups}

A substantial share of the Belgian population is foreign born or born in Belgium having at least one foreign born parent (20\% and 10\% in 2016, respectively) (Noppe et al. 2018). Southern European, Turkish and Maghreb origin groups account for an important share of the Belgian population and constitute - after neighbouring countries - the largest groups in the population of foreign origin ${ }^{2}$. In 2016, 5.9\% of the Belgian population had a Southern European origin, 5.2\% a Maghreb origin and 2.1\% a Turkish origin (constituting 19.8\%, 17.4\% and $7.2 \%$ of the population of foreign origin, respectively). Similar to many other Western European countries, the presence of these origin groups in Belgium is the result of three subsequent migration waves. After the Second World War, Belgium recruited guest workers for mining and heavy industries originating from Southern-Europe, Turkey and Morocco. Turkish immigration had a pronounced rural character, and a large proportion of Moroccan guest workers were also predominantly recruited from low-educated rural areas, resulting in a very selective profile of non-European guest workers in Belgium. In response to the 'migration stop' of non-European guest workers in 1974, many Turkish and Moroccan guest workers decided to settle permanently in Belgium and bring over their spouses and family members. In contrast to the close link between migration and labour market participation among men, their female partners migrated in the context of family reunification,

\footnotetext{
${ }^{2}$ Individuals of foreign origin are defined as individuals who have a foreign nationality, who are born with a foreign nationality or who have at least one foreign born parent.
} 
which resulted in low employment rates among these women and which may also have shaped work-family behaviours of their descendants. In subsequent decades, a substantial share of second-generation Turkish and Moroccan migrants continued to marry a partner from their parents' country of origin (Corijn and Lodewijckx 2009). Since this link between family formation and migration is largely absent among Southern European migrant groups, the latter are considered to be less selective in terms of socioeconomic positions and gender role attitudes.

Although the migrant-native employment gap is more pronounced among the first generation, studies have repeatedly shown that second-generation migrant womenand particularly women of non-European origin - have lower employment rates than natives and are overrepresented in part-time employment, temporary contracts and employment sectors with low wages and irregular working hours (FOD WASO and UNIA 2017; Heath et al. 2008). These disadvantages compared to natives already emerge at the beginning of their professional career, particularly for Turkish or Moroccan origin women (Baert et al. 2016; Maes et al. 2019).

\section{Family Policies}

In Belgium, all employees and women benefiting from unemployment benefits are entitled to 15 weeks of maternity leave, with women being obliged to take leave from at least 1 week before until 9 weeks after the birth of the child ${ }^{3}$ (Koslowski et al. 2016). Women on maternity leave receive a benefit which is calculated as percentage of their previous wage ${ }^{4}$. In addition, parents can take up parental leave until the child is 12 years old $^{5}$ and can reduce their working hours by (i) $100 \%$ for 4 months $^{6}$, (ii) $50 \%$ for 8 months, (iii) $20 \%$ for 20 months, and (iv) $10 \%$ for 40 months, or combine periods of full-time and part-time leave, while receiving a relatively low flat-rate benefit ${ }^{7}$. In contrast to the universal entitlement to maternity leave, parental leave is only available for private sector employees who have been working with their current employer for 12 out of 15 months preceding the application and for public sector employees with an employment contract at the time of the application, regardless the duration of employment (Koslowski et al. 2016). Research for Belgium has shown that these non-universal eligibility criteria result in a strong ethnic gradient in the uptake of parental leave (Kil, Wood and Neels 2017).

For children under the age of 3 , subsidised formal childcare services are available with fees that are income related and tax deductible. Although Belgium is characterised by a high availability of formal childcare, it also has one of the most articulated socioeconomic gradients in the uptake of formal childcare within Europe (Pavolini and Van Lancker 2018; Van Lancker 2018; Van Lancker and Ghysels 2012). This socio-

\footnotetext{
${ }^{3}$ Self-employed mothers have a separate system. They are entitled to 12 weeks of maternity leave, 1 week before and 2 weeks after the birth of the child are obligatory, and receive a flat-rate benefit ( $€ 485$ per week in 2019).

${ }^{4}$ Employees receive $75-82 \%$ of their previous income, and unemployed mothers receive their unemployment benefits plus $15-19 \%$ of their previous wages.

${ }^{5}$ Age limit of 4 years from its introduction in 1997 until 2005 and of 6 years from 2005 until 2009.

${ }^{6}$ Three months until 01.06.2012.

${ }^{7}$ In 2018 , the net benefit for $100 \%, 50 \%$ and $20 \%$ leave amounted to $€ 750.33, € 345.85$ and $€ 117.34$, respectively.
} 
economic gradient has been associated with unequal access to subsidised childcare rather than with problems of affordability (Ghysels and Van Lancker 2009). In a context of supply shortages of subsidised formal childcare and long waiting lists, households with unstable labour force participation face more barriers to access formal childcare services as their demand cannot be planned well in advance. Some lowincome households are also forced to rely on private childcare services (which are generally more expensive) due to unstable employment positions (Ghysels and Van Lancker 2009).

\section{Employment Trajectories Around the Transition to Motherhood of Native and Migrant Origin Women}

\section{Previous Research on Family Formation and Employment}

Cross-sectional studies have shown that the migrant-native employment gap is larger among women with children than among childless women (Bevelander and Groeneveld 2006; Holland and de Valk 2017; Rubin et al. 2008). However, using cross-sectional data it is cumbersome to disentangle the effect of family formation on employment from the effect of employment on family formation or to control for general factors affecting employment positions such as lower human capital, a weaker social network and discrimination on the labour market (Baert et al. 2013; Heath et al. 2008; Verhaeghe et al. 2013). Although Kil et al. (2018) and Vidal-Coso (2019) have used longitudinal microdata for Belgium and panel data from the Swiss Labour Force Survey, respectively, to investigate migrant-native differentials in the effect of family formation on employment, their estimates of this effect may be biased in several ways. First, individual characteristics of native and migrant origin women which affect both fertility and employment positions (e.g. educational level, value-based preferences) may entail a partially spurious relation between family formation and employment. To account for time-constant (un)observed characteristics that could be responsible for diverging employment trajectories between migrant origin and native women around parenthood, this study uses fixed-effects models to focus on within-individual changes in working hours around the birth of the first child (Allison 2009; Stock and Watson 2015). Second, the selection into motherhood and the timing of this transition may differ between migrant origin and native women. In this respect, Wood and Neels (2017) show for Belgium that the employment-fertility link differs between origin groups. While native women perceive a stable foothold in the labour market as a precondition to childbearing and consequently postpone the transition until this condition is fulfilled, non-European origin women are more likely to have their first child in response to unemployment or inactivity. Hence, the selection into parenthood is different across origin groups, which is again likely to bias the comparison of the effect of childbearing on employment across groups. When we compare a woman who is employed before the birth of her first child with a woman who is unemployed after the birth of her first child, for instance, it is impossible to disentangle whether this association reflects a negative effect of family formation on employment or a positive effect of unemployment on family formation (among particular groups) since two different women are being compared. The bias can again be reduced by exploiting 
variation of working hours within individuals over time, and fixed-effects models are considered a more suitable approach than pooled regression strategies where part of the estimated effects reflects variation between women.

Apart from the uncertainty surrounding previous estimates of the differential effect of parenthood on the employment trajectories of migrant origin women and natives, our understanding of the mechanisms that could potentially generate such diverging trajectories also remains limited. Several studies have argued that the extent to which maternal employment differs between native and migrant origin women depends on the social policy context (Holland and de Valk 2017; Rubin et al. 2008), but other studies have emphasised differential socio-economic positions (Vidal-Coso 2019) or differential norms and preferences regarding the timing of family formation and parent roles (de Valk 2008; Khoudja and Fleischmann 2015) to explain migrant-native differentials in the motherhood-employment link. The increasing availability of longitudinal data allows us to explore path-dependency as a potential underlying life course dynamic explaining differential employment trajectories around the transition to motherhood.

\section{Path-Dependency: Hypotheses on Migrant-Native Differentials}

Second-generation migrant women - particularly of Turkish or Moroccan origin - are disadvantaged compared to native women from the start of their professional career (Baert et al. 2016; Maes et al. 2019), which is likely to entail migrant-native differentials in women's employment trajectories around first childbirth due to three mechanisms of path-dependency. First, the Belgian labour market consists of insiders on the one hand who enjoy high job stability as a result of strong job protection and outsiders on the other hand who tend to move between temporary contracts (Van Dooren et al. 2014). Whether or not women have a stable foothold in the labour market prior to family formation has implications for their access to family policies. Due to long waiting lists, migrant origin women (particularly of non-European origin) with unpredictable working hours and temporary contracts often face difficulties to secure a childcare arrangement in time (Vandenbroeck et al. 2008; Wall and José 2004). This may lead to lock-in effects after the transition to parenthood to a larger extent than is the case among natives with more stable employment positions. Similarly, migrant origin women with unstable employment trajectories face more barriers to meet the eligibility criteria for parental leave, which may further hinder the reconciliation of motherhood and employment (Kil et al. 2017).

Second, the birth of a child is associated with direct costs as well as opportunity costs (Becker 1991). Hence, not only women's labour market attachment but also their wage potential prior to family formation shapes employment trajectories around the transition to parenthood. Since native women face stronger opportunity costs compared to migrant origin women (particularly of non-European origin) as a result of a higher wage potential, economic theories suggest that they are more likely to postpone family formation until stable employment has been secured and to subsequently stay (fulltime) employed after the birth of their first child. In contrast, limited net income gains given the cost associated with formal childcare (particularly when relying on private childcare services) in combination with organisational issues (e.g. transport, working hours) may create disincentives for (continued) labour force participation among migrant origin mothers with a low wage potential. 
Third, migrant-native differentials in women's pre-birth labour market outcomes may also entail different employment trajectories around the transition to parenthood due to varying work-family attitudes. The exact role of attitudes is, however, difficult to identify. On the one hand, if migrant origin women have limited labour market prospects and lack role models, they may become demotivated and consider family formation as an alternative career, resulting in family formation at an early age (Elloukmani and Ou-Salah 2018; Friedman et al. 1994). In this view, weaker pre-birth labour market outcomes may thus foster traditional work-family attitudes that subsequently shape employment trajectories around parenthood. On the other hand, there may also be a self-selection of women with more traditional workfamily attitudes in less stable employment positions and low wage jobs before family formation. Although second-generation Southern European, Turkish and Moroccan origin women have been socialised in a generally egalitarian family context in Belgium (Esping-Andersen 1999; Lück 2005), parental attitudes, family networks and the wider migrant community may act as a source for origin-specific attitudes as well (de Valk 2008; de Valk \& Milewski 2011; Holland and de Valk 2017; Khoudja and Fleischmann 2015). To the extent that women limit their investment in education and employment in anticipation of reduced labour force participation after the transition to parenthood (Bass 2015), work-family attitudes may entail a spurious relation between women's pre-birth labour market outcomes and employment trajectories around parenthood.

Considering the aforementioned mechanisms of path-dependency, the following hypotheses on migrant-native differentials in women's employment trajectories around the transition to parenthood are put forward in this study:

H1: The birth of the first child has a stronger impact on the working hours of migrant origin women than those of native women, particularly for Turkish or Moroccan origin women.

H2: Migrant-native differentials in women's changes in working hours over the transition to parenthood are associated with the differential pre-birth labour market attachment of migrant origin and native women.

H3: Migrant-native differentials in women's changes in working hours over the transition to parenthood are further reduced when considering native and migrant origin women's differential wage potential, particularly for Turkish or Moroccan origin women.

\section{Data and Methods}

\section{Data}

We use data from the Belgian Administrative Socio-Demographic Panel (BASD Panel) that links longitudinal microdata from the National Register and the Crossroads Bank for Social Security. The data infrastructure provides information on a sample of women aged 15-50 years legally residing in Belgium on January 1, 1999, using sampling fractions of $2.5 \%(1 / 40)$ for the female population with a Belgian nationality and $5 \%$ $(1 / 20)$ for the female population with a foreign nationality. Sampled women are subsequently followed until (i) the age of 50, (ii) emigration/death or (iii) the end of 
the observation period on December 31, 2010. To maintain cross-sectional representativeness in the 1999-2010 period, supplementary annual samples of 15-year-olds, as well as women aged 16-50 years who settled in Belgium in the preceding year, were drawn. For each observation year, household members of sampled women on the first of January are also included in the data.

The analyses investigate the change in contractual working hours around the transition to parenthood among women who (i) had a first child between the first quarter of 2000 and the third quarter of 2010, (ii) were not enrolled in education, (iii) cohabited with their partner in the year preceding the first birth ${ }^{8}$ and (iv) had known contractual working hours ${ }^{9}$. In our dataset, contractual working hours reflect the percentage of working hours compared to a full-time position in the employment sector considered, which has the advantage of capturing differences in working hours that are not related to differences between sectors ${ }^{10}$. Part-time jobs are combined to determine the total working hours. The possible values range from 0 to $100 \%$, where $0 \%$ reflects unemployment or inactivity and $100 \%$ full-time employment ${ }^{11}$. If women are on maternity leave, their working hours amount to $0 \%$ and the working hours of women on parental leave reflect their reduction in working hours. We follow women from 1 year before the birth of their first child until (i) two quarters before their second child is born ${ }^{12}$, (ii) the first child reaches the age of three or (iii) censoring as a result of death, emigration or the end of the observation period. Women who had their first child in the last quarter they were observed were excluded from the analyses since we are interested in the change in working hours following parenthood. This results in a sample of 7897 women: 6890 native women, 538 second-generation Southern European origin women and 469 second generation Turkish or Moroccan origin women. Since prior research for Belgium has shown limited differences in the motherhood-employment link between second-generation Turkish and Moroccan origin women (Kil et al. 2018) and in order to obtain robust estimations, this study combines Turkish and Moroccan origin women into one group.

\section{Methods}

This study uses individual-level fixed-effects regression models to compare changes in native women's working hours around the birth of their first child to changes observed among second-generation women of Southern European origin and Turkish or Moroccan origin (hereafter, G2 South-EU women and G2 Turkish/Moroccan women). Since

\footnotetext{
${ }^{8}$ Women without an identifiable partner were excluded from the analyses. As a result of this, 999 native, 142 Southern European and 65 Turkish/Moroccan origin women were excluded.

${ }^{9}$ Self-employed women were excluded, as we have no information on their working hours. As a result of unknown working hours (i.e. missing values), 864 native, 48 Southern European and 34 Turkish/Moroccan origin women were excluded (of which respectively 476, 18 and 3 self-employed women).

${ }^{10}$ For instance, while a full-time position implies working $38 \mathrm{~h}$ per week in most employment sectors in Belgium, the contractual working hours for a full-time position are in some sectors less than $38 \mathrm{~h}$ (e.g. education sector).

${ }^{11}$ For example, $80 \%$ reflects working $30 \mathrm{~h}$ per week if a full-time position in the sector considered implies working $38 \mathrm{~h}$ per week. The working hours of individuals whose working hours exceed the standard number of working hours for a full-time position were considered to be $100 \%$.

${ }^{12}$ Descriptive results show that women frequently decrease their working hours or take maternity leave in the quarter preceding the birth of a child.
} 
fixed-effects models consider differences within individuals over time, the analyses account for time-constant (un)observed heterogeneity between native and migrant origin women (Allison 2009; Stock and Watson 2015). However, since spuriousness may still result from time-varying confounding factors, time-varying individual-level covariates can be included in the fixed-effects model. Equation 1 shows the general equation for a fixed-effects model where $Y_{i t}$ is the dependent variable for individual $i$ at time $t, X_{i t}$ a vector of time-varying independent variables, $\beta$ the parameter estimates for these independent variables, $\alpha_{i}$ the time-invariant individual effect and $u_{i t}$ the error term.

$$
Y_{i t}=\beta X_{i t}+\alpha_{i}+u_{i t}
$$

\section{Documenting Employment Trajectories Around the Transition to Parenthood}

The first part of the analyses compares changes in working hours around the transition to parenthood among native and migrant origin women (H1). Similar to the approach developed by Kil et al. (2018), a fixed-effects model is estimated separately for women who were employed and not employed 1 year before family formation, considering (i) time relative to the first birth (distinguishing quarters $-4,-3,-2,-1,0,1,2,3,4-7$, 8-11) and (ii) the interaction between time and origin group (native, G2 South-EU and G2 Turkish/Moroccan). The fourth quarter before the birth of the first child is used as reference point, so each quarter, women's working hours are compared to their working hours 1 year before the first birth.

\section{Explaining Migrant-Native Differentials in Employment Trajectories Around the Transition to Parenthood}

Based on the aforementioned theoretical mechanisms, we expect that migrant-native differentials in women's changes in working hours around the transition parenthood can be explained by women's differential labour market attachment before the transition to parenthood. To have a more robust reflection of women's pre-birth labour market attachment than the observed position they happen to occupy in the fourth quarter preceding the birth of their first child, each quarter, we estimated the probability of being employed for women in the BASD Panel who did not (yet) have children and were no longer enrolled in education as a function of their (i) age (centred at age 18, quadratic specification), (ii) highest educational level (low, medium, high, unknown), (iii) origin group and generation (native, G1 neighbouring countries, G2 neighbouring countries, G1 South-EU, G2 South-EU, G1 Turkey, G2 Turkey, G1 Morocco, G2 Morocco), (iv) region (Flanders, Wallonia, Brussels), (v) LIPRO household position ${ }^{13}$ (child, single, married, cohabiting, other), (vi) the interaction between origin group and age, (vii) the interaction between origin group and educational level, (viii) the interaction between origin group and LIPRO position, (ix) the interaction between educational level and age and (x) the interaction between LIPRO position and age. Equation 2 shows the equation for women's employment probabilities where $A_{i}$ denotes age, $E_{i}$ the dummy variables reflecting highest educational level, $O_{i}$ the dummy variables reflecting origin group and

13 'LIfestyle PROjections' (Van Imhoff and Keilman 1991). 
generation, $R_{i}$ the dummy variables reflecting region and $L_{i}$ the dummy variables reflecting the LIPRO household position, and the product terms denote the two-way interactions (model estimates are included in Appendix Table 4).

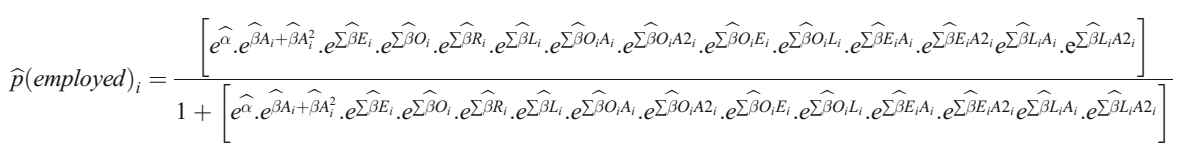

Subsequently, each quarter of observation, women in our sample were assigned the probability of being employed of women who do not have children (yet), but who otherwise have an identical profile in terms of the aforementioned characteristics. Using the estimated employment probabilities of women who do not have children (yet) is not problematic since we consider first-time mothers, and just before childbearing, they were likely to have similar labour market prospects. This would not be the case if we would focus on higher-order births.

For the second part of the analyses, women are no longer stratified in terms of the observed employment position in the fourth quarter before the birth of their first child, but in terms of the probability of being employed at that time ${ }^{14}$ (hereafter referred to as their pre-birth employment rate). We distinguish women with low, medium and high pre-birth employment rates, corresponding to employment rates 1 year prior to parenthood that range from 0 to 0.33 , from 0.33 to 0.66 and from 0.66 to 1 , respectively. In contrast to observed labour market positions, estimated employment rates offer a more robust indicator of women's pre-birth labour market attachment which is not affected by an arbitrary time point. For example, Kil et al. (2018) differentiated their analyses by women's employment positions observed 1 year before the birth of their first child (working full-time, working part-time, unemployed and inactive) to investigate migrant-native differentials in employment positions after parenthood. However, this observed pre-birth employment position disregards variation in employment positions over time that occurs regardless of parenthood and therefore induces bias for women with the least stable labour market trajectories. As the likelihood to leave employment, unemployment or inactivity differs by migration background - regardless of the transition to parenthood - stratification in terms of observed positions at an arbitrary time point makes it difficult to compare the effect of family formation by migration background, as it may partially reflect differential stability of employment positions.

For women with low, medium and high pre-birth employment rates, four models are subsequently estimated to explore migrant-native differentials in employment trajectories around the transition to parenthood (full model estimates available in Appendix Tables 7,8 and 9). Model 0 considers (i) time relative to the first birth and (ii) the interaction between time and origin group to assess whether there are migrant-native differentials among women with similar pre-birth employment rates (H2). Since women's pre-birth employment rates may also differ

\footnotetext{
${ }^{14}$ Since women's pre-birth employment rates depend on their age, migrant-native differentials in women's pre-birth labour market attachment due to an earlier timing of family formation are captured.
} 
within the low, medium and high employment rates group, Model 1 additionally includes the interaction between time and women's pre-birth employment rates. Model 2 additionally controls for women's time-varying parental leave uptake (no uptake, part-time uptake, full-time uptake) and LIPRO household position (child, single, married, cohabiting, other).

In line with economic theories, we expect that migrant-native differentials in women's pre-birth wage potential also account for part of the differential change in working hours around parenthood (H3). To have a robust indicator for women's pre-birth wage potential, a multinomial logit model was used to estimate the probability of being employed with a low, medium or high hourly wage for women in the BASD Panel who did not have children (yet), were employed but not self-employed and were not enrolled in education as a function of their (i) age (quadratic specification), (ii) highest educational level, (iii) origin group and generation, (iv) region, (v) LIPRO household position, (vi) the interaction between origin group and age, (vii) the interaction between origin group and educational level, (viii) the interaction between origin group and LIPRO position and (ix) the interaction between educational level and age (model estimates are provided in Appendix Table 5). Subsequently, each quarter of observation, all women in our sample were assigned what their wage potential would be if they would have no children and would be employed, based on the aforementioned characteristics. In Model 3, we include the interaction between time since first birth and (i) a dummy variable indicating a high pre-birth wage potential (i.e. probability to have a high hourly wage exceeding 0.50 in the fourth quarter before the birth of the first child) and (ii) a dummy variable indicating a low pre-birth wage potential (i.e. probability to have a low hourly wage exceeding 0.50 in the fourth quarter before family formation) to assess whether women's change in working hours around motherhood differs for women with a high and low pre-birth wage potential.

Since omitting partners' characteristics in research on maternal employment may yield biased results (Matysiak and Vignoli 2008), this study also takes partners' pre-birth employment and wage potential and migration background into account. To have an indicator of the employment and wage potential of women's partners, we use a multinomial logit model to estimate the probability of being (i) not employed, (ii) employed with a low hourly wage, (iii) employed with a medium hourly wage and (iv) employed with a high hourly wage for all men in the BASD Panel who were not enrolled in education nor self-employed as a function of their (i) age (quadratic specification), (ii) highest educational level, (iii) origin group and generation, (iv) region, (v) LIPRO household position, (vi) the interaction between origin group and age, (vii) the interaction between origin group and educational level, (viii) the interaction between origin group and LIPRO position and (ix) the interaction between educational level and age (model estimates are provided in Appendix Table 6). Subsequently, each quarter of observation, all partners of women in our sample were assigned what their employment and wage probabilities would be based on the aforementioned characteristics. Model 4 additionally controls for (i) the interaction between time and the partner's pre-birth employment and wage potential (i.e. the estimated 
employment and wage probabilities in the fourth quarter before the birth of the first child) and (ii) the presence and migration background of the partner (no partner in the household, native, G1 South-EU, G2 South-EU, G1/G2 other EU countries $^{15}$, G1 Turkey/Morocco, G2 Turkey/Morocco).

\section{Results}

\section{Employment Trajectories Around the Transition to Parenthood}

Figure 1 shows the change in women's working hours compared to the working hours 1 year before the birth of their first child for women who were employed (Fig. 1a) and unemployed or inactive (Fig. 1b) 1 year before family formation. Considering women who were employed, the same overall pattern can be observed: women's working hours decrease in the quarters preceding birth, drop to low values in the quarter of birth and recover as the child becomes older ${ }^{16}$ but to a level below the level observed 1 year before motherhood. There are, however, strong differences between origin groups. Native women reduce their working hours in the first two quarters after the transition to motherhood on average by 24 and 17 percentage points, respectively, and by 13 percentage points from the third quarter onwards. The decrease in the working hours of G2 South-EU women ranges from 24 percentage points in the first quarter to 19 percentage points 3 years after motherhood. G2 Turkish/Moroccan women show the strongest decrease in their working hours, ranging from 38 percentage points in the first quarter after the child is born to 27 percentage points after 3 years. Hence, G2 South-EU and G2 Turkish/Moroccan women reduce their working hours to a significantly stronger extent than native women in 3 years following family formation (gaps ranging from 0 to 6 and from 14 to 17 percentage points, respectively). Regarding women who were not employed 1 year before motherhood (working hours amounting to $0 \%$ ), Fig. $1 \mathrm{~b}$ shows that the working hours for all origin groups increase in 3 years following the birth of their first child. However, G2 South-EU and G2 Turkish/Moroccan women increase their working hours to a significantly lesser extent than native women. This difference with native women's trajectories ranges from 7 to 10 percentage points for G2 SouthEU women and from 10 to 15 percentage points for G2 Turkish/Moroccan women.

The results in Fig. 1 seem to confirm our first hypothesis. After the transition to parenthood, migrant origin women decrease their working hours to a stronger extent (if they were employed) and increase their working hours to a lesser extent (if they were not employed) compared to native women, with the largest

\footnotetext{
15 The other European countries include neighbouring countries, Northern European and Eastern European countries.

${ }^{16}$ It should be noted that the sample becomes increasingly selective and small as the child approaches the age of three since women are excluded from the analyses two quarters before their second child is born.
} 
a: Women who were employed 1 year before first birth

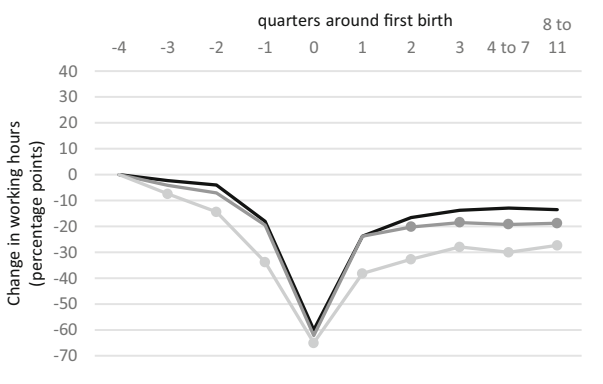

-Belgium G2 South-EU

- significant difference with native women's change in working hours $(p<0.05)$ b: Women who were not employed 1 year before first birth quarters around first birth

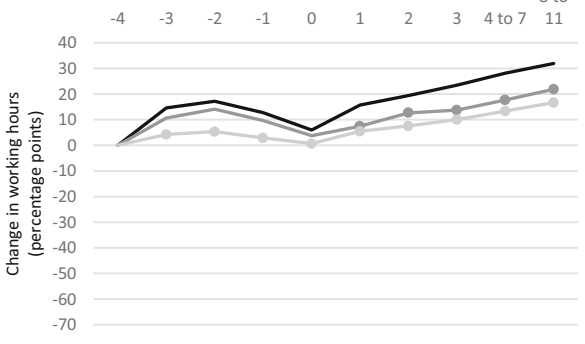

G2 Turkish/Moroccan

Source: BASD Panel, 1999-2010, calculations by authors.

Fig. 1 Change in working hours around first birth compared to working hours 1 year before first birth by origin group. a Women who were employed 1 year before first birth. b Women who were not employed 1 year before first birth. Source: BASD Panel, 1999-2010, calculations by authors

difference emerging among Turkish/Moroccan origin women. However, as women's observed employment positions 1 year before motherhood are only a snapshot at an arbitrary point in time, the migrant-native differentials in Fig. 1 may partially conceal differential stability in employment trajectories across groups, regardless of parenthood. The fact that there is already a stronger decrease in the three quarters preceding the first birth in the working hours of G2 Turkish/ Moroccan women among women who were employed 1 year before motherhood (Fig. 1a) and a stronger increase in the working hours of native and G2 South-EU women among women who were not employed (Fig. 1b) seems to provide empirical support for this line of thought.

\section{Explaining Migrant-Native Differentials}

If we compare women with similar pre-birth employment rates and thus consider women's average employment positions, we find only limited differentials between the trajectories of native women and second-generation women of Southern European and Turkish or Moroccan origin. Figure 2 shows employment trajectories around family formation by origin group for women with low, medium and high pre-birth employment rates separately. Among women with low pre-birth employment rates (Fig. 2a), a likelihood ratio test ( $\Delta$-2LL: $5.6 ; \Delta$ df: 9; p: 0.78$)$ indicates that there is no significant difference between native and G2 Turkish/Moroccan women in their employment trajectories around parenthood (G2 South-EU women are excluded from the analysis due to the small sample size). Further, although the likelihood ratio tests among women with medium and high pre-birth employment rates indicate that including the interaction between time and origin group is a significant improvement compared to the model only including time, differences between origin groups are small. Among women with medium pre-birth employment rates (Fig. 2b), the differentials with native women's trajectories in 3 years following the birth of the first child 


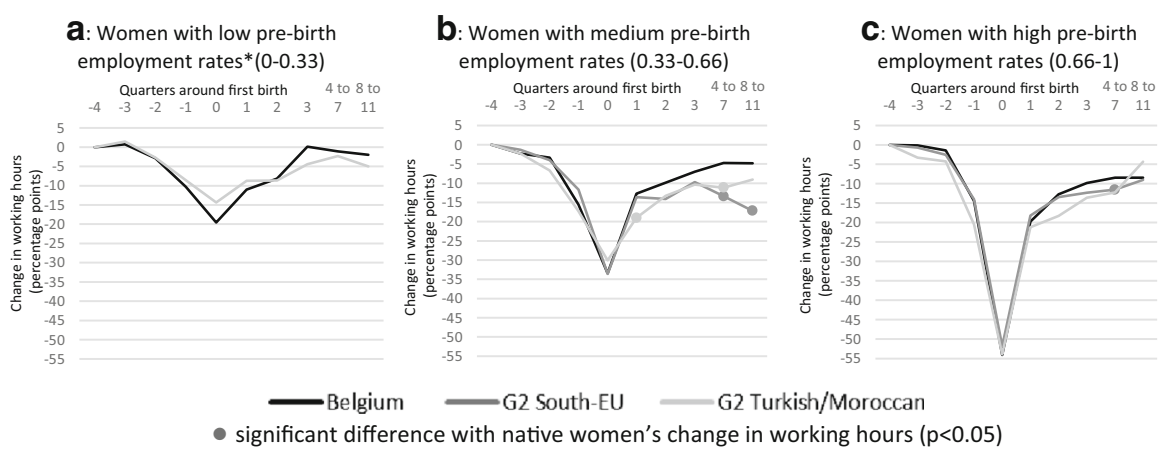

*Among women with low pre-birth employment rates, G2 South-EU women are excluded from the analysis due to the small sample size ( $N: 10)$.

Source: BASD Panel, 1999-2010, calculations by authors.

Fig. 2 Change in working hours around first birth compared to working hours 1 year before first birth by origin group and pre-birth employment rates (Model 0). a Women with low pre-birth employment rates*(0$0.33)$. b Women with medium pre-birth employment rates $(0.33-0.66)$. c Women with high pre-birth employment rates (0.66-1). Source: BASD Panel, 1999-2010, calculations by authors

range from 1 to 12 percentage points for G2 South-EU women and from 3 to 6 percentage points for G2 Turkish/Moroccan women. Among women with high prebirth employment rates (Fig. 2c), the differential change compared to native women after the transition to motherhood ranges from 0.6 to 3 percentage points for G2 SouthEU women. G2 Turkish/Moroccan women reduce their working hours to a stronger extent than native women with high pre-birth employment rates in the first 2 years following motherhood (gaps ranging from 1 to 6 percentage points) but to a lesser extent in the third year after family formation. This differential change in working hours compared to native women is, however, not statistically significant. Hence, we can largely confirm our second hypothesis that migrant-native differentials in women's employment trajectories around parenthood can be largely explained by their differential pre-birth employment rates.

We also investigate whether and to what extent migrant-native differentials in employment trajectories after family formation can be further explained by differences in (i) women's parental leave uptake and variation in LIPRO household positions (Model 2), (ii) women's pre-birth wage potential (Model 3) and (iii) the migration background and pre-birth employment and wage potential of women's partners (Model 4). As Model 0 indicated no significant differentials by origin group among women with low pre-birth employment rates, we only focus on women with medium and high pre-birth employment rates. For G2 South-EU and G2 Turkish/Moroccan women, Table 2 shows the differential change in working hours after the transition to motherhood compared to native women over the subsequent models ${ }^{17}$. Since women's employment rates also vary within the medium and high pre-birth employment rates group, Model 1 takes women's estimated pre-birth employment rates into account. Additionally controlling for parental leave uptake and LIPRO household positions in Model 2 significantly improves our models. Due to migrant-native differentials in (fulltime) parental leave uptake (Tables 1,2), the difference with native women's

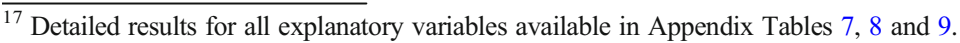




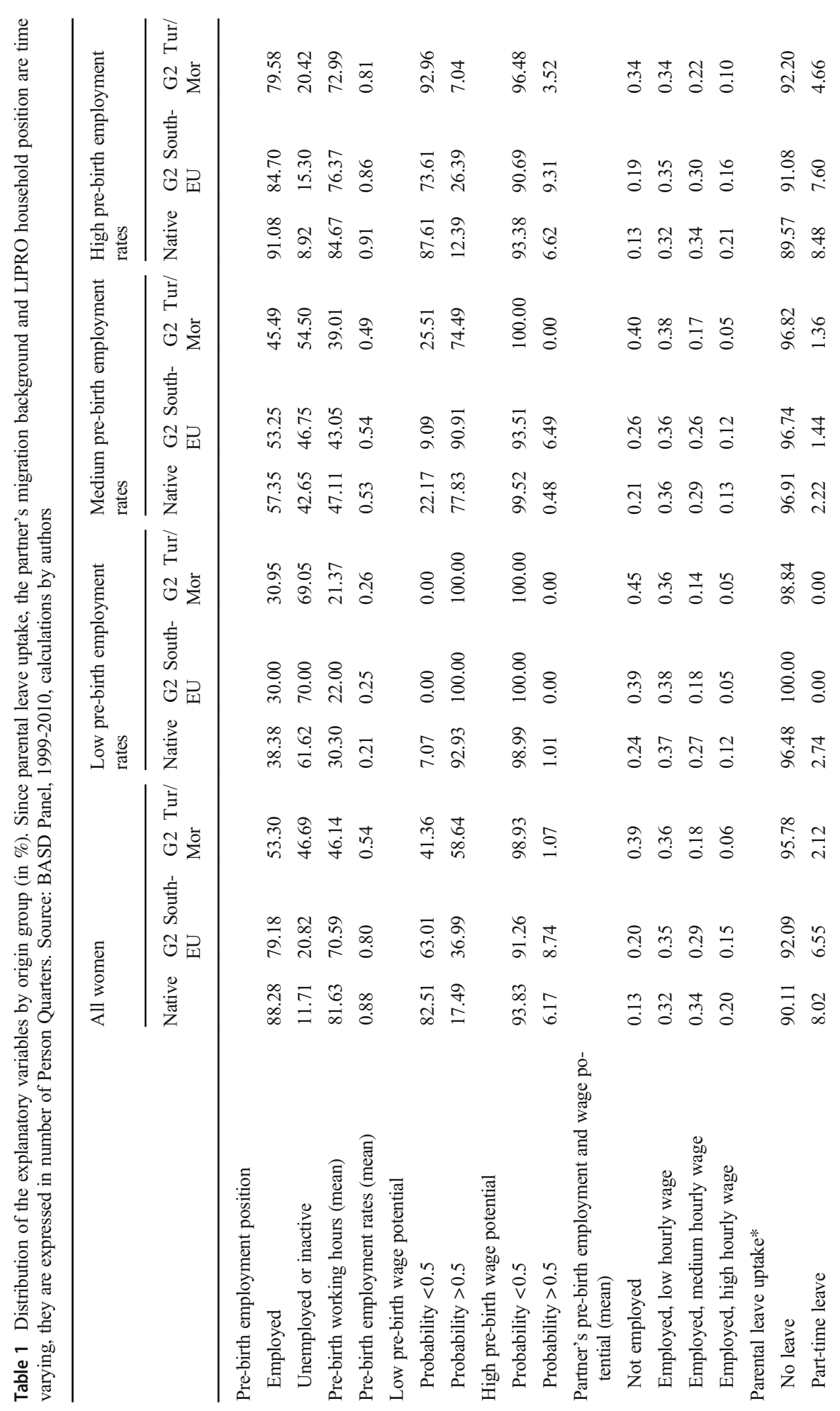




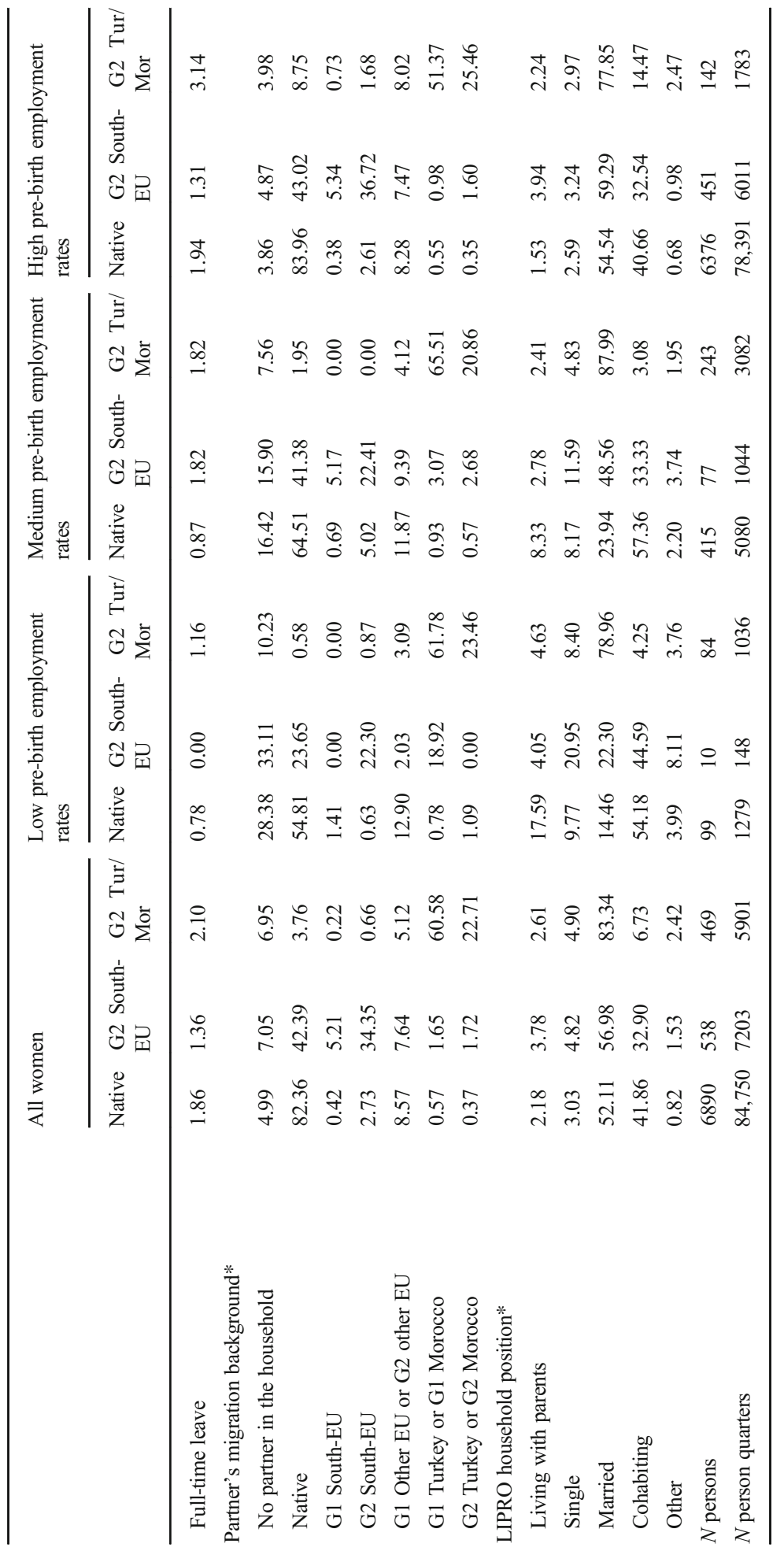


Table 2 Differential change in working hours after first birth compared to native women by origin group and pre-birth employment rates (in percentage points), Models 0-4

2.1: Women with medium pre-birth employment rates $(0.33-0.66)$

Model $0 \quad$ Sig. Model $1 \quad$ Sig. Model $2 \quad$ Sig. Model $3 \quad$ Sig. Model 4 Sig.

a: G2 South-EU women (N: 77)

\begin{tabular}{|c|c|c|c|c|c|c|c|c|c|c|}
\hline Quarter 1 & -0.914 & & 0.625 & & 0.468 & & -1.048 & & -1.329 & \\
\hline Quarter 2 & -4.241 & & -2.892 & & -0.618 & & -2.130 & & -2.168 & \\
\hline Quarter 3 & -2.729 & & -1.257 & & 0.888 & & -0.717 & & 0.112 & \\
\hline Quarters 4-7 & -8.670 & $*$ & -6.676 & & -5.670 & & -7.060 & & -6.248 & \\
\hline Quarters 8-11 & -12.361 & $* *$ & -9.874 & * & -9.932 & $*$ & -10.720 & $* *$ & -10.368 & * \\
\hline \multicolumn{11}{|c|}{ b: G2 Turkish/Moroccan women (N: 243) } \\
\hline Quarter 1 & -6.315 & $*$ & -7.246 & $*$ & -3.227 & & -3.045 & & -5.491 & \\
\hline Quarter 2 & -3.423 & & -4.242 & & -1.309 & & -1.271 & & -3.128 & \\
\hline Quarter 3 & -3.361 & & -4.297 & & -1.513 & & -1.518 & & -1.682 & \\
\hline Quarters 4-7 & -6.413 & $*$ & -7.794 & $*$ & -6.259 & $*$ & -6.436 & $*$ & -6.008 & $*$ \\
\hline Quarters 8-11 & -4.194 & & -6.642 & $*$ & -5.901 & $*$ & -6.090 & $*$ & -7.263 & $*$ \\
\hline$\Delta-2 \mathrm{LL}(\Delta \mathrm{df})$ & $48.2(18)$ & $* * *$ & $44.1(9)$ & $* * *$ & $471.4(6)$ & $* * *$ & 76.2 (19) & $* * *$ & $52.8(33)$ & $* * *$ \\
\hline
\end{tabular}

2.2: Women with high pre-birth employment rates (0.66-1)

Model 0 Sig. Model 1 Sig. Model $2 \quad$ Sig. Model 3 Sig. Model 4 Sig.

a: G2 South-EU women (N: 451)

\begin{tabular}{|c|c|c|c|c|c|c|c|c|c|c|}
\hline Quarter 1 & 1.601 & & 0.797 & & -0.073 & & -0.105 & & -0.005 & \\
\hline Quarter 2 & -0.777 & & -1.007 & & -0.705 & & -0.856 & & -0.724 & \\
\hline Quarter 3 & -2.505 & & -2.099 & & -1.684 & & -1.753 & & -1.714 & \\
\hline Quarters 4-7 & -3.081 & $*$ & -3.496 & $*$ & -2.963 & $*$ & -3.041 & $*$ & -3.011 & $*$ \\
\hline Quarters 8-11 & -0.608 & & -1.480 & & -1.045 & & -1.026 & & -1.336 & \\
\hline \multicolumn{11}{|c|}{ b: G2 Turkish/Moroccan women (N: 142) } \\
\hline Quarter 1 & -1.385 & & -2.523 & & 0.258 & & -0.398 & & -0.057 & \\
\hline Quarter 2 & -5.594 & & -5.908 & & -2.321 & & -3.292 & & -2.770 & \\
\hline Quarter 3 & -3.741 & & -3.167 & & 0.055 & & -1.015 & & -0.900 & \\
\hline Quarters 4-7 & -3.796 & & -4.343 & & -2.105 & & -2.467 & & -2.552 & \\
\hline Quarters 8-11 & 4.048 & & 2.858 & & 3.501 & & 4.000 & & 2.694 & \\
\hline$\Delta-2 \mathrm{LL}(\Delta \mathrm{df})$ & $50.3(18)$ & $* * *$ & $140.4(9)$ & $* * *$ & $13,346.9(6)$ & $* * *$ & 95.5 (18) & $* * *$ & $80.6(33)$ & $* * *$ \\
\hline
\end{tabular}

Model 0 includes (i) time around first birth and (ii) time*origin group; Model 1 additionally includes women's pre-birth employment rates; Model 2 additionally includes (i) parental leave uptake and (ii) LIPRO position; Model 3 additionally includes time*women's pre-birth wage potential; Model 4 additionally includes (i) time*partner's pre-birth employment and wage potential and (ii) the presence and migration background of the partner

Significant levels: $* p<0.05, * * p<0.01 ; * * * p<0.001$

Source: BASD Panel, 1999-2010, calculations by authors

trajectories after family formation decreases in Model 2. This decrease ranges from 0.05 percentage points to 4 percentage points for G2 South-EU and G2 Turkish/ Moroccan women with medium pre-birth employment rates, respectively.

Additionally including women's pre-birth wage potential in Model 3 again significantly improves our models. The results indicate that among women with 
medium pre-birth employment rates, women with a high pre-birth wage potential decrease their working hours to a significantly lesser extent in the second and third year after the birth of their first child than women without a high wage potential. By contrast, there is no significant difference in the change in working hours after family formation between women with and without a low pre-birth wage potential. Among women with high pre-birth employment rates, there is no significant difference in the change in working hours after family formation between women with and without a high wage potential. On the other hand, women with a low prebirth wage potential decrease their working hours by an additional 4 percentage points in the second and third quarter after family formation compared to women without a low pre-birth wage potential. Although migrant-native differentials in women's pre-birth wage potential become less pronounced when comparing women with similar pre-birth employment rates, there are still differences among women with medium and high pre-birth employment rates (Table 1). However, controlling for women's pre-birth wage potential results in almost no change in the difference with native women's change in working hours after family formation for G2 South-EU and G2 Turkish/Moroccan women (difference with natives is maximum 1.5 percentage points smaller compared to Model 2) ${ }^{18}$. Hence, we must reject our third hypothesis since differences between native and migrant origin women's pre-birth wage potential do not substantially reduce migrantnative differentials in women's changes in working hours after family formation when already controlling for differential pre-birth employment probabilities.

Finally, the likelihood ratio tests indicate that women's employment trajectories around the transition to parenthood are also shaped by their partners' migration background and pre-birth employment and wage potential. Despite differences between native and migrant origin women's partners among women with medium and high employment rates, there is almost no change in migrant-native differentials after controlling for these differences (changes of maximum 2 percentage points compared to Model 3).

\section{Sensitivity Analyses}

In the main analyses, women's reduced working hours can be either the result of (i) staying employed but working less hours per week, (ii) becoming unemployed or (ii) becoming inactive. This distinction is, however, particularly important in the Belgian context of a rigid labour market. Whereas some women enjoy a great job security and can choose to work part-time after the birth of their child, outsiders may not find a job and get 'locked' in unemployment after the transition to parenthood. In addition, becoming unemployed can be interpreted as an involuntary reduction of working hours, while becoming inactive as a voluntary decision of women, but both have been treated as working hours of $0 \%$. To gain more insight in the mechanisms behind women's reduced working hours, the

\footnotetext{
${ }^{18}$ If we change the order of the models and additionally control for women's pre-birth wage potential, but not for parental leave uptake and LIPRO position, we find the same results.
} 
analyses of Model 0 have been replicated three times but successively excluding quarters in which women are (i) inactive, (ii) unemployed and (iii) both inactive or unemployed.

Tables 3.1a and 3.2a show that the gap with natives generally becomes smaller for both G2 South-EU women with medium and high pre-birth employment rates when unemployed quarters are excluded. This suggests that G2 South-EU women overall show a stronger reduction of their working hours than natives because they are more likely to become unemployed after the transition to parenthood. For G2 Turkish/Moroccan women with medium pre-birth employment rates, Table $3.1 \mathrm{~b}$ shows that part of the difference with native women's trajectories after family formation is due to a shift into inactivity, as the gap with native women is smaller from the third quarter onwards after excluding inactive quarters. Excluding both inactive and unemployed quarters leads, however, to an increased difference with native women, indicating that G2 Turkish/Moroccan women with medium prebirth employment rates reduce their working hours to a stronger extent than native women if they stay employed after family formation. Among G2 Turkish/ Moroccan women with high pre-birth employment rates, the gap with native women becomes slightly smaller when unemployed and inactive quarters are excluded (except for quarters 4-7 after family formation), suggesting that the strong decrease in working hours of G2 Turkish/Moroccan women after family formation is due to inactivity or unemployment being more prevalent than is the case among native women.

\section{Discussion}

Belgium has one of the largest employment gaps between native and secondgeneration migrant women in Europe (Heath et al. 2008; OECD 2010). In a context of accelerated population ageing and increasing diversity, understanding the factors that generate differences between the employment trajectories of native and migrant origin women stands high on the academic and policy agenda. Since a sizeable body of literature has shown that the migrant-native employment gap is especially large among women with children (FOD WASO and UNIA 2017; Holland and de Valk 2017; Rubin et al. 2008), this study investigates whether the transition to parenthood has a stronger impact on the employment trajectories of second-generation women of Southern European and Turkish or Moroccan origin compared to native women, using longitudinal microdata for Belgium. In addition to the societal importance of migrant origin mothers' labour force participation, a reduced labour force participation after family formation has also implications for women's financial independence, future labour market trajectories and social security (e.g. pensions) (Koelet et al. 2015; Neels et al. 2018).

By considering within-individual changes in women's contractual working hours from 1 year before the transition to parenthood to 3 years after, we control for timeconstant (un)observed heterogeneity between native and migrant origin women, in a way more rigorous than previous studies (Holland and de Valk 2017; Kil et al. 2018; 
Table 3 Differential change in working hours after first birth compared to native women by origin group and pre-birth employment rates (in percentage points), sensitivity analyses of Model 0

3.1: Women with medium pre-birth employment rates $(0.33-0.66)$

\begin{tabular}{|c|c|c|c|}
\hline $\begin{array}{l}\text { Inactive and } \\
\text { unemployed } \\
\text { quarters included }\end{array}$ & $\begin{array}{l}\text { Sig. Inactive } \\
\text { quarters } \\
\text { excluded }\end{array}$ & $\begin{array}{l}\text { Sig. Unemployed } \\
\text { quarters } \\
\text { excluded }\end{array}$ & $\begin{array}{l}\text { Sig. Inactive and } \\
\text { unemployed } \\
\text { quarters excluded }\end{array}$ \\
\hline
\end{tabular}

a: G2 South-EU women

\begin{tabular}{|c|c|c|c|c|c|c|c|c|}
\hline $\begin{array}{c}\text { Quarter } \\
1\end{array}$ & -0.914 & & -1.138 & & 2.306 & & 1.670 & \\
\hline $\begin{array}{c}\text { Quarter } \\
2\end{array}$ & -4.241 & & -7.927 & & -3.105 & & -10.426 & $*$ \\
\hline $\begin{array}{c}\text { Quarter } \\
3\end{array}$ & -2.729 & & -5.283 & & 3.165 & & -2.290 & \\
\hline $\begin{array}{c}\text { Quarters } \\
4-7\end{array}$ & -8.670 & $*$ & -11.429 & $* *$ & -3.141 & & -5.467 & \\
\hline $\begin{array}{c}\text { Quarters } \\
8-11\end{array}$ & -12.361 & $* *$ & -10.319 & $*$ & -5.151 & & -0.559 & \\
\hline$N$ & persons & 77 & & 61 & & 57 & & 41 \\
\hline & b: G2 Turk & can $\mathrm{w}$ & omen & & & & & \\
\hline $\begin{array}{c}\text { Quarter } \\
1\end{array}$ & -6.315 & * & -7.673 & $*$ & -13.790 & $* *$ & -17.049 & $* * *$ \\
\hline $\begin{array}{c}\text { Quarter } \\
2\end{array}$ & -3.423 & & -3.933 & & -9.194 & $*$ & -12.227 & $* * *$ \\
\hline $\begin{array}{c}\text { Quarter } \\
3\end{array}$ & -3.361 & & -1.356 & & -10.695 & $*$ & -10.433 & $* *$ \\
\hline $\begin{array}{c}\text { Quarters } \\
4-7\end{array}$ & -6.413 & $*$ & -4.264 & & -11.773 & $* * *$ & -6.833 & $*$ \\
\hline $\begin{array}{c}\text { Quarters } \\
8-11\end{array}$ & -4.194 & & -2.718 & & -6.306 & & -5.516 & \\
\hline$N$ & persons & 243 & & 209 & & 145 & & 111 \\
\hline
\end{tabular}

3.2: Women with high pre-birth employment rates (0.66-1)

\begin{tabular}{|c|c|c|c|c|c|c|}
\hline $\begin{array}{l}\text { Inactive and } \\
\text { unemployed } \\
\text { quarters included }\end{array}$ & Sig. & $\begin{array}{l}\text { Inactive } \\
\text { quarters } \\
\text { excluded }\end{array}$ & Sig. & $\begin{array}{c}\text { Unemployed } \\
\text { quarters } \\
\text { excluded }\end{array}$ & Sig. & $\begin{array}{l}\text { Inactive and } \\
\text { unemployed } \\
\text { quarters excluded }\end{array}$ \\
\hline
\end{tabular}

a: G2 South-EU women

\begin{tabular}{|c|c|c|c|c|c|c|c|}
\hline $\begin{array}{c}\text { Quarter } \\
1\end{array}$ & 1.601 & & 1.819 & & 2.766 & 3.904 & $*$ \\
\hline $\begin{array}{c}\text { Quarter } \\
2\end{array}$ & -0.777 & & -1.134 & & -0.049 & 0.388 & \\
\hline $\begin{array}{c}\text { Quarter } \\
3\end{array}$ & -2.505 & & -3.372 & $*$ & -1.239 & -0.761 & $*$ \\
\hline $\begin{array}{c}\text { Quarters } \\
4-7\end{array}$ & -3.081 & $*$ & -3.035 & $*$ & -2.114 & -1.093 & \\
\hline $\begin{array}{c}\text { Quarters } \\
8-11\end{array}$ & -0.608 & & -0.930 & & -0.649 & -0.321 & $*$ \\
\hline$N$ & persons & 451 & & 416 & & 417 & 382 \\
\hline
\end{tabular}


Table 3 (continued)

\begin{tabular}{|c|c|c|c|c|c|c|c|}
\hline \multirow[b]{2}{*}{$\begin{array}{l}\text { Quarter } \\
1\end{array}$} & \multicolumn{7}{|c|}{ b: G2 Turkish/Moroccan women } \\
\hline & -1.385 & -1.702 & & -2.212 & & -0.701 & $* *$ \\
\hline $\begin{array}{l}\text { Quarter } \\
2\end{array}$ & -5.594 & -5.255 & $*$ & -6.475 & $*$ & -4.945 & \\
\hline $\begin{array}{l}\text { Quarter } \\
3\end{array}$ & -3.741 & -4.712 & & -3.729 & & -2.437 & \\
\hline $\begin{array}{l}\text { Quarters } \\
4-7\end{array}$ & -3.796 & -4.853 & $*$ & -4.339 & & -4.172 & \\
\hline $\begin{array}{l}\text { Quarters } \\
8-11\end{array}$ & 4.048 & 2.636 & & 1.560 & & 0.645 & \\
\hline $\begin{array}{l}N \\
\text { persons }\end{array}$ & 142 & 130 & & 125 & & 113 & \\
\hline
\end{tabular}

Significant levels: $* p<0.05, * * p<0.01 ; * * * p<0.001$

Source: BASD Panel, 1999-2010, calculations by authors

Rubin et al. 2008; Vidal-Coso 2019). In line with prior research for Belgium (Kil et al. 2018), the stratification in terms of observed pre-birth labour market positions seems to suggest that the birth of a first child has a stronger impact on the labour market participation of migrant origin women compared to native women, with the largest difference for Turkish or Moroccan origin women (which would seemingly confirm H1). Employed second-generation migrant women reduce their working hours to a larger extent compared to natives and are also less likely to substantially increase their working hours in case they were not employed before childbirth, but this may reflect differential employment stability rather than a differential impact of parenthood on employment trajectories.

In contrast, the stratification in terms of employment rates-which reflects women's predicted or average employment intensity - suggests that migrantnative differentials in the adjustment of working hours after the birth of the first child can be largely explained by native and migrant origin women's differential pre-birth labour market attachment (thus largely confirming H2). As an indicator for women's pre-birth labour market attachment, we use estimated employment rates of women who do not (yet) have children, but otherwise have similar age and socio-economic characteristics. Estimated pre-birth employment rates offer a more representative and robust indicator of women's pre-birth labour market attachment than observed pre-birth employment positions measured at a specific time point as the latter disregard variation in employment stability, which may differ between migrants and natives. Using an indicator that is robust to such differential stability in pre-birth employment trajectories, we find no migrant-native differentials among women with low pre-birth employment rates and only limited differentials among women with medium and high pre-birth employment rates. This indicates that there is a strong path-dependency of both native and migrant women's employment trajectories around the transition to parenthood but that migrant 
origin women generally have lower pre-birth employment rates compared to native women.

In line with economic theories, our results indicate that women's pre-birth wage potential significantly affects their changes in working hours after the transition to parenthood. Migrant-native differentials in women's pre-birth wage potential appear to be less pronounced among women with similar pre-birth employment, rates and additionally controlling for women's pre-birth wage potential results in (almost) no change in the difference with native women's employment trajectories after the transition to parenthood (H3 rejected). This suggests that it is mostly the differential pre-birth labour market attachment that accounts for the migrant-native gap in employment trajectories around the transition to parenthood, which may reflect the rigidity of the Belgian labour market consisting of insiders and outsiders (Van Dooren et al. 2014).

Since omitting partners' characteristics in research on maternal employment may yield biased results, this study also takes the migration background and prebirth employment and wage potential of women's partners into account. Additionally controlling for these partner characteristics results, however, in almost no change in migrant-native differentials. In addition to absolute labour market positions of women and their partners, micro-economic and bargaining theories suggest that women's relative position in the household also potentially determines their employment trajectories around family formation (Becker 1991; Lundberg and Pollak 1996; Wood et al. 2018). To get more insight on the couple dynamics and gender impact of family formation among native and migrant origin couples, future research could focus in more detail on partners' relative household positions using couples as research units.

Some limitations of this study should be mentioned. First, despite the fact that fixed-effects models provide a more convincing tool to approximate the causal effects of family formation on employment trajectories compared to crosssectional or pooled regression strategies by accounting for time-constant (un)observed heterogeneity between women, spuriousness may still result from time-varying individual-level characteristics that are not captured in our models (e.g. gender role attitudes may not be stable over the life course ${ }^{19}$ ), and potential bias may remain due to reverse causality. Second, although the Belgian social security registers provide longitudinal microdata on the labour market positions of women and their partners, they do not allow us to consider (i) the flexibility and irregularity of working hours, (ii) involuntary part-time employment and (iii) gender role attitudes. Third, the focus of this study was limited to employment trajectories around first births, resulting in increasingly selective and small sample sizes as the firstborn approaches the age of three due to potentially selective higher-order childbearing patterns. As migrant-native differentials in employment trajectories around first births may be different than around second and higherorder births, and the wage potential of both partners may be more important among higher-order births, it would be worthwhile to investigate employment trajectories over subsequent births in future research. Fourth, we only considered

\footnotetext{
${ }^{19}$ Research indicates that the transition to parenthood results in more traditional gender role attitudes among both men and women (Baxter et al. 2015; Schober and Scott 2012).
} 
women who cohabited with their partner before the birth of the first child. Although we took into account whether women are no longer cohabiting with their partner, employment trajectories around parenthood may differ among lone mothers (Milewski et al. 2018). Fifth, small sample sizes for migrant origin women may have affected the precision of the estimates and significance levels. In addition, due to small sample sizes, we did not obtain robust estimates for Turkish and Moroccan origin women separately. Although prior research for Belgium indicates only limited differences in the motherhood-employment link of second-generation Turkish and Moroccan origin women (Kil et al. 2018), future research could elaborate more on the potentially different trajectories of Turkish and Moroccan origin women.

Despite these limitations, this study highlights the importance of a longitudinal and path-dependent life course perspective in research on and policy development for migrant origin women's labour force participation. In addition, our analyses advocate the use of more robust proxies of women's pre-birth labour market attachment by estimating pre-birth employment rates of women who do not (yet) have children, but otherwise similar age and socio-economic characteristics, over observed employment positions at an arbitrary moment before family formation as the latter potentially confound the effect of parenthood with differential stability of employment trajectories. As the results point out, migrant-native differentials in employment trajectories around the transition to parenthood can (largely) be traced back to women's differential prebirth labour market attachment. From a policy point of view, it is therefore vital to invest in improving employment positions of migrant origin women by tackling inequalities prior to childbearing to avoid unemployment and inactivity traps after motherhood. In addition, precarious pre-birth employment positions of migrant origin women appear to be reinforced by family policies that primarily support women who are firmly established in the labour market, since access to formal childcare and parental leave in Belgium are conditioned on stable employment positions (Kil et al. 2017; Van Lancker and Ghysels 2012; Vandenbroeck et al. 2008). Universal access to flexible family policies is therefore likely to support migrant origin women with a low labour market attachment to combine motherhood with spells of employment. Future research should assess whether the same patterns arise in other contexts characterised by (i) universal access to childcare and parental leave (e.g. Sweden), resulting in small migrant-native differentials in the uptake of family policies (Mussino and Duvander 2016), or (ii) family policies in favour of the one-and-a-half-earner model (e.g. Germany).

Authors' Contributions The three authors designed the study jointly. JM prepared the literature review, analysed the data and drafted, revised and finalised the manuscript. $\mathrm{KN}$ is responsible for data acquisition and developed the predicted employment probabilities used in the model stratification. JW developed the fixedeffects design. Both $\mathrm{KN}$ and JW helped with the interpretation of the results and critically revised the paper. All authors read and approved the final manuscript.

Funding This research was funded by the Federal Science Policy (Grant Number BR/165/A4/IMMIGBEL) and by the Research Foundation Flanders (Grant Number G066217N). The funders had no role in the study design, data collection and analysis and decision to publish of preparation of the manuscript. 


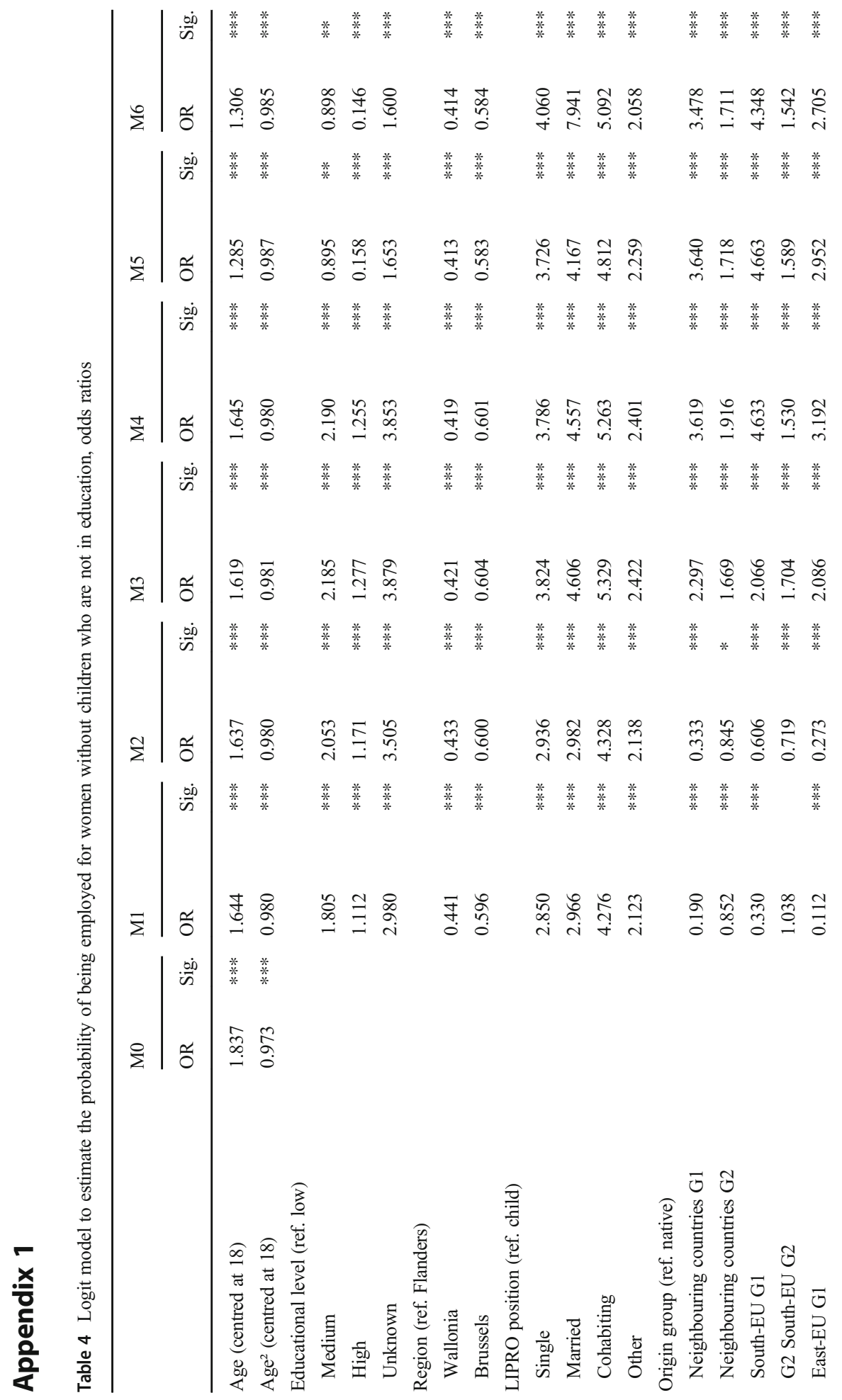




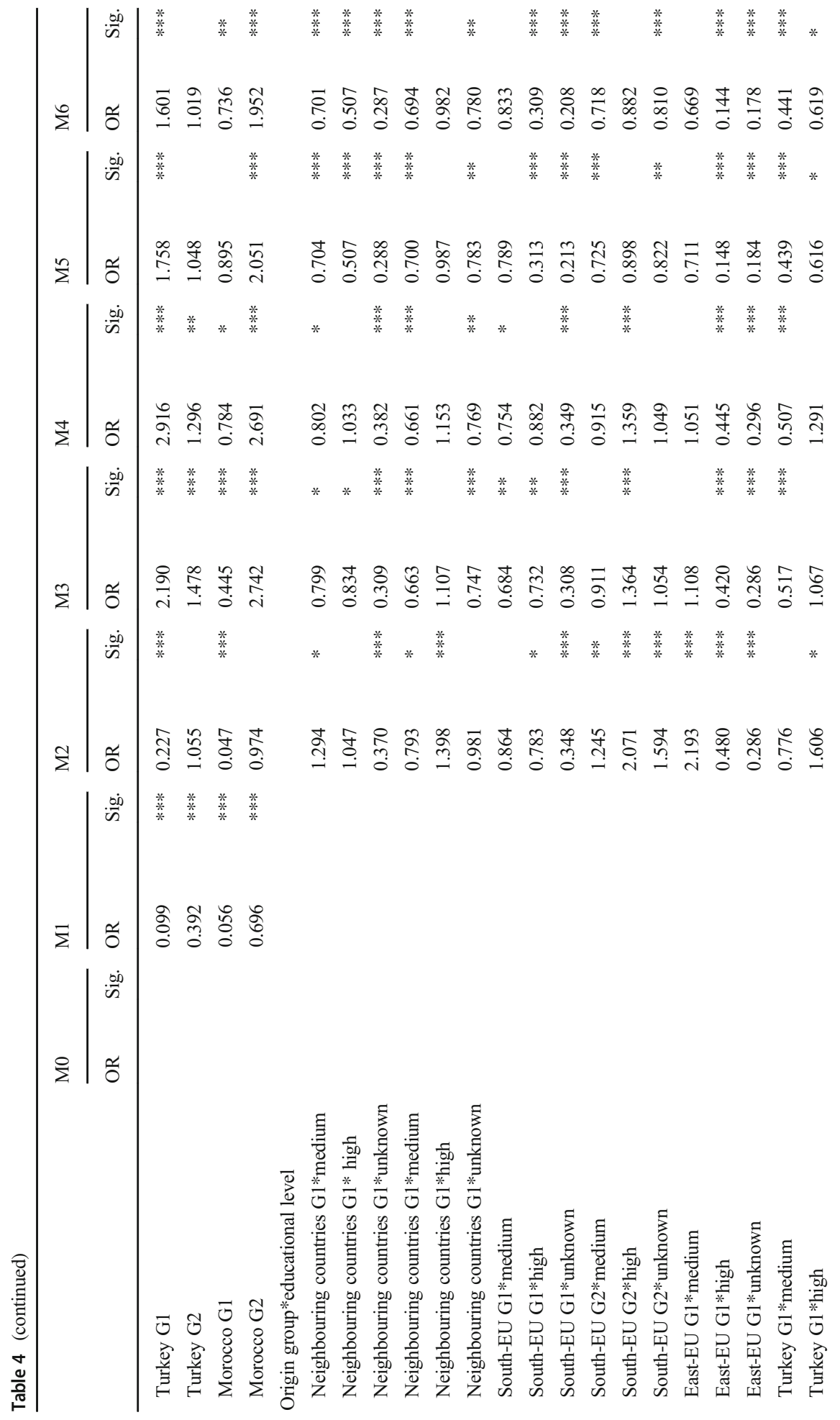




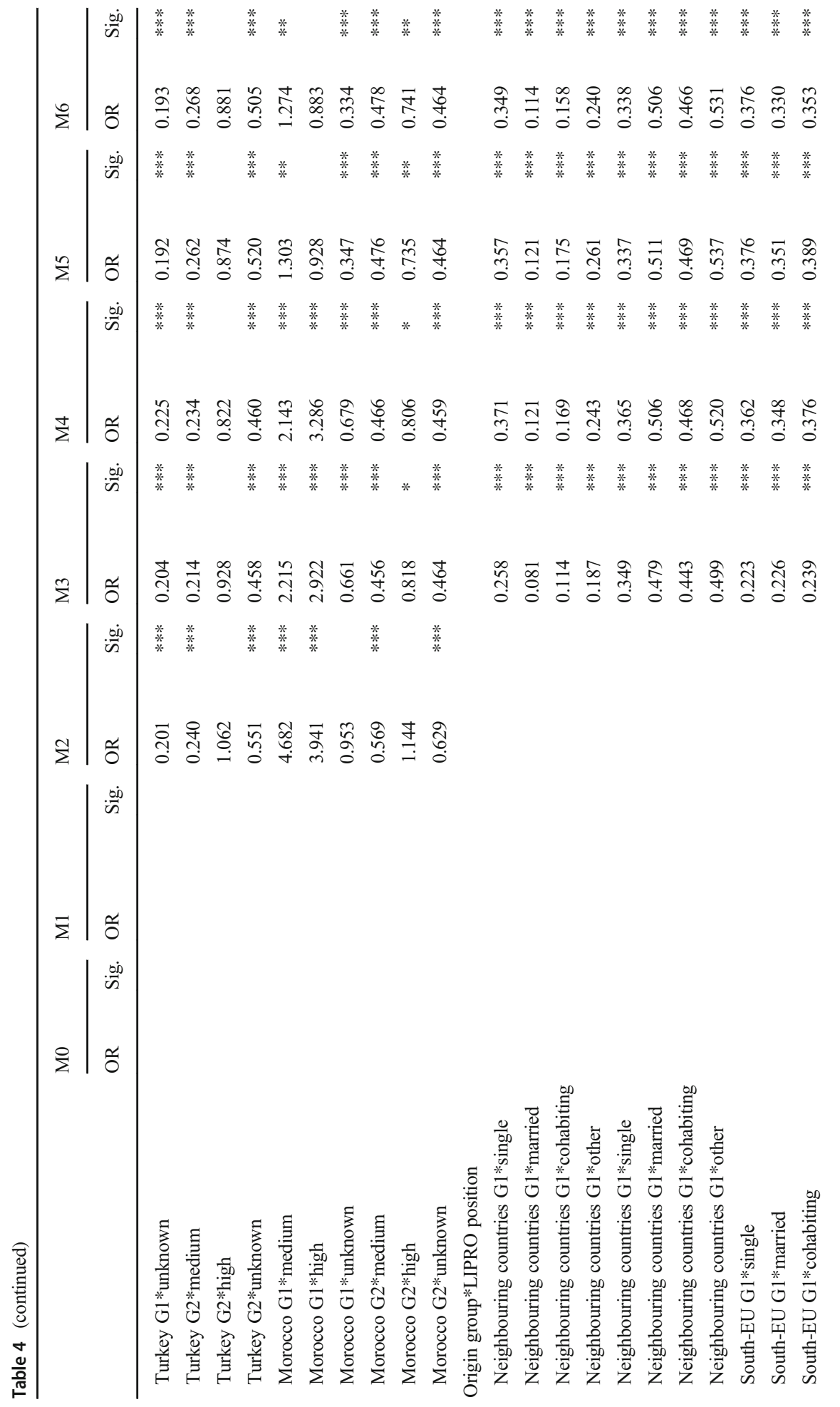




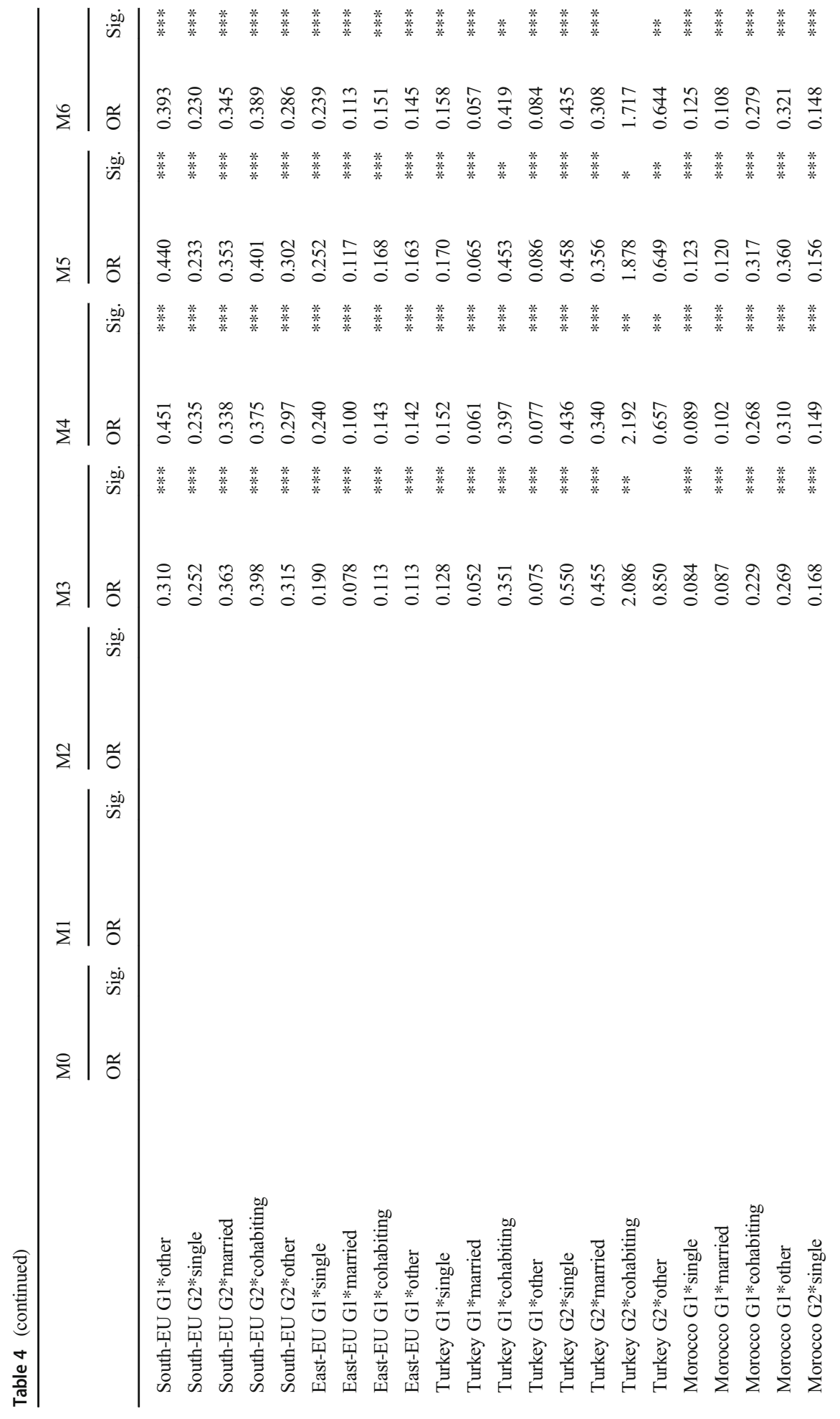




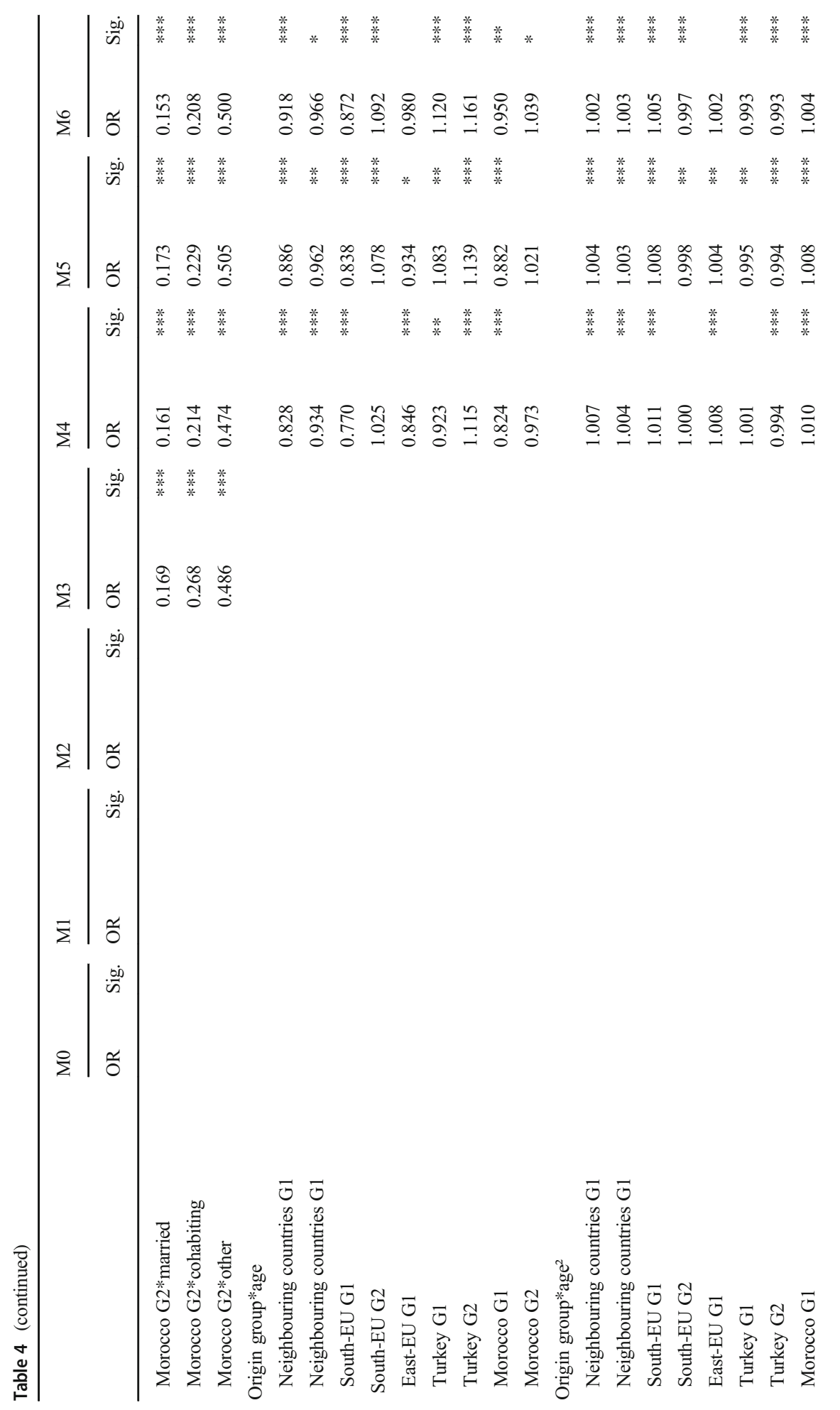




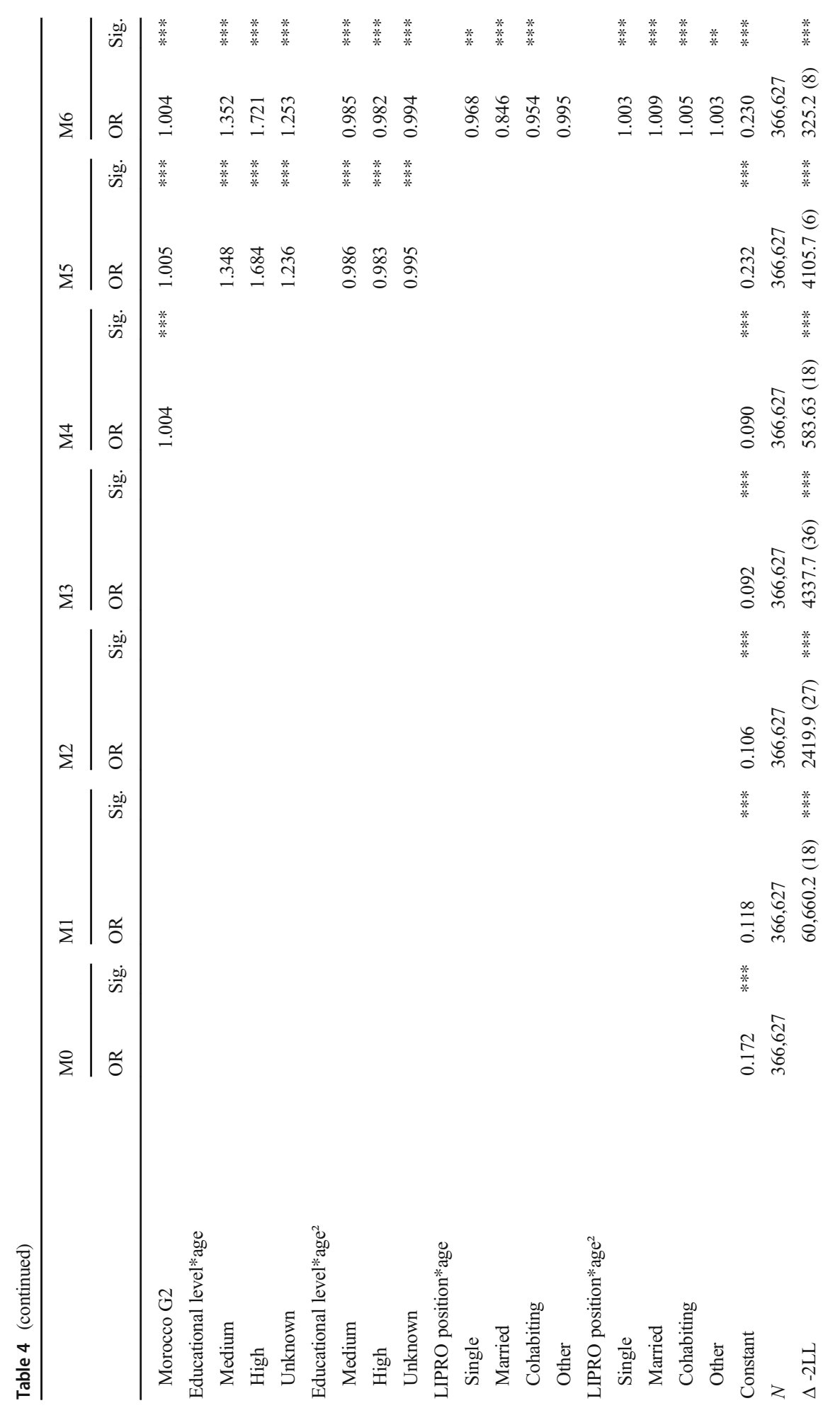




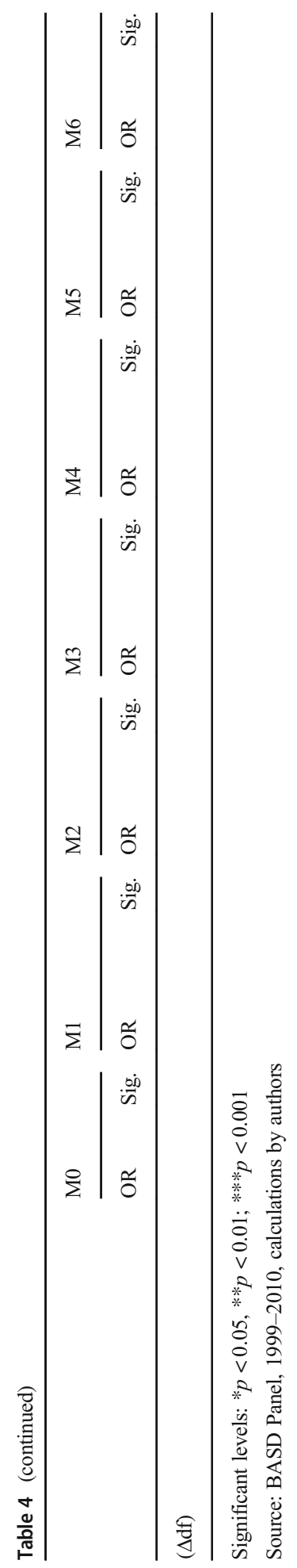

를 Springer 
Table 5 Multinomial logit model to estimate the probability of being employed with a low, medium or high hourly wage for women who have no children and are employed and not in education

\begin{tabular}{|c|c|c|c|c|c|c|c|c|c|c|}
\hline & \multicolumn{2}{|l|}{ M0 } & \multicolumn{2}{|l|}{ M1 } & \multicolumn{2}{|l|}{ M2 } & \multicolumn{2}{|l|}{ M3 } & \multicolumn{2}{|l|}{ M4 } \\
\hline & Coef. & Sig. & Coef. & Sig. & Coef. & Sig. & Coef. & Sig. & Coef. & Sig. \\
\hline Low hourly wage & \multicolumn{10}{|c|}{ Base outcome } \\
\hline \multicolumn{11}{|l|}{ Medium hourly wage } \\
\hline Age (centred at 18) & 0.653 & $* * *$ & 0.580 & $* * *$ & 0.576 & $* * *$ & 0.580 & $* * *$ & 9.380 & $* * *$ \\
\hline $\mathrm{Age}^{2}$ (centred at 18) & -0.026 & $* * *$ & -0.022 & $* * *$ & -0.022 & $* * *$ & -0.022 & $* * *$ & -6.700 & $* * *$ \\
\hline \multicolumn{11}{|l|}{ Educational level (ref. low) } \\
\hline Medium & & & 0.813 & $* * *$ & 1.059 & $* * *$ & 1.066 & $* * *$ & 6.120 & $* * *$ \\
\hline High & & & 2.052 & $* * *$ & 2.305 & $* * *$ & 2.311 & $* * *$ & 9.000 & $* * *$ \\
\hline Unknown & & & 1.348 & $* * *$ & 1.509 & $* * *$ & 1.512 & $* * *$ & - & \\
\hline 10.320 & $* * *$ & & & & & & & & & \\
\hline \multicolumn{11}{|l|}{ Region (ref. Flanders) } \\
\hline Wallonia & & & -0.048 & $* * *$ & -0.039 & $* *$ & -0.042 & $* *$ & -3.970 & $* * *$ \\
\hline Brussels & & & 0.108 & $* * *$ & 0.110 & $* * *$ & 0.102 & $* * *$ & 3.320 & $* * *$ \\
\hline \multicolumn{11}{|l|}{ LIPRO position (ref. child) } \\
\hline Single & & & 0.262 & $* * *$ & 0.381 & $* * *$ & 0.369 & $* * *$ & 12.190 & $* * *$ \\
\hline Married & & & 0.304 & $* * *$ & 0.376 & $* * *$ & 0.361 & $* * *$ & 13.500 & $* * *$ \\
\hline Cohabiting & & & 0.424 & $* * *$ & 0.449 & $* * *$ & 0.438 & $* * *$ & 19.910 & $* * *$ \\
\hline Other & & & 0.170 & $* * *$ & 0.194 & $* * *$ & 0.183 & $* * *$ & 2.100 & $*$ \\
\hline \multicolumn{11}{|l|}{ Origin group (ref. native) } \\
\hline $\begin{array}{l}\text { Neighbouring countries } \\
\text { G1 }\end{array}$ & & & -0.492 & $* * *$ & 0.152 & & 0.507 & $*$ & 0.780 & \\
\hline $\begin{array}{l}\text { Neighbouring countries } \\
\text { G2 }\end{array}$ & & & -0.446 & $* * *$ & -0.562 & $*$ & -0.506 & $*$ & -2.460 & $*$ \\
\hline South-EU G1 & & & -0.884 & $* * *$ & -0.386 & & -0.476 & & -1.640 & \\
\hline South-EU G2 & & & -0.362 & $* * *$ & -0.273 & & -0.024 & & 0.680 & \\
\hline East-EU G1 & & & -1.058 & $* * *$ & 1.541 & $* * *$ & 1.892 & $* * *$ & 5.270 & $* * *$ \\
\hline Turkey G1 & & & -0.411 & $* * *$ & 1.367 & $* * *$ & 2.068 & $* * *$ & 4.170 & $* * *$ \\
\hline Turkey G2 & & & 0.253 & $* * *$ & 1.125 & $* * *$ & 0.796 & $* * *$ & 0.490 & \\
\hline Morocco G1 & & & -1.182 & $* * *$ & 0.277 & & 0.293 & & 0.770 & \\
\hline Morocco G2 & & & 0.060 & & -0.031 & & 0.230 & & -1.680 & \\
\hline \multicolumn{11}{|l|}{$\begin{array}{l}\text { Origin group*educational } \\
\text { level }\end{array}$} \\
\hline $\begin{array}{l}\text { Neighbouring countries } \\
\text { G1*medium }\end{array}$ & & & & & -0.569 & $* *$ & -0.559 & $* *$ & -2.490 & $*$ \\
\hline $\begin{array}{l}\text { Neighbouring countries } \\
\text { G1*high }\end{array}$ & & & & & -0.895 & $* * *$ & -0.840 & $* * *$ & -3.620 & $* * *$ \\
\hline $\begin{array}{l}\text { Neighbouring countries } \\
\text { G1*unknown }\end{array}$ & & & & & -0.509 & $* *$ & -0.481 & $* *$ & -4.320 & $* * *$ \\
\hline $\begin{array}{l}\text { Neighbouring countries } \\
\text { G1*medium }\end{array}$ & & & & & 0.220 & & 0.210 & & 0.840 & \\
\hline
\end{tabular}


Table 5 (continued)

\begin{tabular}{|c|c|c|c|c|c|c|c|c|c|c|}
\hline & \multicolumn{2}{|l|}{ M0 } & \multicolumn{2}{|l|}{ M1 } & \multicolumn{2}{|l|}{ M2 } & \multicolumn{2}{|l|}{ M3 } & \multicolumn{2}{|l|}{ M4 } \\
\hline & Coef. & Sig. & Coef. & Sig. & Coef. & Sig. & Coef. & Sig. & Coef. & Sig. \\
\hline $\begin{array}{l}\text { Neighbouring countries } \\
\text { G1*high }\end{array}$ & & & & & 0.086 & & 0.078 & & 0.350 & \\
\hline $\begin{array}{l}\text { Neighbouring countries } \\
\text { G1*unknown }\end{array}$ & & & & & 0.573 & $* *$ & 0.571 & $* *$ & 1.830 & \\
\hline South-EU G1*medium & & & & & -0.589 & $* *$ & -0.642 & $* *$ & -2.090 & $*$ \\
\hline South-EU G1*high & & & & & -0.547 & $*$ & -0.552 & $*$ & -2.480 & $*$ \\
\hline South-EU G1*unknown & & & & & -0.382 & $*$ & -0.386 & $*$ & -4.900 & $* * *$ \\
\hline South-EU G2*medium & & & & & -0.611 & $* * *$ & -0.619 & $* * *$ & -3.640 & $* * *$ \\
\hline South-EU G2*high & & & & & 0.199 & & 0.176 & & 0.600 & \\
\hline South-EU G2*unknown & & & & & 0.402 & $* *$ & 0.405 & $* *$ & 1.410 & \\
\hline East-EU G1*medium & & & & & -0.176 & & -0.272 & & -0.870 & \\
\hline East-EU G1*high & & & & & -2.225 & $* * *$ & -2.175 & $* * *$ & -8.530 & $* * *$ \\
\hline East-EU G1*unknown & & & & & -1.298 & $* * *$ & -1.312 & $* * *$ & -9.050 & $* * *$ \\
\hline Turkey G1*medium & & & & & -2.400 & $* * *$ & -2.490 & $* * *$ & -5.050 & $* * *$ \\
\hline Turkey G1*high & & & & & -3.318 & $* * *$ & -2.652 & $* * *$ & -6.020 & $* * *$ \\
\hline Turkey G1*unknown & & & & & -1.825 & $* * *$ & -1.384 & $* * *$ & -4.870 & $* * *$ \\
\hline Turkey G2*medium & & & & & -0.698 & $* *$ & -0.671 & $* *$ & -2.730 & $* *$ \\
\hline Turkey G2*high & & & & & -0.915 & $* * *$ & -0.954 & $* * *$ & -2.570 & $* *$ \\
\hline Turkey G2*unknown & & & & & -0.363 & & -0.443 & & -0.460 & \\
\hline Morocco G1*medium & & & & & -0.429 & $*$ & -0.434 & $*$ & -2.330 & $*$ \\
\hline Morocco G1*high & & & & & -2.150 & $* * *$ & -2.158 & $* * *$ & -9.910 & $* * *$ \\
\hline Morocco G1*unknown & & & & & -0.362 & $*$ & -0.364 & $* *$ & -5.740 & $* * *$ \\
\hline Morocco G2*medium & & & & & 0.152 & & 0.088 & & 0.900 & \\
\hline Morocco G2*high & & & & & -0.419 & $*$ & -0.473 & $*$ & -2.150 & $*$ \\
\hline Morocco G2*unknown & & & & & 0.212 & & 0.173 & & 1.410 & \\
\hline \multicolumn{11}{|l|}{$\begin{array}{l}\text { Origin group*LIPRO } \\
\text { position }\end{array}$} \\
\hline $\begin{array}{l}\text { Neighbouring countries } \\
\text { G1*single }\end{array}$ & & & & & -0.397 & $*$ & -0.320 & & -0.920 & \\
\hline $\begin{array}{l}\text { Neighbouring countries } \\
\text { G1*married }\end{array}$ & & & & & -0.160 & & -0.092 & & 0.260 & \\
\hline $\begin{array}{l}\text { Neighbouring countries } \\
\text { G1*cohabiting }\end{array}$ & & & & & 0.001 & & 0.051 & & 1.670 & \\
\hline $\begin{array}{l}\text { Neighbouring countries } \\
\text { G1*other }\end{array}$ & & & & & -0.056 & & -0.037 & & 0.660 & \\
\hline $\begin{array}{l}\text { Neighbouring countries } \\
\text { G1*single }\end{array}$ & & & & & -0.762 & $* * *$ & -0.737 & $* * *$ & -5.860 & $* * *$ \\
\hline $\begin{array}{l}\text { Neighbouring countries } \\
\text { G1*married }\end{array}$ & & & & & -0.366 & $* * *$ & -0.341 & $* * *$ & -2.460 & $*$ \\
\hline $\begin{array}{l}\text { Neighbouring countries } \\
\text { G1*cohabiting }\end{array}$ & & & & & -0.235 & $*$ & -0.217 & $*$ & -1.540 & \\
\hline $\begin{array}{l}\text { Neighbouring countries } \\
\text { G1*other }\end{array}$ & & & & & -0.469 & $*$ & -0.450 & $*$ & -1.170 & \\
\hline
\end{tabular}


Table 5 (continued)

\begin{tabular}{|c|c|c|c|c|c|c|c|c|c|c|}
\hline & \multicolumn{2}{|l|}{ M0 } & \multicolumn{2}{|l|}{ M1 } & \multicolumn{2}{|l|}{ M2 } & \multicolumn{2}{|l|}{ M3 } & \multicolumn{2}{|l|}{ M4 } \\
\hline & Coef. & Sig. & Coef. & Sig. & Coef. & Sig. & Coef. & Sig. & Coef. & Sig. \\
\hline South-EU G1*single & & & & & 0.095 & & 0.049 & & 0.560 & \\
\hline South-EU G1*married & & & & & -0.393 & $*$ & -0.434 & $*$ & -1.750 & \\
\hline South-EU G1*cohabiting & & & & & 0.053 & & 0.018 & & 0.030 & \\
\hline South-EU G1*other & & & & & -0.730 & $*$ & -0.767 & $*$ & -2.040 & $*$ \\
\hline South-EU G2*single & & & & & -0.431 & $* * *$ & -0.328 & $* * *$ & -3.240 & $* * *$ \\
\hline South-EU G2*married & & & & & -0.534 & $* * *$ & -0.456 & $* * *$ & -5.530 & $* * *$ \\
\hline South-EU G2*cohabiting & & & & & -0.440 & $* * *$ & -0.363 & $* * *$ & -4.090 & $* * *$ \\
\hline South-EU G2*other & & & & & 0.070 & & 0.117 & & 1.460 & \\
\hline East-EU G1*single & & & & & -1.769 & $* * *$ & -1.517 & $* * *$ & -3.560 & $* * *$ \\
\hline East-EU G1*married & & & & & -1.481 & $* * *$ & -1.191 & $* * *$ & -2.670 & $* *$ \\
\hline East-EU G1*cohabiting & & & & & -1.168 & $* * *$ & -0.885 & $* *$ & -1.470 & \\
\hline East-EU G1*other & & & & & -1.333 & $* * *$ & -1.202 & $* *$ & -1.640 & \\
\hline Turkey G1*single & & & & & -0.610 & & -0.130 & & 0.970 & \\
\hline Turkey G1*married & & & & & -0.482 & & -0.029 & & 0.330 & \\
\hline Turkey G1*cohabiting & & & & & 1.565 & $* * *$ & 1.726 & $* * *$ & 4.830 & $* * *$ \\
\hline Turkey G1*other & & & & & -1.602 & $* *$ & -1.353 & $* *$ & -1.920 & \\
\hline Turkey G2*single & & & & & -1.501 & $* * *$ & -1.859 & $* * *$ & -6.160 & $* * *$ \\
\hline Turkey G2*married & & & & & -0.435 & $* *$ & -0.681 & $* * *$ & -2.500 & $*$ \\
\hline Turkey G2*cohabiting & & & & & 0.166 & & -0.250 & & -0.510 & \\
\hline Turkey G2*other & & & & & -0.704 & $*$ & -0.933 & $* *$ & -2.140 & $*$ \\
\hline Morocco G1*single & & & & & -1.225 & $* * *$ & -1.210 & $* * *$ & -4.910 & $* * *$ \\
\hline Morocco G1*married & & & & & -1.065 & $* * *$ & -1.044 & $* * *$ & -4.140 & $* * *$ \\
\hline Morocco G1*cohabiting & & & & & -0.953 & $* * *$ & -0.949 & $* * *$ & -2.540 & $*$ \\
\hline Morocco G1*other & & & & & -0.876 & $* * *$ & -0.866 & $* * *$ & -2.520 & $*$ \\
\hline Morocco G2*single & & & & & -0.403 & $* *$ & -0.331 & $* *$ & -1.710 & \\
\hline Morocco G2*married & & & & & -0.003 & & 0.039 & & 1.360 & \\
\hline Morocco G2*cohabiting & & & & & 0.740 & $* * *$ & 0.818 & $* * *$ & 4.430 & $* * *$ \\
\hline Morocco G2*other & & & & & 0.177 & & 0.193 & & 1.840 & \\
\hline \multicolumn{11}{|l|}{ Origin group*age } \\
\hline $\begin{array}{l}\text { Neighbouring countries } \\
\text { G1 }\end{array}$ & & & & & & & -0.046 & $* * *$ & -1.180 & \\
\hline $\begin{array}{l}\text { Neighbouring countries } \\
\text { G1 }\end{array}$ & & & & & & & -0.008 & & 0.510 & \\
\hline South-EU G1 & & & & & & & 0.011 & & 2.020 & $*$ \\
\hline South-EU G2 & & & & & & & -0.035 & $* * *$ & -4.900 & $* * *$ \\
\hline East-EU G1 & & & & & & & -0.059 & $* *$ & -2.200 & $*$ \\
\hline Turkey G1 & & & & & & & -0.160 & $* * *$ & -3.130 & $* *$ \\
\hline Turkey G2 & & & & & & & 0.092 & $* * *$ & 6.170 & $* * *$ \\
\hline Morocco G1 & & & & & & & -0.003 & & 1.240 & \\
\hline Morocco G2 & & & & & & & -0.033 & $* *$ & 1.920 & \\
\hline
\end{tabular}

Educational level*age 
Table 5 (continued)

\begin{tabular}{|c|c|c|c|c|c|c|c|c|c|c|}
\hline & \multicolumn{2}{|l|}{ M0 } & \multicolumn{2}{|l|}{ M1 } & \multicolumn{2}{|l|}{ M2 } & \multicolumn{2}{|l|}{ M3 } & \multicolumn{2}{|l|}{ M4 } \\
\hline & Coef. & Sig. & Coef. & Sig. & Coef. & Sig. & Coef. & Sig. & Coef. & Sig. \\
\hline Medium & & & & & & & & & 2.670 & $* *$ \\
\hline High & & & & & & & & & 10.780 & $* * *$ \\
\hline Unknown & & & & & & & & & 22.260 & $* * *$ \\
\hline \multicolumn{11}{|l|}{ Educational level*age ${ }^{2}$} \\
\hline Medium & & & & & & & & & -2.260 & $*$ \\
\hline High & & & & & & & & & -9.470 & $* * *$ \\
\hline Unknown & & & & & & & & & - & \\
\hline 16.090 & $* * *$ & & & & & & & & & \\
\hline Constant & -3.230 & $* * *$ & -4.430 & $* * *$ & -4.641 & $* * *$ & -4.666 & $* * *$ & - & \\
\hline 28.770 & $* * *$ & & & & & & & & & \\
\hline \multicolumn{11}{|l|}{ High hourly wage } \\
\hline Age (centred at 18) & 0.935 & $* * *$ & 0.845 & $* * *$ & 0.848 & $* * *$ & 0.854 & $* * *$ & 2.060 & $* * *$ \\
\hline $\operatorname{Age}^{2}$ (centred at 18) & -0.031 & $* * *$ & -0.026 & $* * *$ & -0.026 & $* * *$ & -0.027 & $* * *$ & -1.110 & $* * *$ \\
\hline \multicolumn{11}{|l|}{ Educational level (ref. low) } \\
\hline Medium & & & 1.139 & $* * *$ & 2.231 & $* * *$ & 2.236 & $* * *$ & 5.740 & $* * *$ \\
\hline High & & & 4.118 & $* * *$ & 5.398 & $* * *$ & 5.399 & $* * *$ & -0.990 & $* * *$ \\
\hline Unknown & & & 2.975 & $* * *$ & 4.085 & $* * *$ & 4.087 & $* * *$ & -3.990 & $* * *$ \\
\hline \multicolumn{11}{|l|}{ Region (ref. Flanders) } \\
\hline Wallonia & & & 0.522 & $* * *$ & 0.521 & $* * *$ & 0.518 & $* * *$ & 28.360 & $* * *$ \\
\hline Brussels & & & 0.443 & $* * *$ & 0.475 & $* * *$ & 0.468 & $* * *$ & 15.670 & $* * *$ \\
\hline \multicolumn{11}{|l|}{ LIPRO position (ref. child) } \\
\hline Single & & & 1.304 & $* * *$ & 1.536 & $* * *$ & 1.528 & $* * *$ & 52.500 & $* * *$ \\
\hline Married & & & 0.519 & $* * *$ & 0.601 & $* * *$ & 0.593 & $* * *$ & 19.160 & $* * *$ \\
\hline Cohabiting & & & 0.556 & $* * *$ & 0.566 & $* * *$ & 0.561 & $* * *$ & 19.440 & $* * *$ \\
\hline Other & & & 0.216 & $* * *$ & 0.195 & $* * *$ & 0.190 & $* * *$ & 1.860 & \\
\hline \multicolumn{11}{|l|}{ Origin group (ref. native) } \\
\hline $\begin{array}{l}\text { Neighbouring countries } \\
\text { G1 }\end{array}$ & & & -0.475 & $* * *$ & 0.619 & & 0.072 & & -0.500 & \\
\hline $\begin{array}{l}\text { Neighbouring countries } \\
\text { G2 }\end{array}$ & & & -0.794 & $* * *$ & 1.262 & $* *$ & 1.239 & $* *$ & 2.330 & $*$ \\
\hline South-EU G1 & & & -0.935 & $* * *$ & -0.138 & & -0.783 & & -0.620 & \\
\hline South-EU G2 & & & -1.293 & $* * *$ & 0.342 & & 0.414 & & 0.760 & \\
\hline East-EU G1 & & & -1.248 & $* * *$ & 2.357 & $* * *$ & 2.947 & $* * *$ & 4.860 & $* * *$ \\
\hline Turkey G1 & & & -1.203 & $* * *$ & 2.249 & $* * *$ & 3.514 & $* * *$ & 2.710 & $* *$ \\
\hline Turkey G2 & & & -0.581 & $* * *$ & 2.856 & $* * *$ & 2.635 & $* * *$ & 2.320 & $*$ \\
\hline Morocco G1 & & & -2.592 & $* * *$ & 1.557 & $* * *$ & 2.772 & $* * *$ & 4.000 & $* * *$ \\
\hline Morocco G2 & & & -0.513 & $* * *$ & 0.975 & $* *$ & 1.317 & $* * *$ & 1.460 & \\
\hline \multicolumn{11}{|l|}{$\begin{array}{l}\text { Origin group*educational } \\
\text { level }\end{array}$} \\
\hline $\begin{array}{l}\text { Neighbouring countries } \\
\text { G1*medium }\end{array}$ & & & & & -2.176 & $* * *$ & -2.207 & $* * *$ & -4.440 & $* * *$ \\
\hline
\end{tabular}


Table 5 (continued)

\begin{tabular}{|c|c|c|c|c|c|c|c|c|c|c|}
\hline & \multicolumn{2}{|l|}{ M0 } & \multicolumn{2}{|l|}{ M1 } & \multicolumn{2}{|l|}{ M2 } & \multicolumn{2}{|l|}{ M3 } & \multicolumn{2}{|l|}{ M4 } \\
\hline & Coef. & Sig. & Coef. & Sig. & Coef. & Sig. & Coef. & Sig. & Coef. & Sig. \\
\hline $\begin{array}{l}\text { Neighbouring countries } \\
\text { G1*high }\end{array}$ & & & & & -2.820 & $* * *$ & -2.828 & $* * *$ & -8.270 & $* * *$ \\
\hline $\begin{array}{l}\text { Neighbouring countries } \\
\text { G1*unknown }\end{array}$ & & & & & -1.389 & $* * *$ & -1.332 & $* * *$ & -5.390 & $* * *$ \\
\hline $\begin{array}{l}\text { Neighbouring countries } \\
\text { G1*medium }\end{array}$ & & & & & -0.570 & & -0.573 & & -1.030 & \\
\hline $\begin{array}{l}\text { Neighbouring countries } \\
\text { G1*high }\end{array}$ & & & & & -2.123 & $* * *$ & -2.122 & $* * *$ & -5.080 & $* * *$ \\
\hline $\begin{array}{l}\text { Neighbouring countries } \\
\text { G1*unknown }\end{array}$ & & & & & -1.170 & $* *$ & -1.171 & $* *$ & -3.220 & $* * *$ \\
\hline South-EU G1*medium & & & & & -2.599 & $* * *$ & -2.695 & $* * *$ & -5.280 & $* * *$ \\
\hline South-EU G1*high & & & & & -2.291 & $* * *$ & -2.205 & $* * *$ & -7.040 & $* * *$ \\
\hline South-EU G1*unknown & & & & & -1.240 & $* * *$ & -1.153 & $* * *$ & -6.100 & $* * *$ \\
\hline South-EU G2*medium & & & & & -0.766 & & -0.777 & & -1.030 & \\
\hline South-EU G2*high & & & & & -1.449 & $* *$ & -1.484 & $* * *$ & -3.270 & $* * *$ \\
\hline South-EU G2*unknown & & & & & -0.799 & & -0.825 & & -2.110 & $*$ \\
\hline East-EU G1*medium & & & & & -14.141 & & - & & & \\
\hline 16.017 & & - & 0.020 & & & & & & & \\
\hline East-EU G1*high & & & & & -3.016 & $* * *$ & -3.041 & $* * *$ & -7.250 & $* * *$ \\
\hline East-EU G1*unknown & & & & & -1.709 & $* * *$ & -1.813 & $* * *$ & -5.570 & $* * *$ \\
\hline Turkey G1*medium & & & & & -2.428 & $* *$ & -2.495 & $* *$ & -2.550 & $*$ \\
\hline Turkey G1*high & & & & & -5.930 & $* * *$ & -5.280 & $* * *$ & -6.110 & $* * *$ \\
\hline Turkey G1*unknown & & & & & -3.288 & $* * *$ & -2.857 & $* * *$ & -3.950 & $* * *$ \\
\hline Turkey G2*medium & & & & & -2.470 & $* * *$ & -2.426 & $* * *$ & -3.610 & $* * *$ \\
\hline Turkey G2*high & & & & & -3.006 & $* * *$ & -2.973 & $* * *$ & -3.550 & $* * *$ \\
\hline Turkey G2*unknown & & & & & -2.620 & $* * *$ & -2.662 & $* * *$ & -3.010 & $* * *$ \\
\hline Morocco G1*medium & & & & & -2.833 & $* * *$ & -3.098 & $* * *$ & -5.950 & $* * *$ \\
\hline Morocco G1*high & & & & & -5.642 & $* * *$ & -5.772 & $* * *$ & - & \\
\hline 16.330 & $* * *$ & & & & & & & & & \\
\hline Morocco G1*unknown & & & & & -3.341 & $* * *$ & -3.378 & $* * *$ & - & \\
\hline 15.350 & $* * *$ & & & & & & & & & \\
\hline Morocco G2*medium & & & & & -0.621 & & -0.717 & $*$ & -1.930 & \\
\hline Morocco G2*high & & & & & -1.389 & $* * *$ & -1.499 & $* * *$ & -4.020 & $* * *$ \\
\hline Morocco G2*unknown & & & & & -1.116 & $* * *$ & -1.207 & $* * *$ & -3.710 & $* * *$ \\
\hline \multicolumn{11}{|l|}{$\begin{array}{l}\text { Origin group*LIPRO } \\
\text { position }\end{array}$} \\
\hline $\begin{array}{l}\text { Neighbouring countries } \\
\text { G1*single }\end{array}$ & & & & & -0.193 & & -0.197 & & -0.270 & \\
\hline $\begin{array}{l}\text { Neighbouring countries } \\
\text { G1*married }\end{array}$ & & & & & 0.796 & $* *$ & 0.792 & $* *$ & 3.360 & $* * *$ \\
\hline $\begin{array}{l}\text { Neighbouring countries } \\
\text { G1*cohabiting }\end{array}$ & & & & & 0.968 & $* * *$ & 0.986 & $* * *$ & 4.410 & $* * *$ \\
\hline
\end{tabular}


Table 5 (continued)

\begin{tabular}{|c|c|c|c|c|c|c|c|c|c|c|}
\hline & \multicolumn{2}{|l|}{ M0 } & \multicolumn{2}{|l|}{ M1 } & \multicolumn{2}{|l|}{ M2 } & \multicolumn{2}{|l|}{ M3 } & \multicolumn{2}{|l|}{ M4 } \\
\hline & Coef. & Sig. & Coef. & Sig. & Coef. & Sig. & Coef. & Sig. & Coef. & Sig. \\
\hline $\begin{array}{l}\text { Neighbouring countries } \\
\text { G1*other }\end{array}$ & & & & & 0.502 & & 0.574 & & 2.030 & $*$ \\
\hline $\begin{array}{l}\text { Neighbouring countries } \\
\text { G1*single }\end{array}$ & & & & & -1.762 & $* * *$ & -1.760 & & - & \\
\hline 12.030 & $* * *$ & & & & & & & & & \\
\hline $\begin{array}{l}\text { Neighbouring countries } \\
\text { G1*married }\end{array}$ & & & & & -0.586 & $* * *$ & -0.584 & $* * *$ & -3.790 & $* * *$ \\
\hline $\begin{array}{l}\text { Neighbouring countries } \\
\text { G1*cohabiting }\end{array}$ & & & & & -0.399 & $* *$ & -0.400 & $* *$ & -2.560 & $* *$ \\
\hline $\begin{array}{l}\text { Neighbouring countries } \\
\text { G1*other }\end{array}$ & & & & & 0.284 & & 0.288 & & 2.350 & $*$ \\
\hline South-EU G1*single & & & & & 0.252 & & 0.041 & & 0.060 & \\
\hline South-EU G1*married & & & & & 0.593 & & 0.336 & & 0.820 & \\
\hline South-EU G1*cohabiting & & & & & 0.952 & $*$ & 0.736 & & 1.560 & \\
\hline South-EU G1*other & & & & & 1.235 & $* *$ & 1.035 & $*$ & 2.250 & $*$ \\
\hline South-EU G2*single & & & & & -1.499 & $* * *$ & -1.464 & $* * *$ & - & \\
\hline 11.650 & $* * *$ & & & & & & & & & \\
\hline South-EU G2*married & & & & & -0.933 & $* * *$ & -0.903 & $* * *$ & -7.640 & $* * *$ \\
\hline South-EU G2*cohabiting & & & & & -0.463 & $* * *$ & -0.435 & $* * *$ & -3.280 & $* * *$ \\
\hline South-EU G2*other & & & & & -0.887 & $* *$ & -0.883 & $* *$ & -2.760 & $* *$ \\
\hline East-EU G1*single & & & & & -2.637 & $* * *$ & -2.336 & $* * *$ & -4.430 & $* * *$ \\
\hline East-EU G1*married & & & & & -2.072 & $* * *$ & -1.712 & $* * *$ & -3.190 & $* * *$ \\
\hline East-EU G1*cohabiting & & & & & -0.603 & & -0.275 & & 0.070 & \\
\hline East-EU G1*other & & & & & -1.342 & $*$ & -1.168 & $*$ & -1.340 & \\
\hline Turkey G1*single & & & & & -1.269 & & -0.813 & & -0.470 & \\
\hline Turkey G1*married & & & & & -0.289 & & 0.417 & & 0.680 & \\
\hline Turkey G1*cohabiting & & & & & 1.250 & & 1.528 & $*$ & 2.480 & $*$ \\
\hline Turkey G1*other & & & & & 0.902 & & 1.143 & & 1.870 & \\
\hline Turkey G2*single & & & & & -2.112 & $* * *$ & -2.404 & $* * *$ & -5.010 & $* * *$ \\
\hline Turkey G2*married & & & & & -0.811 & $*$ & -1.044 & $* *$ & -1.960 & $*$ \\
\hline Turkey G2*cohabiting & & & & & -0.499 & & -0.779 & & -1.140 & \\
\hline Turkey G2*other & & & & & -0.726 & & -0.917 & & -0.590 & \\
\hline Morocco G1*single & & & & & -1.803 & $* * *$ & -1.392 & $* *$ & -2.060 & \\
\hline Morocco G1*married & & & & & -0.681 & & -0.305 & & 0.240 & \\
\hline Morocco G1*cohabiting & & & & & 0.276 & & 0.675 & & 2.130 & $*$ \\
\hline Morocco G1*other & & & & & -0.531 & & -0.222 & & 0.410 & \\
\hline Morocco G2*single & & & & & -1.356 & $* * *$ & -1.293 & $* * *$ & -5.960 & $* * *$ \\
\hline Morocco G2*married & & & & & -0.551 & $* * *$ & -0.520 & $* *$ & -2.500 & $*$ \\
\hline Morocco G2*cohabiting & & & & & 0.791 & $* *$ & 0.870 & $* * *$ & 3.660 & $* * *$ \\
\hline Morocco G2*other & & & & & 0.181 & & 0.179 & & 1.050 & \\
\hline
\end{tabular}

Origin group*age 
Table 5 (continued)

\begin{tabular}{|c|c|c|c|c|c|c|c|c|c|c|}
\hline & \multicolumn{2}{|l|}{ M0 } & \multicolumn{2}{|l|}{ M1 } & \multicolumn{2}{|l|}{ M2 } & \multicolumn{2}{|l|}{ M3 } & \multicolumn{2}{|l|}{ M4 } \\
\hline & Coef. & Sig. & Coef. & Sig. & Coef. & Sig. & Coef. & Sig. & Coef. & Sig. \\
\hline $\begin{array}{l}\text { Neighbouring countries } \\
\text { G1 }\end{array}$ & & & & & & & 0.038 & $* * *$ & 6.690 & $* * *$ \\
\hline $\begin{array}{l}\text { Neighbouring countries } \\
\text { G1 }\end{array}$ & & & & & & & 0.001 & & 2.550 & $*$ \\
\hline South-EU G1 & & & & & & & 0.061 & $* * *$ & 4.830 & $* * *$ \\
\hline South-EU G2 & & & & & & & -0.011 & & -0.480 & \\
\hline East-EU G1 & & & & & & & -0.073 & $* *$ & -2.050 & $*$ \\
\hline Turkey G1 & & & & & & & -0.218 & $* * *$ & -2.220 & $*$ \\
\hline Turkey G2 & & & & & & & 0.065 & $*$ & 3.170 & $*$ \\
\hline Morocco G1 & & & & & & & -0.111 & $* * *$ & -1.800 & \\
\hline Morocco G2 & & & & & & & -0.033 & & 2.680 & $* *$ \\
\hline \multicolumn{11}{|l|}{ Educational level*age } \\
\hline Medium & & & & & & & & & 0.180 & \\
\hline High & & & & & & & & & 18.520 & $* * *$ \\
\hline Unknown & & & & & & & & & 16.900 & $* * *$ \\
\hline \multicolumn{11}{|l|}{ Educational level*age $^{2}$} \\
\hline Medium & & & & & & & & & 0.630 & \\
\hline High & & & & & & & & & - & \\
\hline 15.260 & $* * *$ & & & & & & & & & \\
\hline Unknown & & & & & & & & & - & \\
\hline 11.780 & $* * *$ & & & & & & & & & \\
\hline Constant & & & & & & & & & - & \\
\hline 21.810 & $* * *$ & & & & & & & & & \\
\hline$N$ & 178,669 & & 178,669 & & 178,669 & & 178,669 & & 178,669 & \\
\hline$\Delta-2 \mathrm{LL}(\Delta \mathrm{df})$ & & & $\begin{array}{l}22,318.1 \\
\quad(36)\end{array}$ & $* * *$ & $\begin{array}{r}2206.8 \\
(126)\end{array}$ & $* * *$ & $\begin{array}{r}184.9 \\
(18)\end{array}$ & $* * *$ & $\begin{array}{r}3543.3 \\
(12)\end{array}$ & $* * *$ \\
\hline
\end{tabular}

Significant levels: $* p<0.05,{ }^{* *} p<0.01 ; * * * p<0.001$

Source: BASD Panel, 1999-2010, calculations by authors 


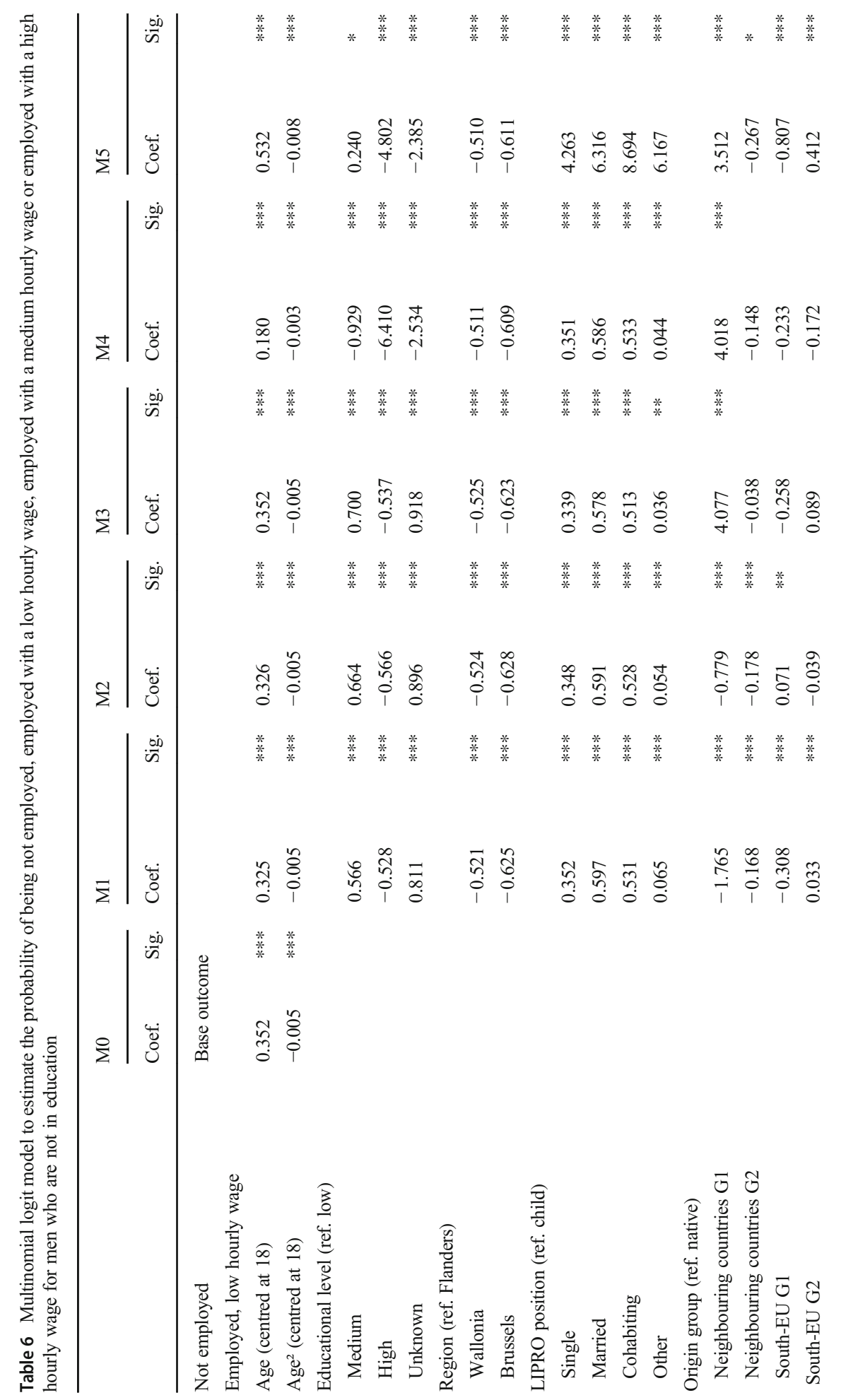




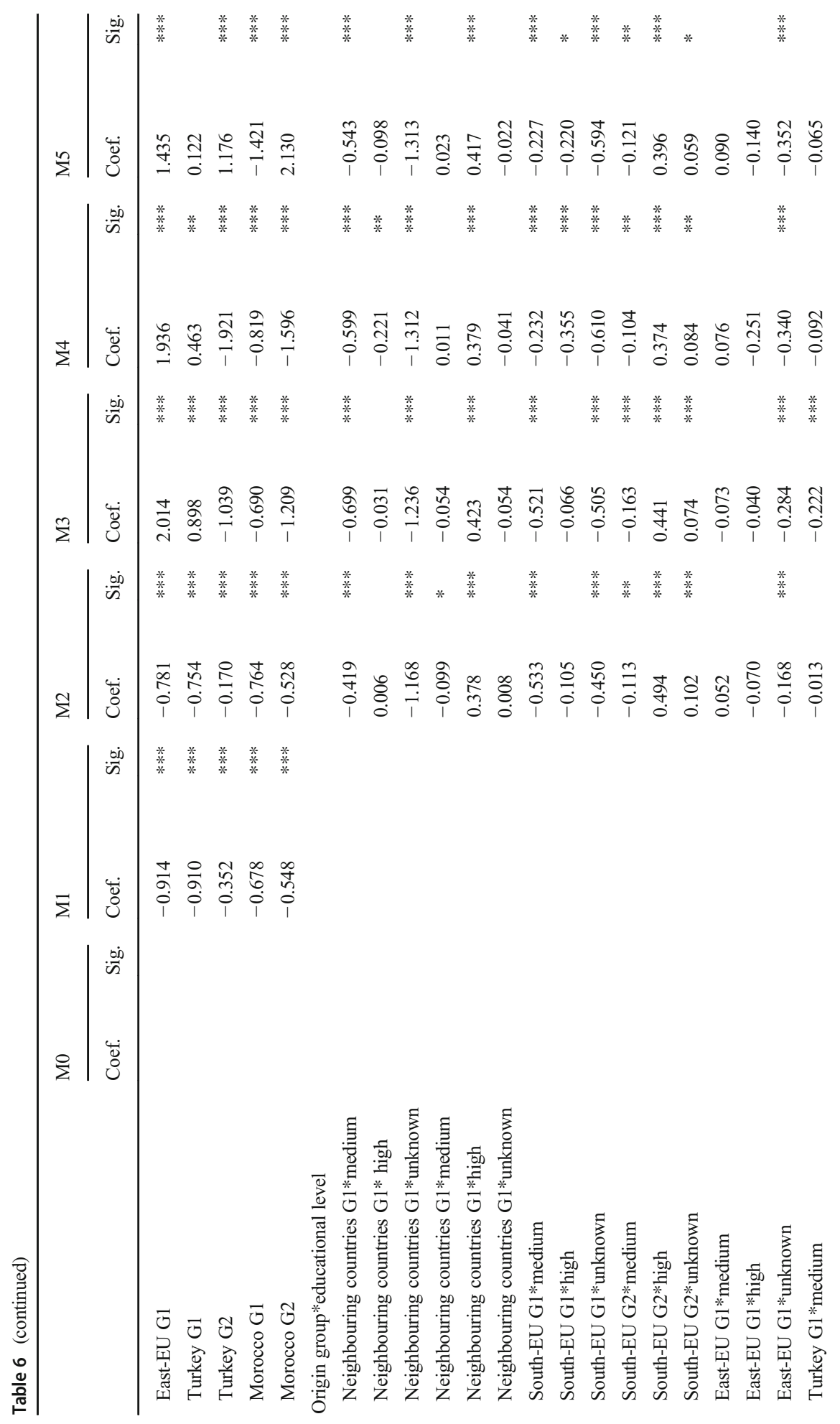




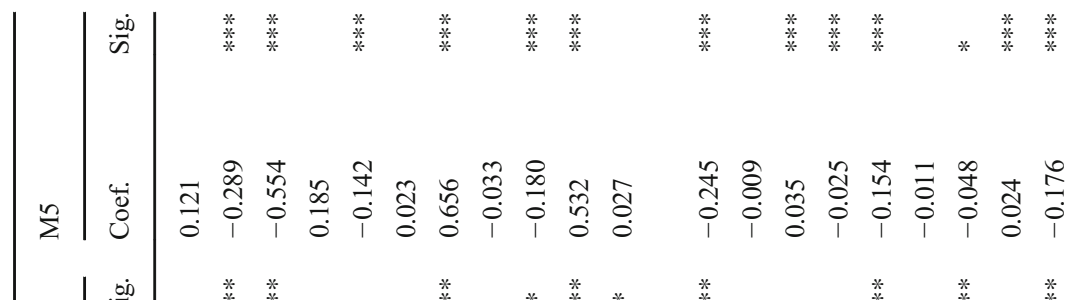

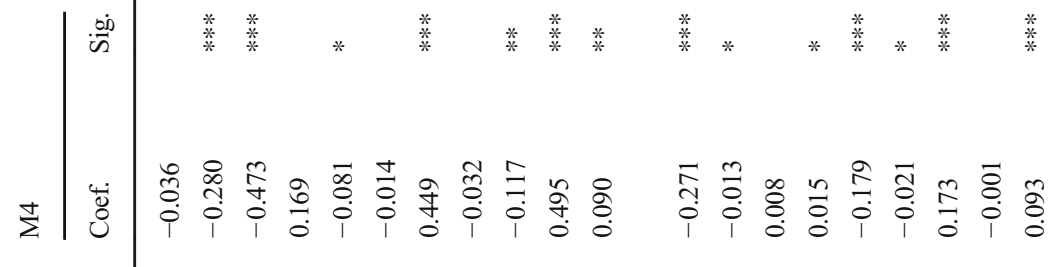

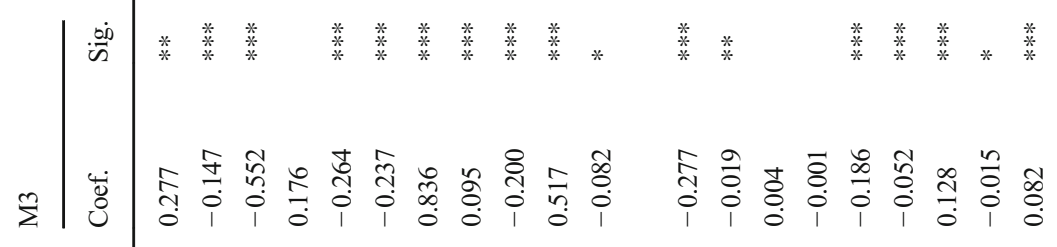

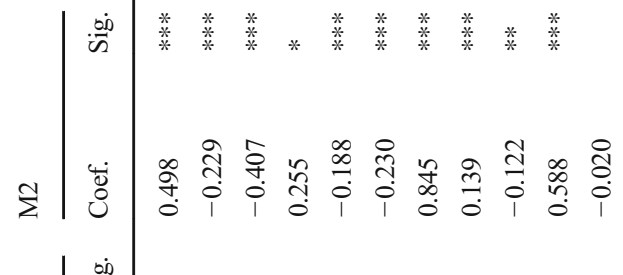

$$
\begin{aligned}
& \text { in } \\
& \bar{\Sigma} \mid \begin{array}{l}
\dot{8} \\
\dot{0}
\end{array}
\end{aligned}
$$

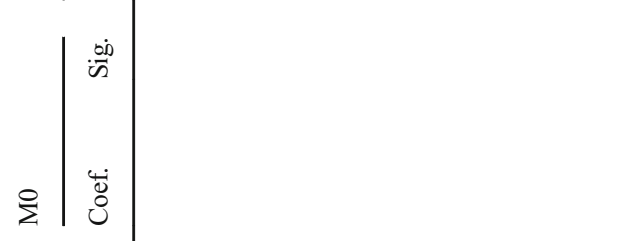




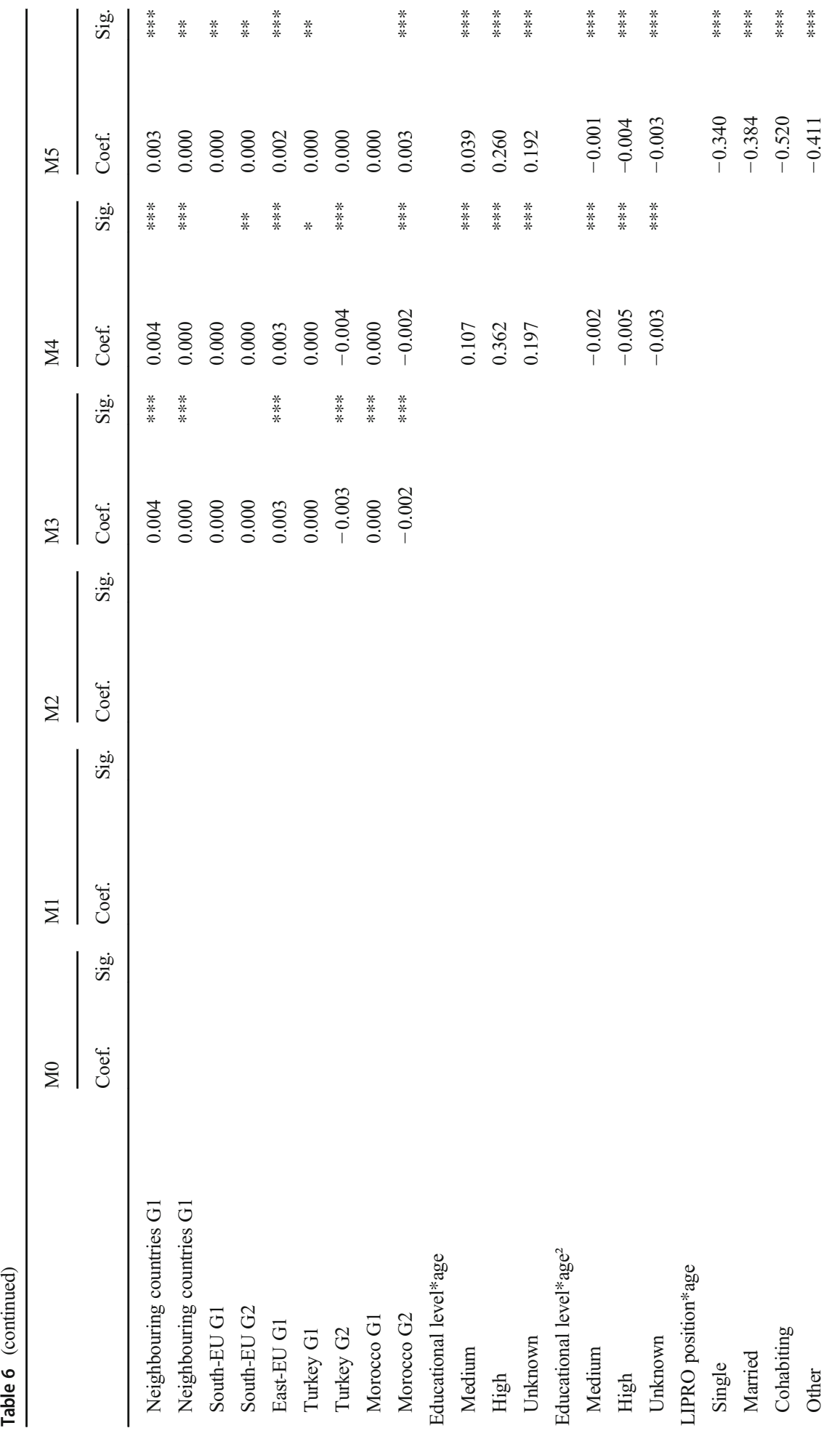




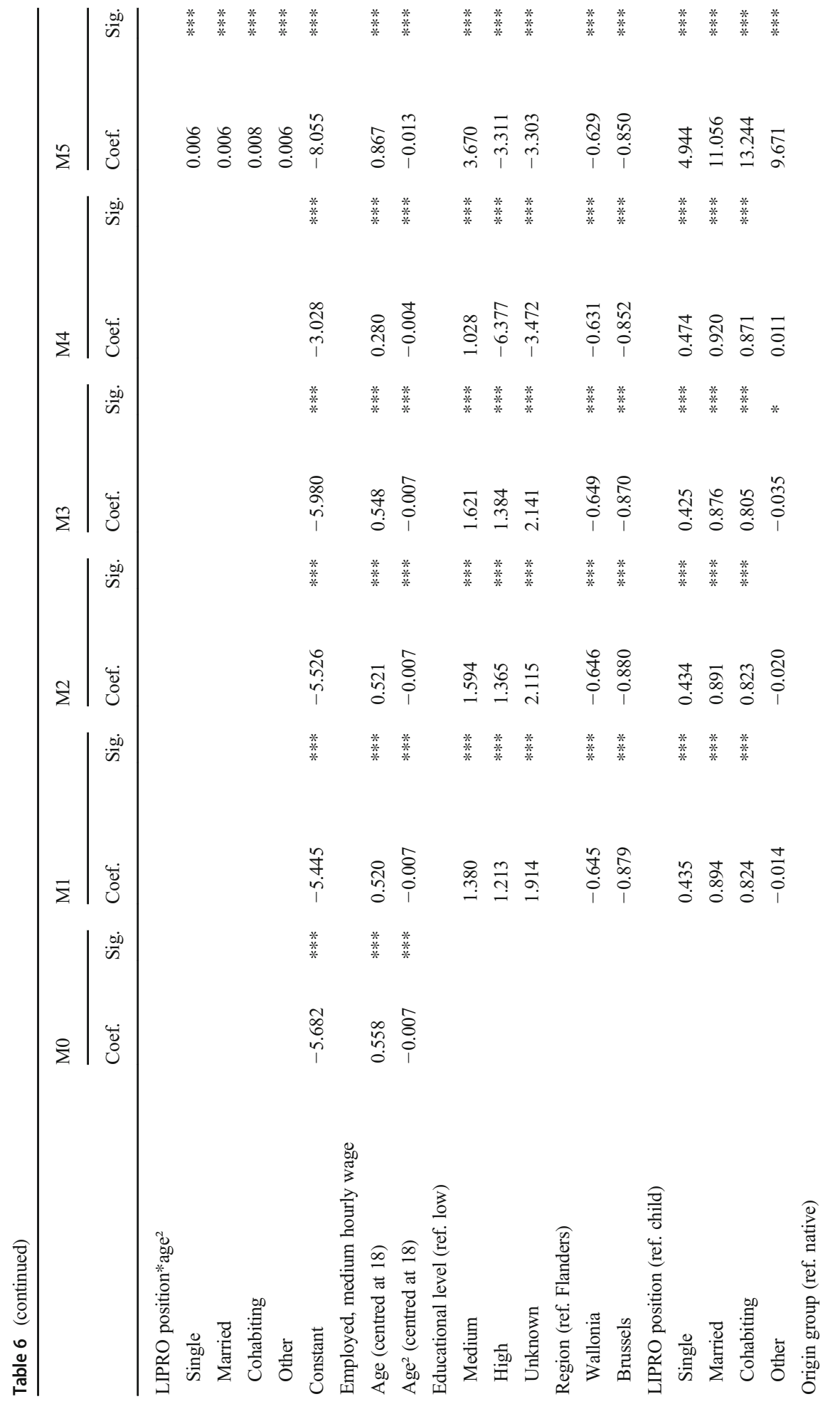




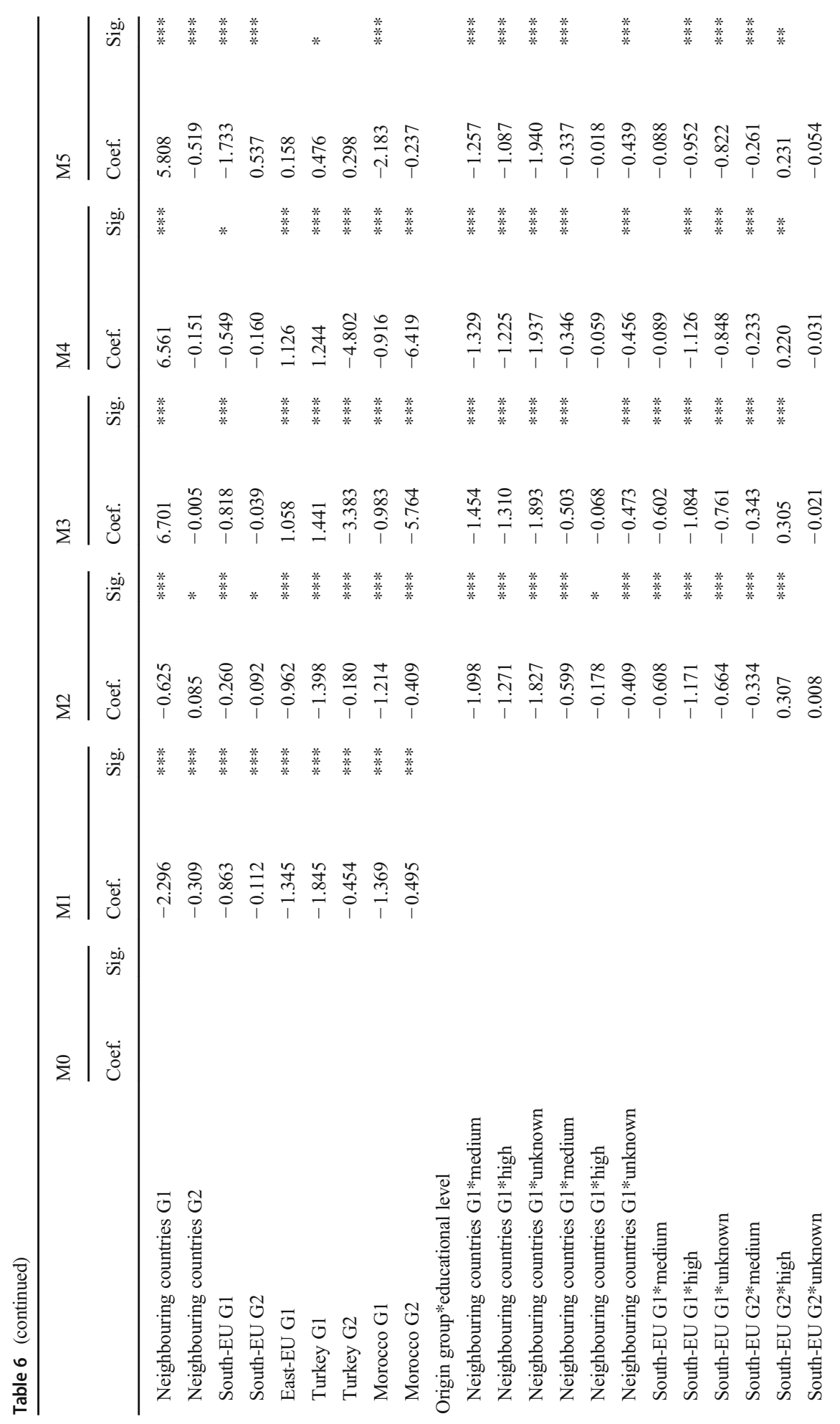




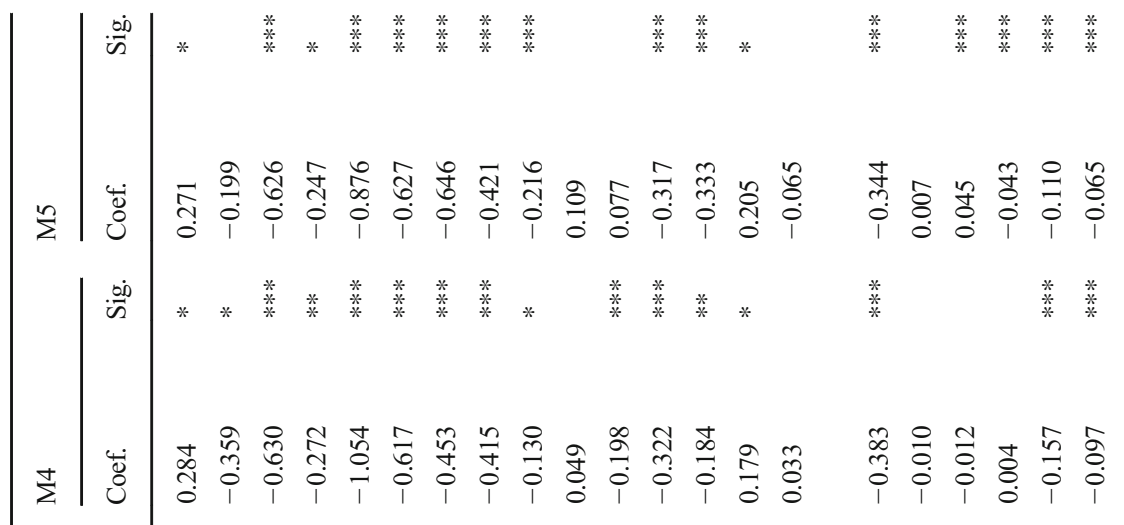

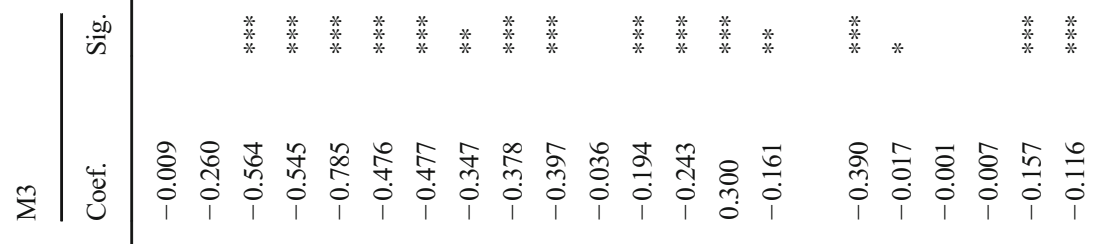

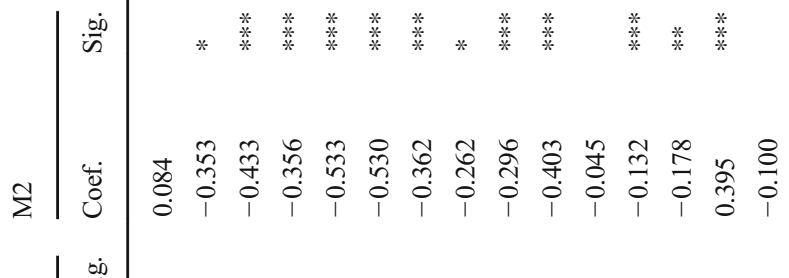

ind

$\bar{\Sigma} \mid \vec{\delta}$

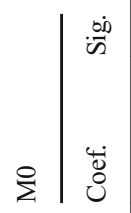




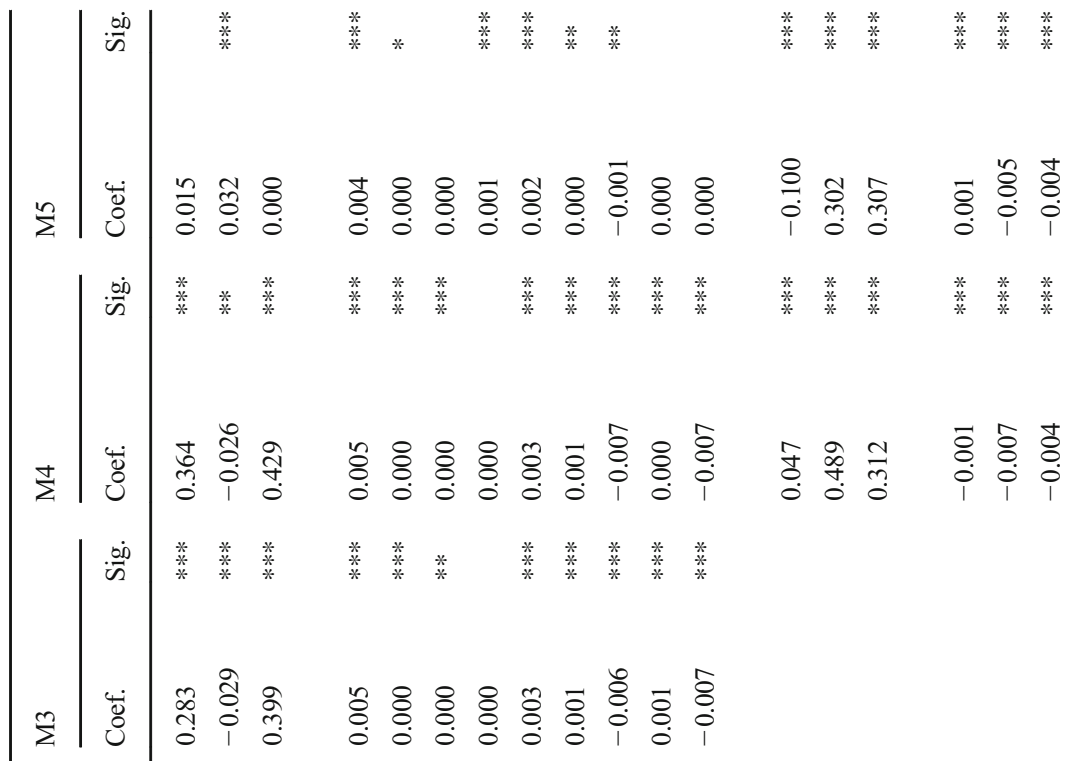

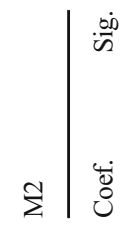

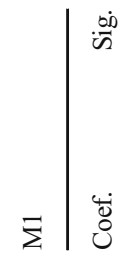

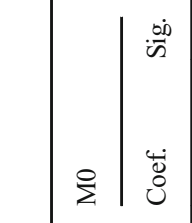

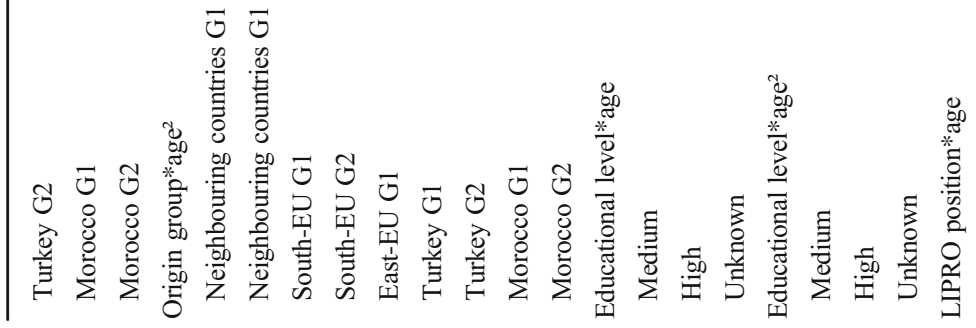




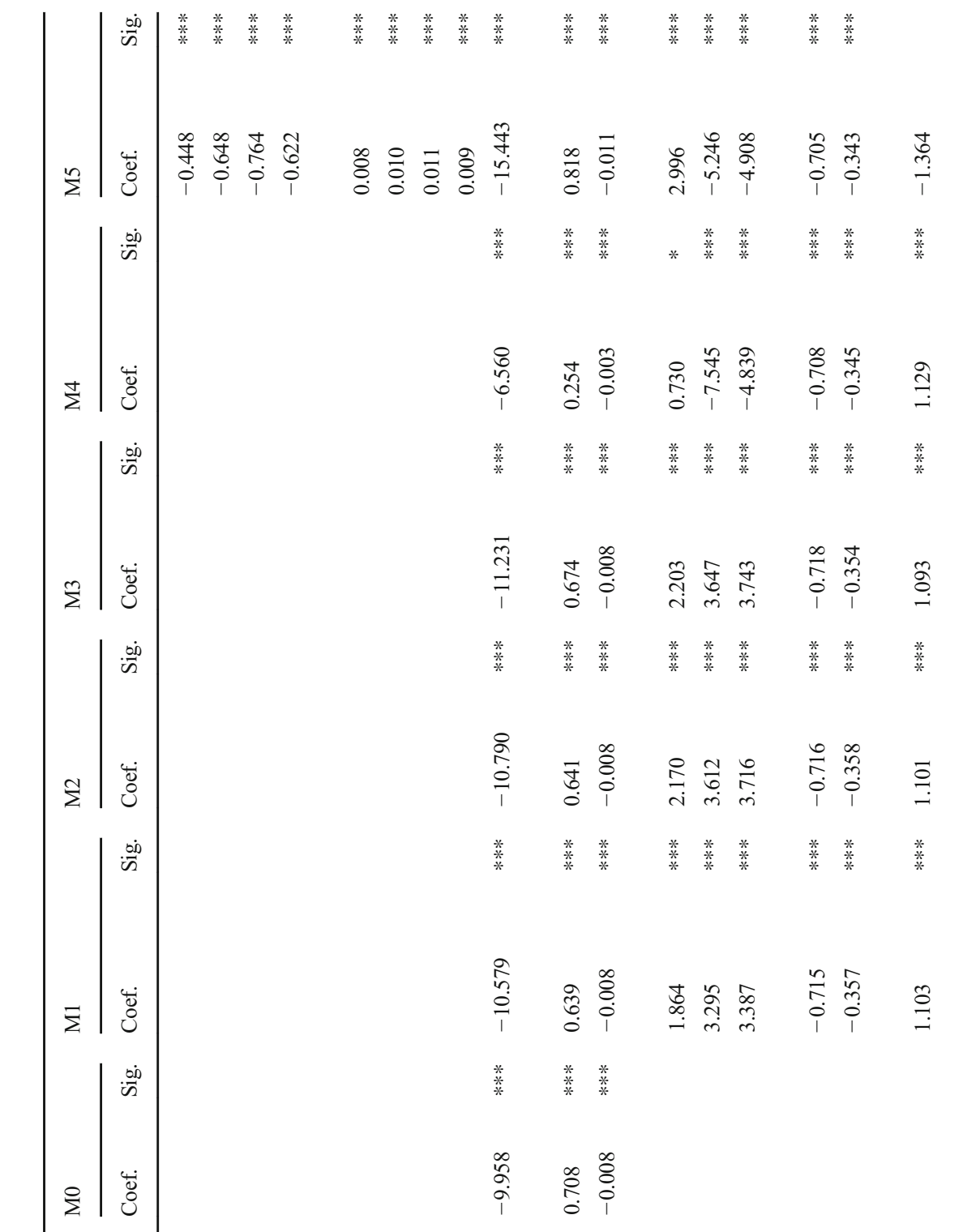

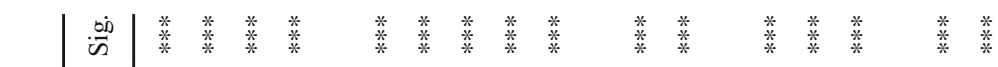




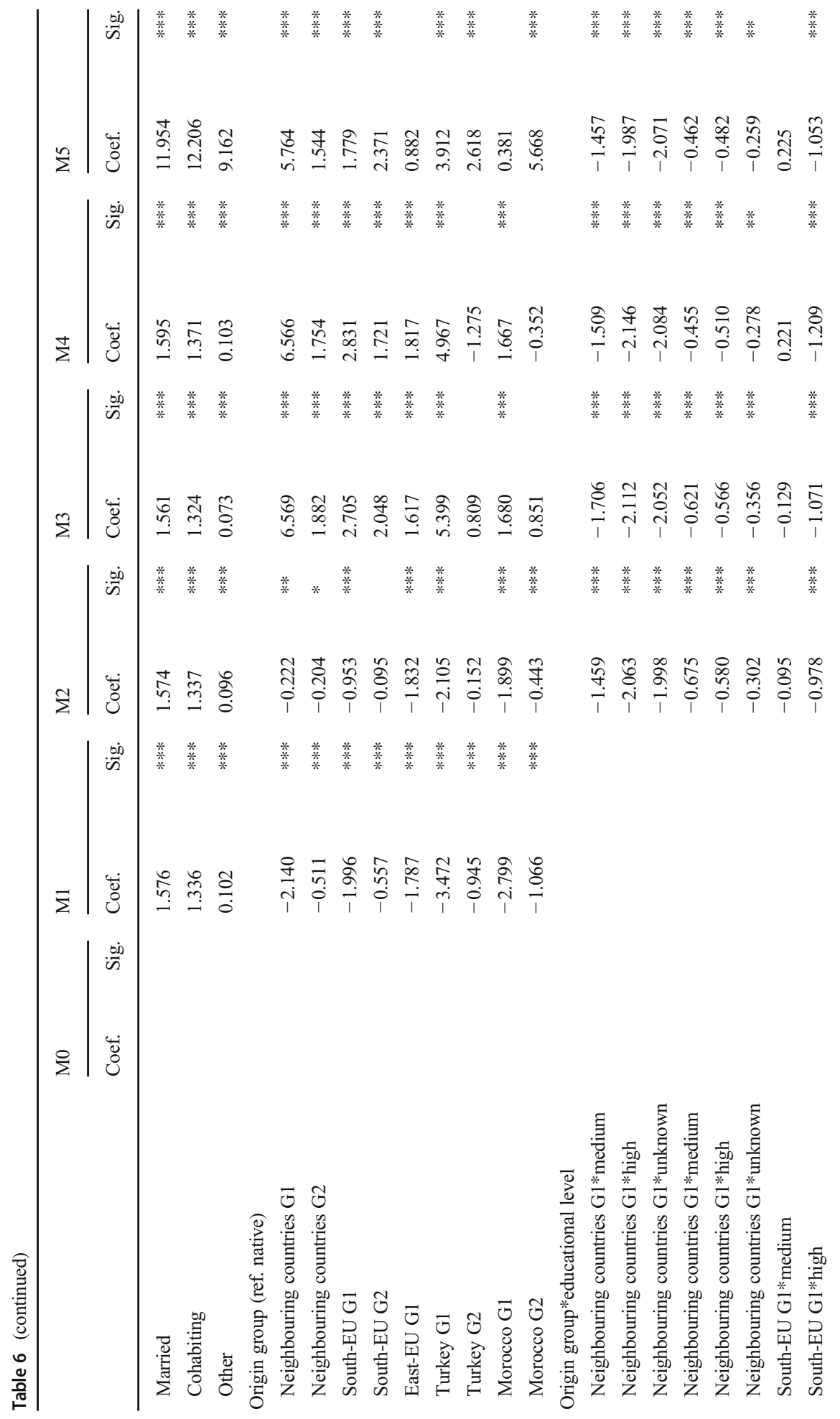




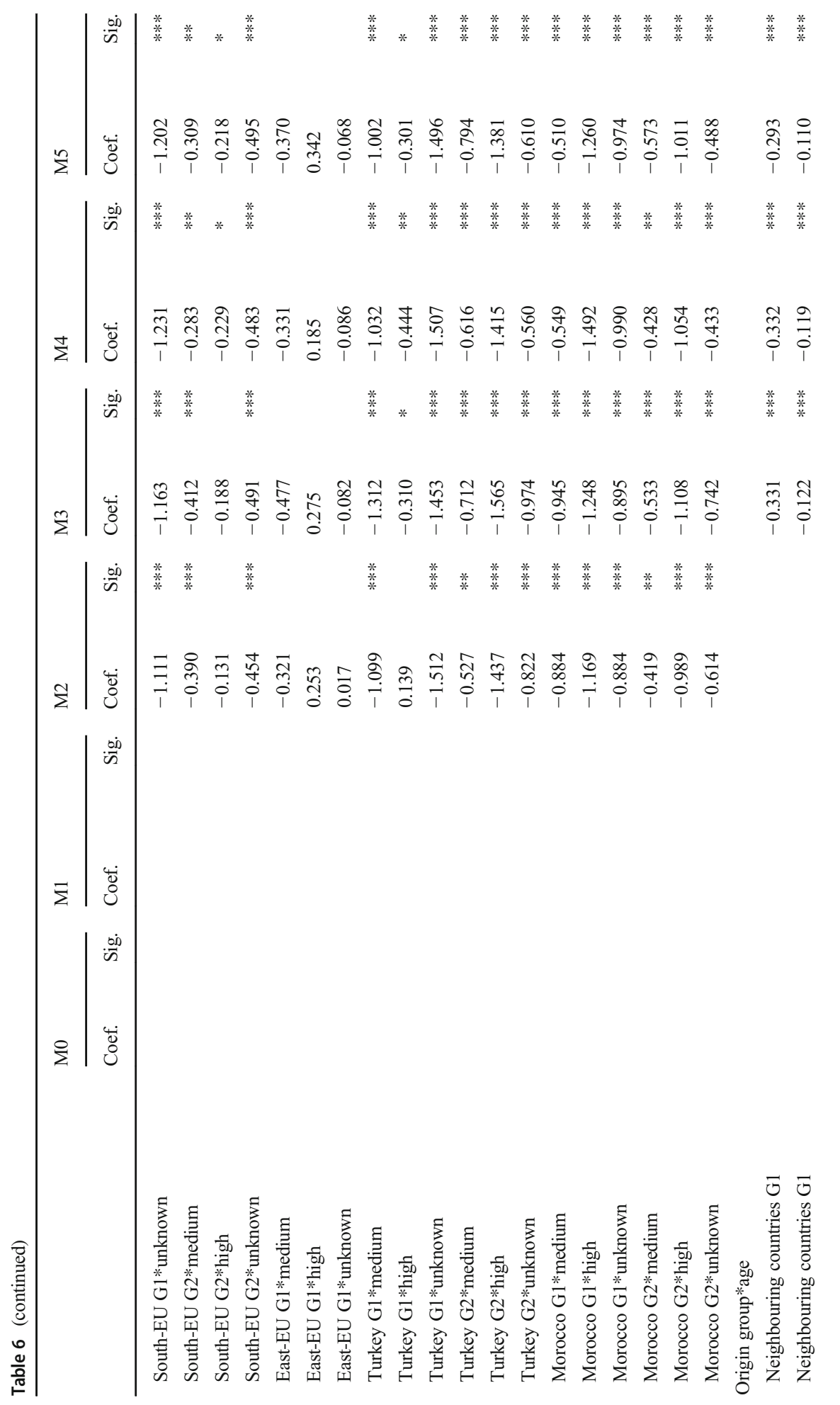




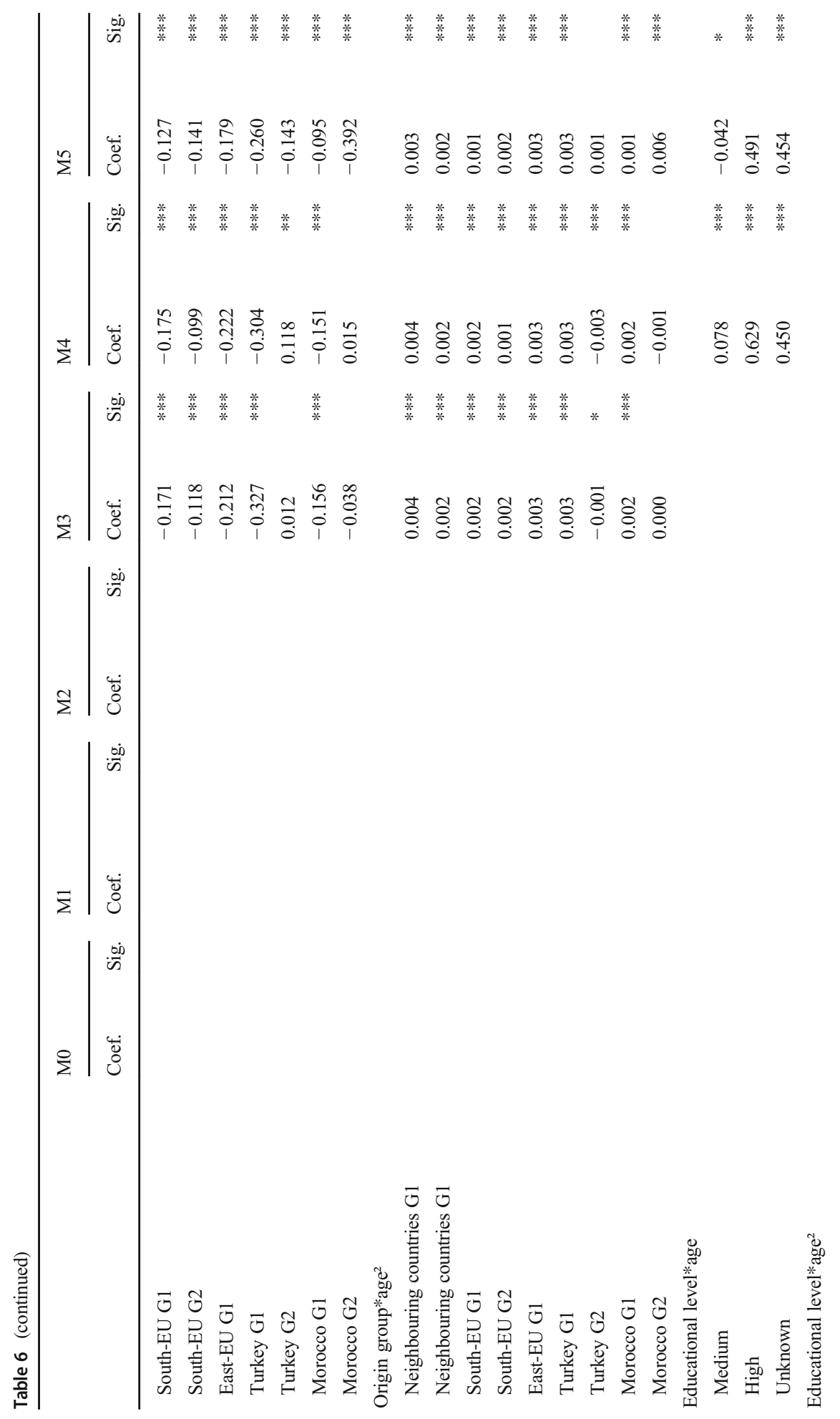




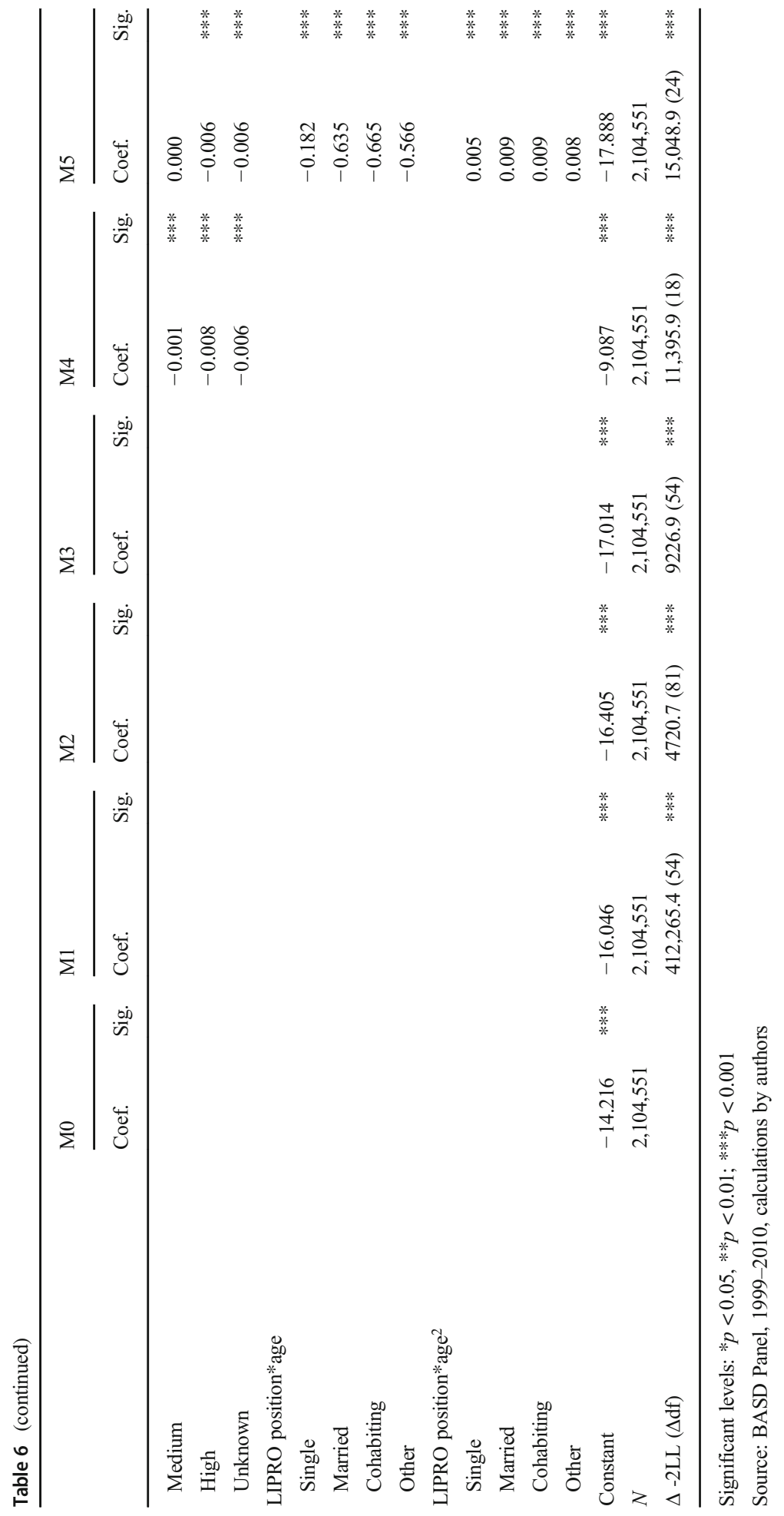




\section{Appendix 2}

Table 7 Fixed-effects models for the change in work intensity around first childbirth among women with low pre-birth employment rates (in percentage points), Model 0

\begin{tabular}{|c|c|c|c|c|}
\hline & & Sig. & Model 0 & Sig. \\
\hline \multicolumn{5}{|c|}{ Time around first birth (ref. $-4 \mathrm{Q}$ ) } \\
\hline$-3 \mathrm{Q}$ & 1.065 & & 0.737 & \\
\hline$-2 \mathrm{Q}$ & -2.802 & & -2.857 & \\
\hline$-1 \mathrm{Q}$ & -9.501 & $* * *$ & -10.307 & $* *$ \\
\hline $0 \mathrm{Q}$ & -17.191 & $* * *$ & -19.560 & $* * *$ \\
\hline $1 \mathrm{Q}$ & -9.942 & $* * *$ & -11.026 & $* *$ \\
\hline $2 \mathrm{Q}$ & -8.380 & $* * *$ & -8.185 & $*$ \\
\hline $3 \mathrm{Q}$ & -1.920 & & 0.158 & \\
\hline 4-7 Q & -1.621 & & -1.074 & \\
\hline $8-11 \mathrm{Q}$ & -3.229 & & -1.989 & \\
\hline \multicolumn{5}{|c|}{ Time* origin group (ref. native) } \\
\hline-3 Q* G2 Tur/Mor & & & 0.719 & \\
\hline$-2 Q^{*}$ G2 Tur/Mor & & & 0.136 & \\
\hline$-1 \mathrm{Q} * \mathrm{G} 2$ Tur/Mor & & & 1.718 & \\
\hline 0 Q* G2 Tur/Mor & & & 5.200 & \\
\hline $1 \mathrm{Q} * \mathrm{G} 2$ Tur/Mor & & & 2.290 & \\
\hline 2 Q* G2 Tur/Mor & & & -0.439 & \\
\hline 3Q* G2 Tur/Mor & & & -4.594 & \\
\hline 4-7Q* G2 Tur/Mor & & & -1.223 & \\
\hline $8-11 Q^{*}$ G2 Tur/Mor & & & -3.002 & \\
\hline Constant & 26.713 & $* * *$ & 26.711 & $* * *$ \\
\hline$N$ persons & 183 & & 183 & \\
\hline$N$ person quarters & 2315 & & 2315 & \\
\hline$\Delta-2 \mathrm{LL}(\Delta \mathrm{df})$ & & & $5.6(9)$ & \\
\hline
\end{tabular}

Significant levels: $* p<0.05, * * p<0.01 ; * * p<0.001$

Source: BASD Panel, 1999-2010, calculations by authors 


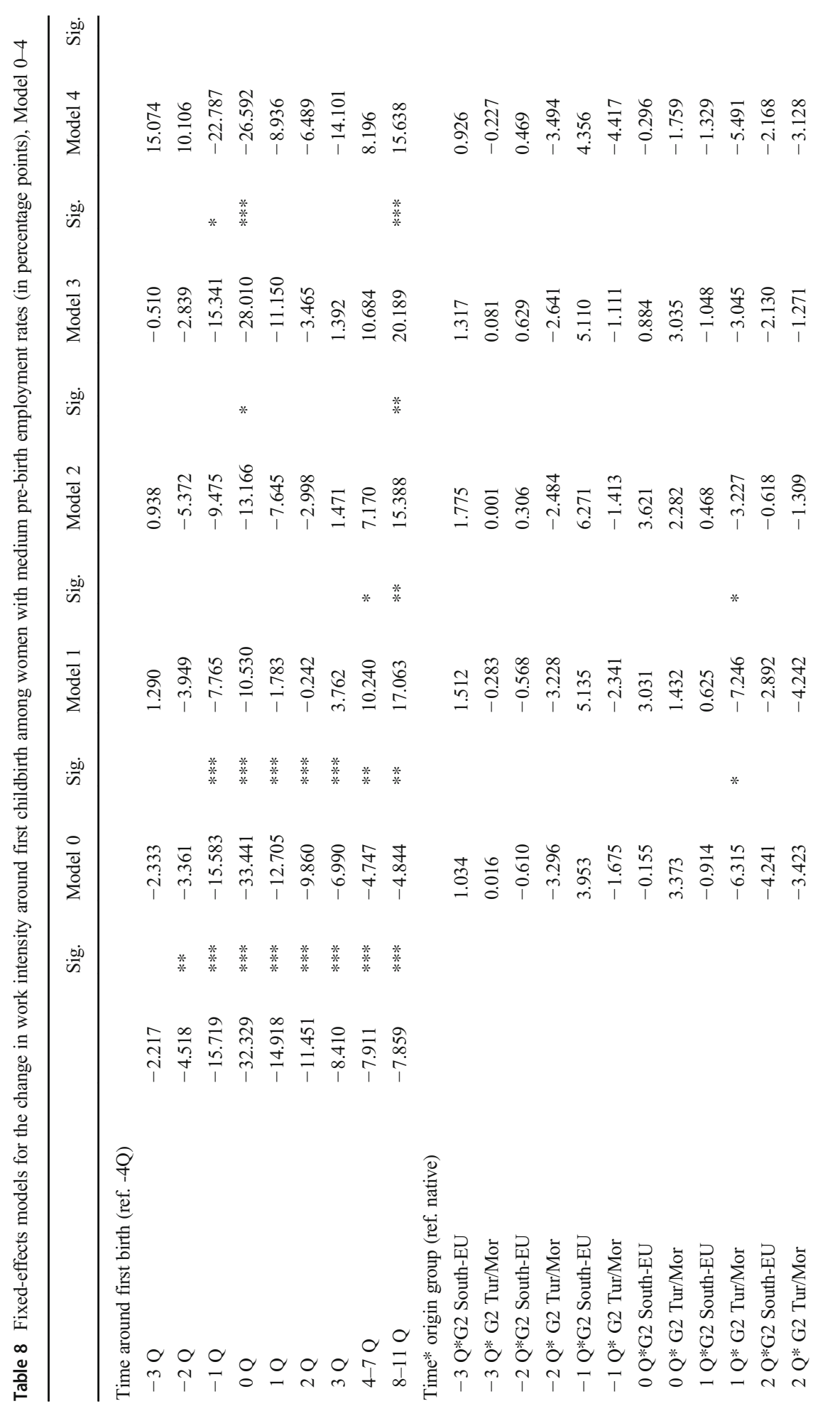




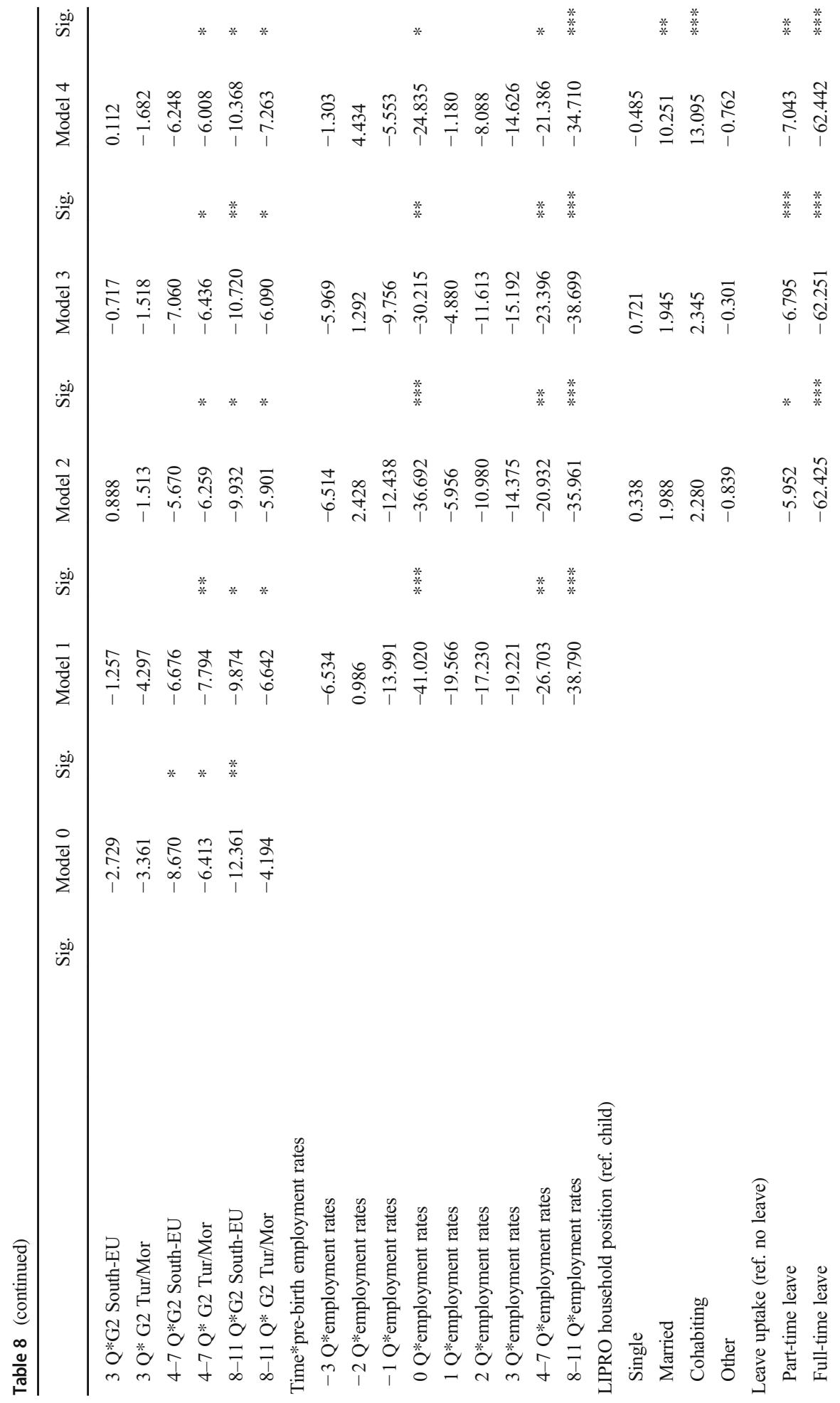




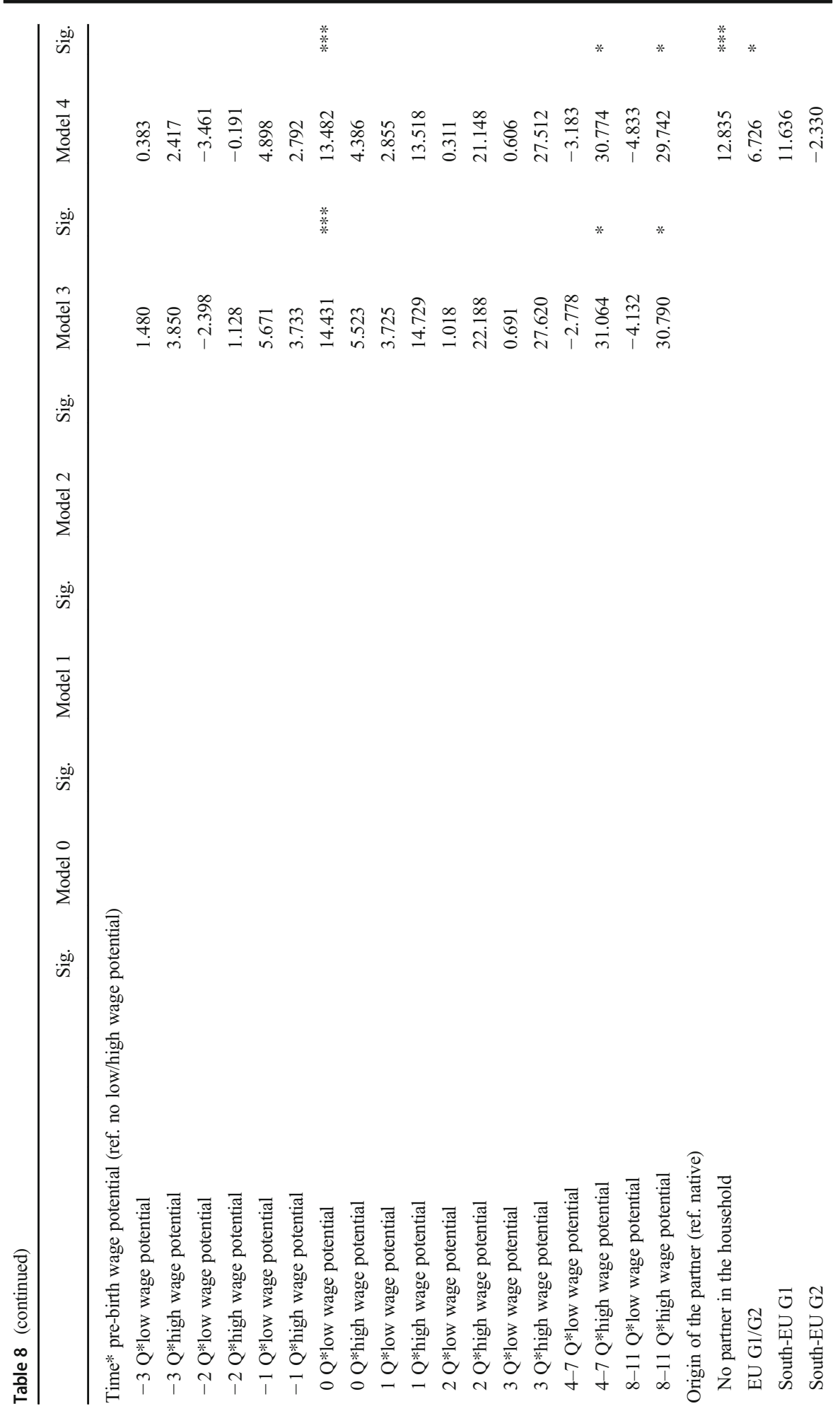




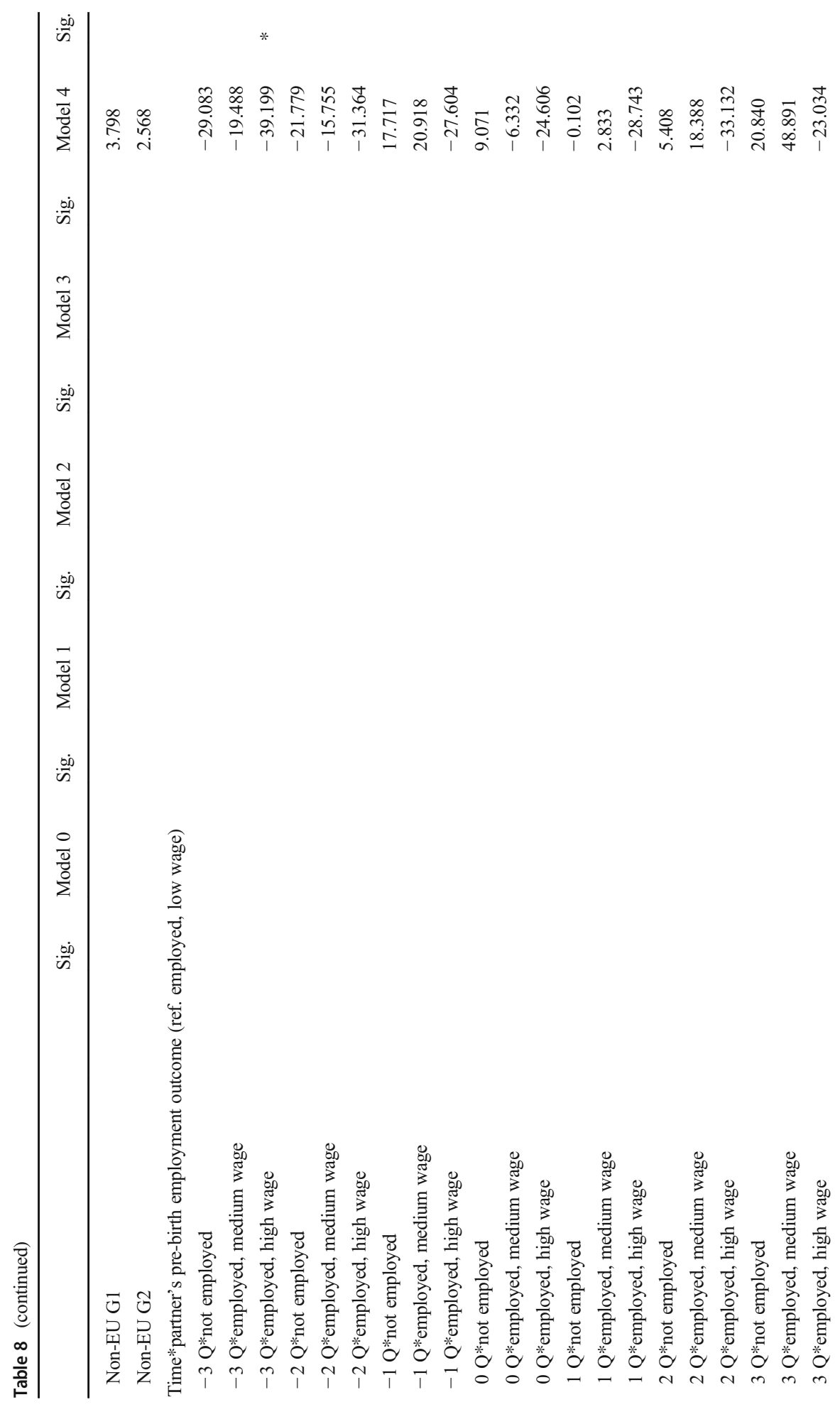




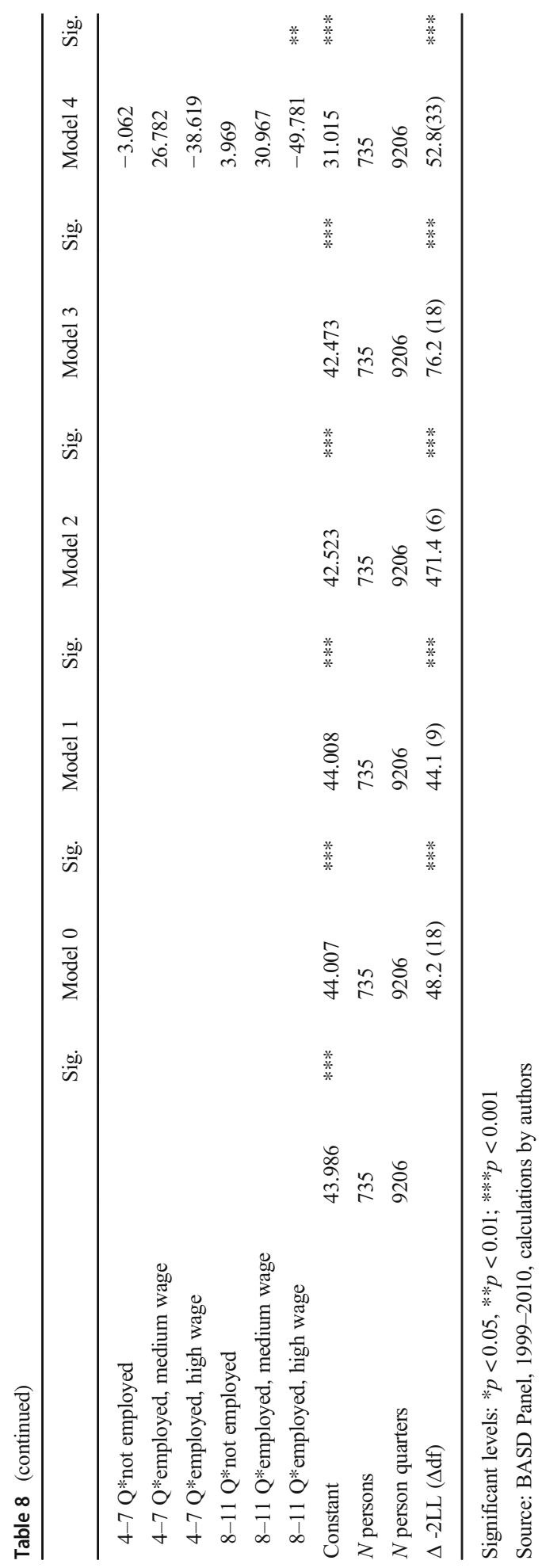




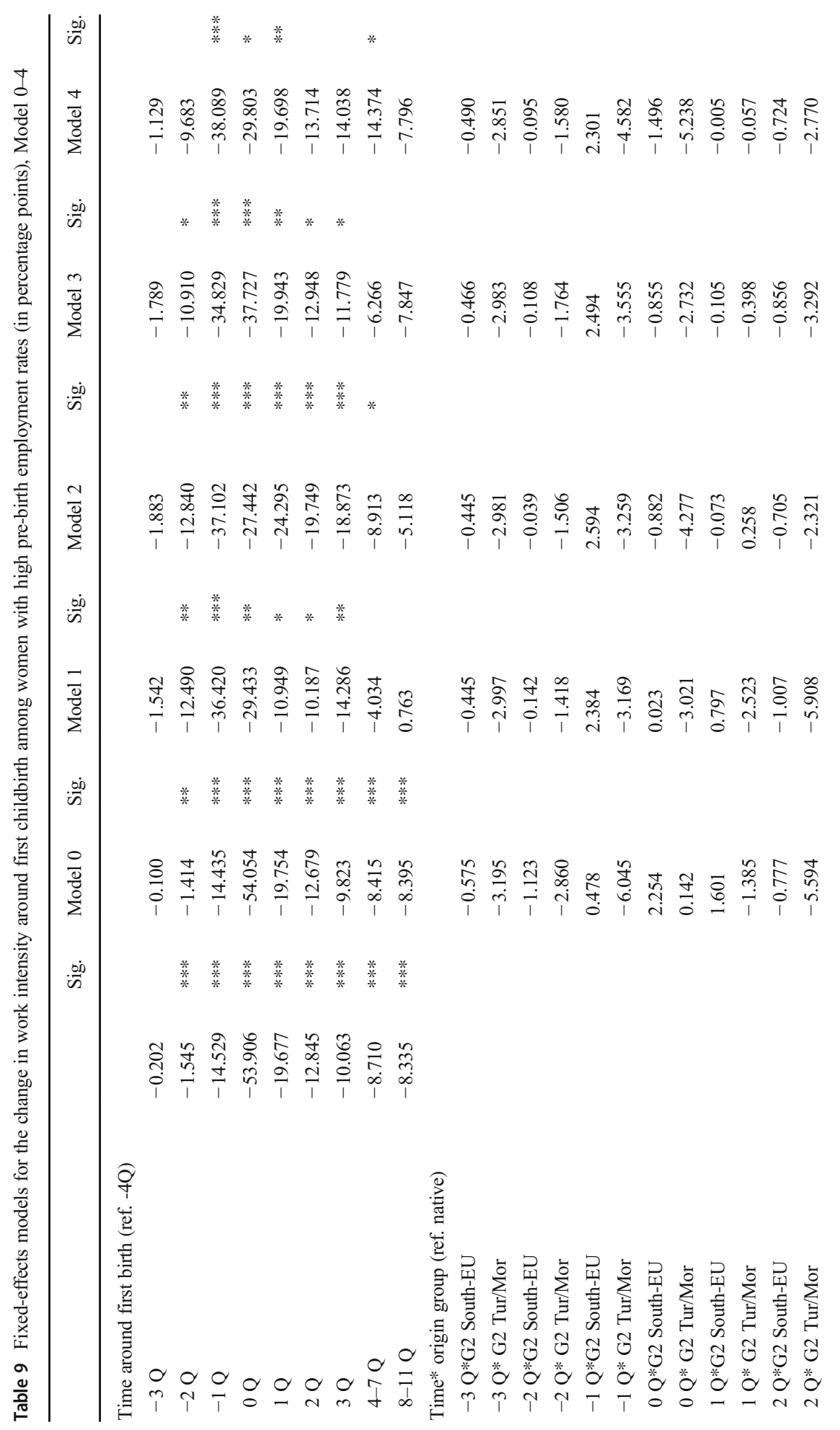




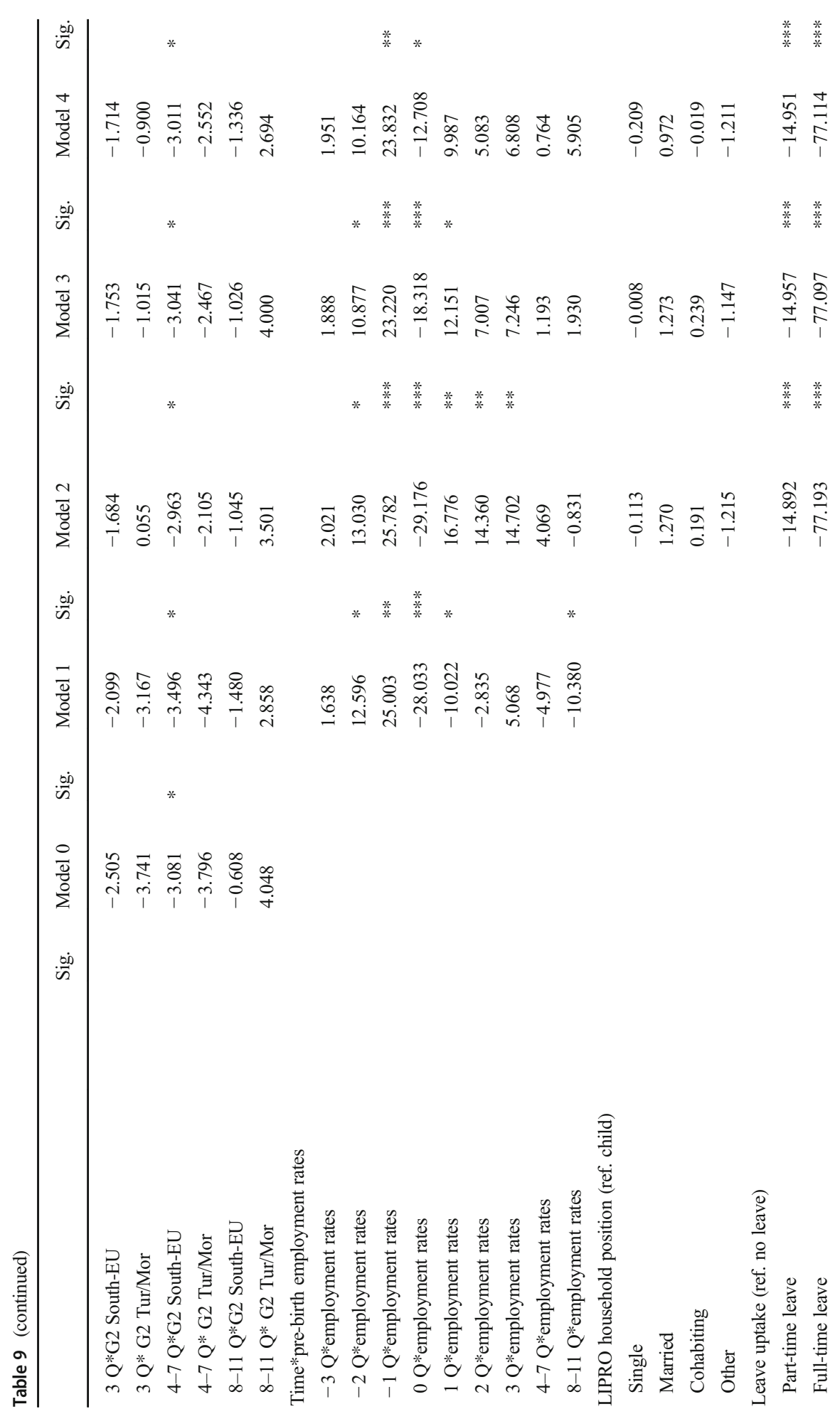




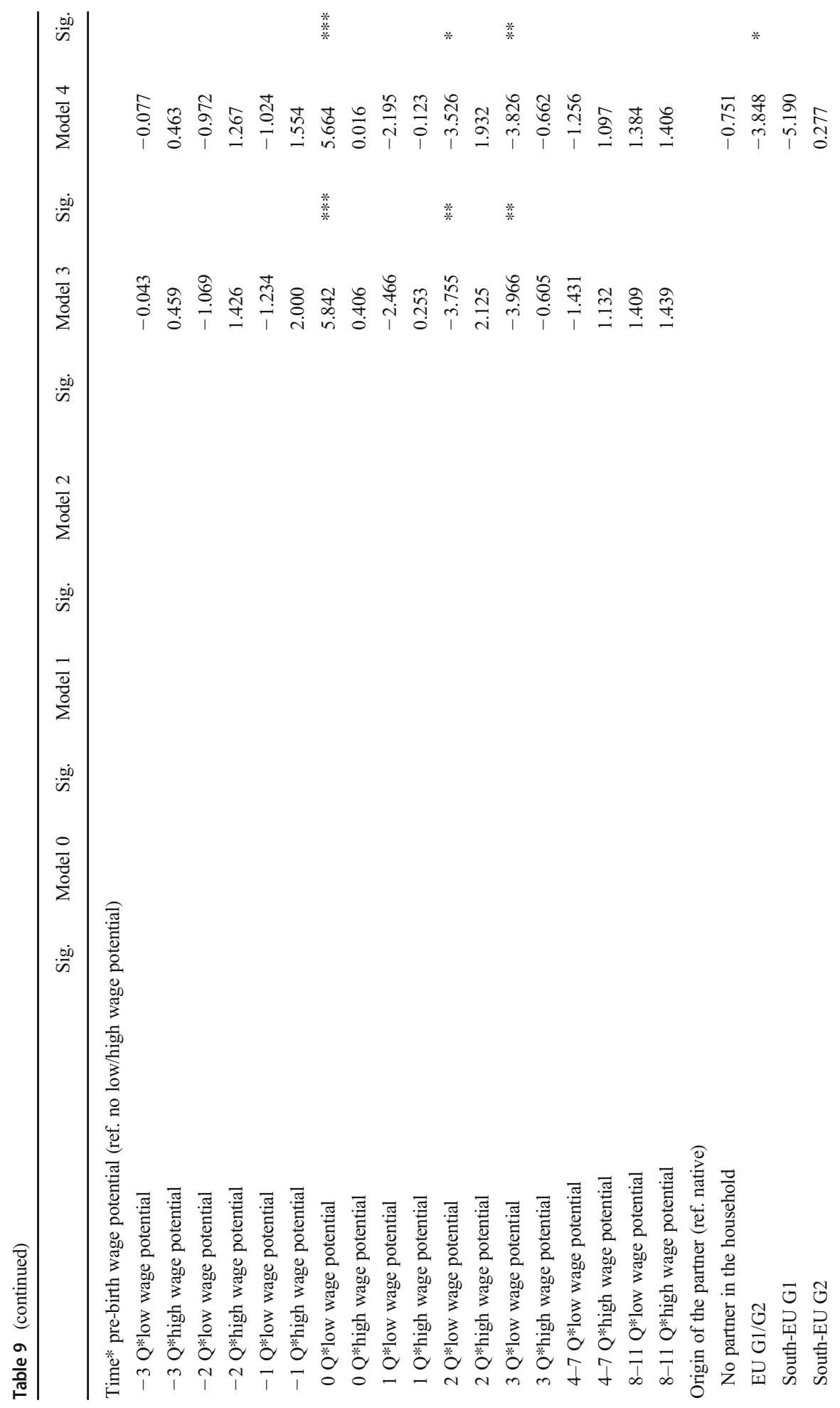




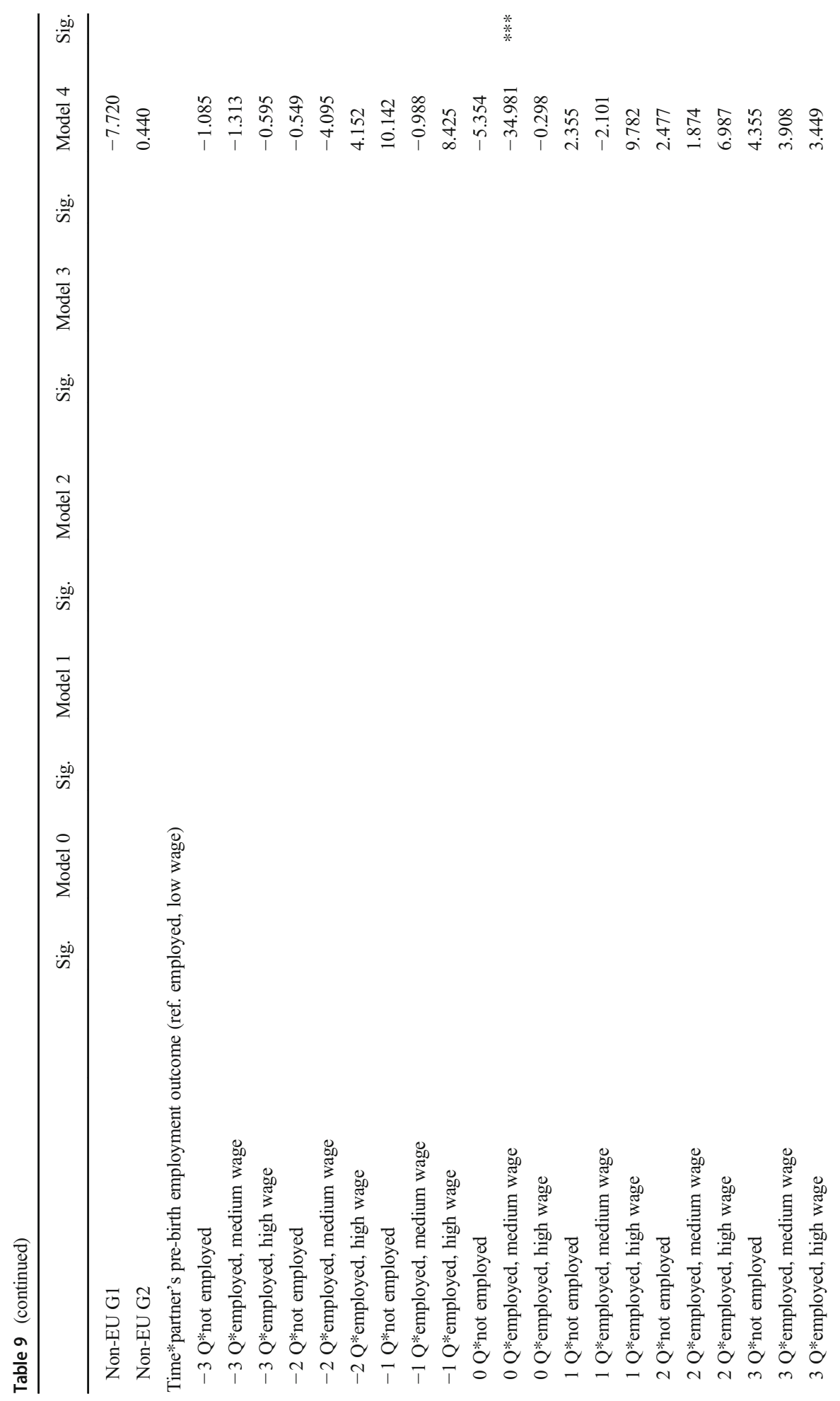




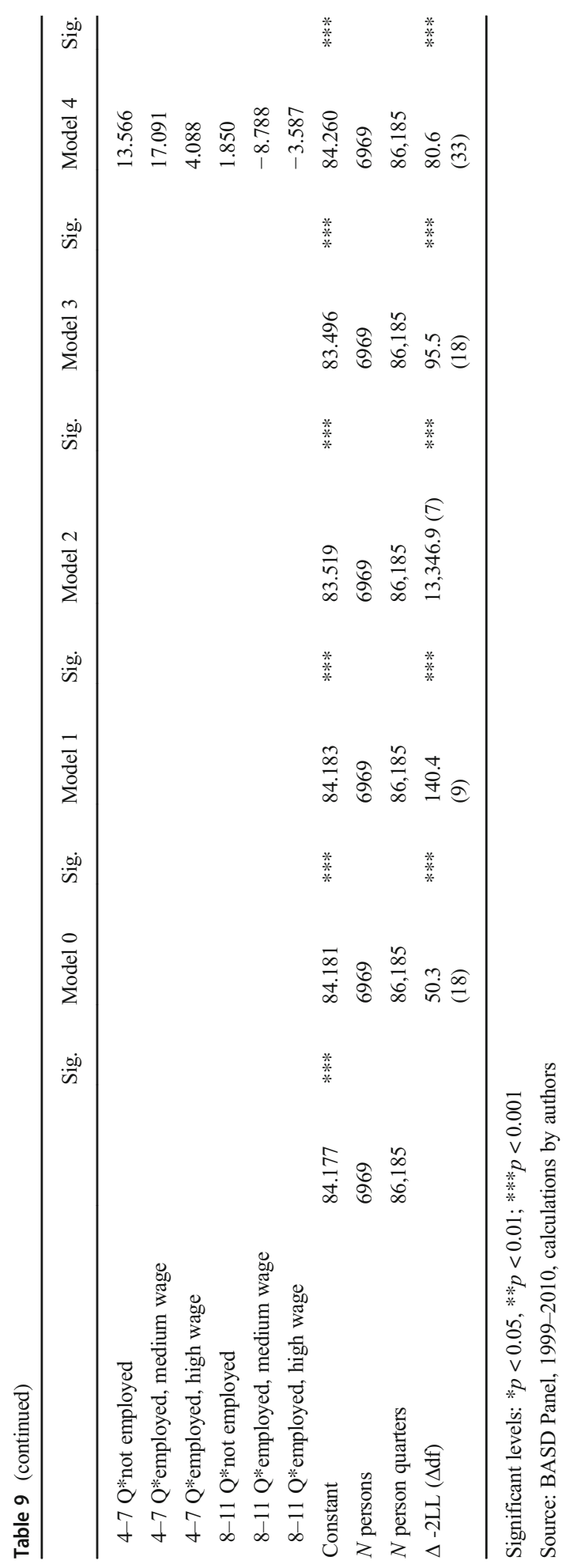


Open Access This article is licensed under a Creative Commons Attribution 4.0 International License, which permits use, sharing, adaptation, distribution and reproduction in any medium or format, as long as you give appropriate credit to the original author(s) and the source, provide a link to the Creative Commons licence, and indicate if changes were made. The images or other third party material in this article are included in the article's Creative Commons licence, unless indicated otherwise in a credit line to the material. If material is not included in the article's Creative Commons licence and your intended use is not permitted by statutory regulation or exceeds the permitted use, you will need to obtain permission directly from the copyright holder. To view a copy of this licence, visit http://creativecommons.org/licenses/by/4.0/.

\section{References}

Abroms, L. C., \& Goldscheider, F. K. (2002). More work for mother: How spouses, cohabiting partners and relatives affect the hours mothers work. Journal of Family and Economic Issues, 23(2), 147-166.

Allison, P. D. (2009). Fixed effects regression models (Vol. 160). Thousand Oaks: SAGE publications.

Anderson, D. J., Binder, M., \& Krause, K. (2003). The motherhood wage penalty revisited: Experience, heterogeneity, work effort, and work-schedule flexibility. ILR Review, 56(2), 273-294.

Baert, S., Cockx, B., Gheyle, N., \& Vandamme, C. (2013). Do employers discriminate less if vacancies are difficult to fill? Evidence from a field experiment. CESifo Working Paper, No. 4093.

Baert, S., Heiland, F. W., \& Korenman, S. (2016). Native-immigrant gaps in educational and school-to-work transitions in the 2nd generation: The role of gender and ethnicity. De Economist, 164(2), 159-186.

Bass, B. C. (2015). Preparing for parenthood? Gender, aspirations, and the reproduction of labor market inequality. Gender \& Society, 29(3), 362-385.

Baxter, J., Buchler, S., Perales, F., \& Western, M. (2015). A life-changing event: First births and men's and women's attitudes to mothering and gender divisions of labor. Social forces, 93(3), 989-1014.

Becker. (1991). A Treatise on the Family. Cambridge: Harvard University Press.

Bevelander, P., \& Groeneveld, S. (2006). Patterns of transition: Female native Dutch and ethnic minority employment patterns in the Dutch labour market, 1991 and 2002. Journal of Ethnic and Migration Studies, 32(5), 785-807.

Budig, M. J., \& England, P. (2001). The wage penalty for motherhood. American sociological review, 66(2), $204-225$.

Corijn, M., \& Lodewijckx, E. (2009). De start van de gezinsvorming bij de Turkse en Marokkaanse tweede generatie in het Vlaamse Gewest. Brussel: Studiedienst van de Vlaamse Regering.

de Valk. (2008). Parental influence on work and family plans of adolescents of different ethnic backgrounds in the Netherlands. Sex Roles, 59(9-10), 738-751.

Elloukmani, S., \& Ou-Salah, L. (2018). Thuisblijven of Werken? Ervaren drempels van Marokkaanse vrouwen. In J. Coene, P. Raeymaeckers, B. Hubeau, T. Goedemé, R. Remmen, \& A. Van Haarlem (Eds.), Armoede en sociale uitsluiting: jaarboek 2018 (pp. 149-172). Leuven: Acco.

Esping-Andersen, G. (1999). Social foundations of postindustrial economies. Oxford: OUP.

FOD WASO, \& UNIA. (2017). Socio-economische monitoring: Arbeidsmark en Origine. Brussel Interfederaal Gelijkekansencentrum en Federale Overheidsdienst Werkgelegenheid en Sociaal Overleg.

Friedman, D., Hechter, M., \& Kanazawa, S. (1994). A theory of the value of children. Demography, 31(3), 375-401.

Ghysels, J., \& Van Lancker, W. (2009). Het Matteüseffect onder de loep: over het ongelijke gebruik van kinderopvang in Vlaanderen. CSB Berichten. Antwerpen: Centrum voor Sociaal Beleid Herman Deleeck.

Gutierrez-Domenech, M. (2005). Employment after motherhood: A European comparison. Labour Economics, 12(1), 99-123.

Heath, A. F., Rothon, C., \& Kilpi, E. (2008). The second generation in Western Europe: Education, unemployment, and occupational attainment. Annual review of sociology, 34, 211-235.

Holland, J. A., \& de Valk, H. A. (2017). Differences in labour force participation by motherhood status among second-generation Turkish and majority women across Europe. Population studies, 71(3), 363-378.

Khoudja, Y., \& Fleischmann, F. (2015). Ethnic differences in female labour force participation in the Netherlands: Adding gender role attitudes and religiosity to the explanation. European Sociological Review, 31(1), 91-102.

Kil, T., Wood, J., \& Neels, K. (2017). Parental leave uptake among migrant and native mothers: Can precarious employment trajectories account for the difference? Ethnicities, 18(1), 106-141. 
Kil, T., Neels, K., Wood, J., \& de Valk, H. (2018). Employment after parenthood: Women of migrant origin and natives compared. European Journal of Population, 34(3), 413-440.

Koelet, S., De Valk, H. A., Glorieux, I., Laurijssen, I., \& Willaert, D. (2015). The timing of family commitments in the early work career: Work-family trajectories of young adults in Flanders. Demographic research, 32, 657-690.

Koslowski, A., Blum, S., \& Moss, P. (2016). 12th International Review of Leave Policies and Related Research 2016. Vienna: International Network on Leave Policies and Related Research.

Kreyenfeld, M. (2015). Maternal and paternal employment across the life course. In R. Scott \& S. Kosslyn (Eds.), Emerging Trends in the Social and Behavioral Sciences: An Interdisciplinary, Searchable, and Linkable Resource (pp. 1-15). Hoboken, NJ: John Wiley \& Sons.

Kuhhirt, M. (2011). Childbirth and the long-term division of labour within couples: How do substitution, bargaining power, and norms affect parents' time allocation in West Germany? European Sociological Review, 28(5), 565-582.

Lück, D. (2005). Cross-national comparison of gender role attitudes and their impact on women's life courses. In Globalization, Uncertainty, and Women in Society. Cheltenham, UK/Northampton, USA: Edward Elgar.

Lundberg, S., \& Pollak, R. A. (1996). Bargaining and distribution in marriage. Journal of economic perspectives, 10(4), 139-158.

Maes, J., Wood, J., \& Neels, K. (2019). Early labour market trajectories of intermediate and second generation Turkish and Maghreb women in Belgium. Research in Social Stratification and Mobility, 61, 65-78.

Matysiak, A., \& Vignoli, D. (2008). Fertility and women's employment: A meta-analysis. European Journal of Population, 24(4), 363-384.

de Valk, \& Milewski, N. (2011). Family life transitions among children of immigrants: An introduction. Advances in Life Course Research, 16(4), 145-151.

Milewski, N., Struffolino, E., \& Bernardi, L. (2018). Migrant status and lone motherhood-risk factors of female labour force participation in Switzerland. In L. bernardi \& D. Mortelmans (Eds.), Lone Parenthood in the Life Course (pp. 141-163): Springer, Cham.

Mussino, E., \& Duvander, A.-Z. (2016). Use it or save it? Migration background and parental leave uptake in Sweden. European Journal of Population, 32(2), 189-210.

Myrskylä, M., \& Margolis, R. (2014). Happiness: Before and after the kids. Demography, 51(5), 1843-1866.

Neels, K., De Wachter, D., \& Peeters, H. (2018). The effect of family formation on the build-up of pension rights among minority ethnic groups and native women in Belgium. Ageing \& Society, 38(6), 1253-1278.

Noppe, J., Vanweddingen, M., Doyen, G., Stuyck, K., Feys, Y., \& Buysschaert, P. (2018). Vlaamse Migratieen Integratiemonitor 2018. Brussel: Agentschap Binnenlands Bestuur.

OECD. (2010). Equal opportunities? The labour market integration of the children of immigrants. Paris: OECD Publishing.

Pavolini, E., \& Van Lancker, W. (2018). The Matthew effect in childcare use: a matter of policies or preferences? Journal of European Public Policy, 25(6), 878-893.

Rubin, J., Rendall, M. S., Rabinovich, L., Tsang, F., van Oranje-Nassau, C., \& Janta, B. (2008). Migrant women in the European labour force: Current situation and future prospects. Cambridge, UK: RAND Europe.

Schober, P., \& Scott, J. (2012). Maternal employment and gender role attitudes: dissonance among British men and women in the transition to parenthood. Work, employment and society, 26(3), 514-530.

Stock, J. H., \& Watson, M. W. (2015). Introduction to econometrics. Harlow: Pearson.

Van Dooren, G., Struyven, L., \& Sam, C. (2014). National report on the labour market position of vulnerable groups in Belgium. (2215-1605). Leuven: Univeristy of Leuven.

Van Imhoff, E., \& Keilman, N. (1991). LIPRO 2.0: An application of a dynamic demographic projection model to household structure in the Netherlands (Vol. 23). Amsterdam: Swets \& Zeitlinger.

Van Lancker, W. (2018). Reducing inequality in childcare service use across European countries: What (if any) is the role of social spending? Social policy \& administration, 52(1), 271-292.

Van Lancker, W., \& Ghysels, J. (2012). Who benefits? The social distribution of subsidized childcare in Sweden and Flanders. Acta Sociologica, 55(2), 125-142.

Vandenbroeck, M., De Visscher, S., Van Nuffel, K., \& Ferla, J. (2008). Mothers' search for infant child care: The dynamic relationship between availability and desirability in a continental European welfare state. Early Childhood Research Quarterly, 23(2), 245-258.

Verhaeghe, P.-P., Li, Y., \& Van de Putte, B. (2013). Socio-economic and ethnic inequalities in social capital from the family among labour market entrants. European Sociological Review, 29(4), 683-694.

Vidal-Coso, E. (2019). Female employment following childbirth: differences between native and immigrant women in Switzerland. Journal of Ethnic and Migration Studies, 45(9), 1667-1692.

Wall, K., \& José, J. S. (2004). Managing work and care: A difficult challenge for immigrant families. Social policy \& administration, 38(6), 591-621. 
Wood, J., \& Neels, K. (2017). First a job, then a child? Subgroup variation in women's employment-fertility link. Advances in Life Course Research, 33, 38-52.

Wood, J., Neels, K., De Wachter, D., \& Kil, T. (2016). Family formation and labour force participation. Population, 71(1), 53-81.

Wood, J., Kil, T., \& Marynissen, L. (2018). Do women's pre-birth relative wages moderate the parenthood effect on gender inequality in working hours? Advances in Life Course Research, 36, 57-69.

Publisher's Note Springer Nature remains neutral with regard to jurisdictional claims in published maps and institutional affiliations. 